\title{
Short chain fatty acids in human gut and metabolic health
}

\author{
E.E. Blaak ${ }^{1 *}$, E.E. Canfora ${ }^{1}$, S. Theis ${ }^{2}$, G. Frost ${ }^{3}$, A.K. Groen ${ }^{4,5}$, G. Mithieux ${ }^{6}$, A. Nauta ${ }^{7}$, K. Scott ${ }^{8}$, B. Stahl ${ }^{9,10}$, \\ J. van Harsselaar ${ }^{2}$, R. van Tol ${ }^{11}$, E.E. Vaughan ${ }^{12}$ and K. Verbeke ${ }^{13}$ \\ ${ }^{1}$ Department of Human Biology, NUTRIM School of Nutrition and Translational Research in Metabolism, Maastricht \\ University, Universiteitssingel 50, 6229 ER Maastricht, The Netherlands.; ${ }^{2}$ Südzucker Group - Beneo, Wormser Str. 11, \\ Mannheim, 67283, Germany; ${ }^{3}$ Faculty of Medicine, Department of Metabolism, Digestion and Reproduction, Imperial \\ College London, SW7 2AZ London, United Kingdom; ${ }^{4}$ Diabetes Center, Department of Internal and Vascular Medicine, \\ Amsterdam University Medical Centers, location AMC, Amsterdam, the Netherlands; ${ }^{5}$ Quantitative Systems Biology, \\ Department of Pediatrics, Centre for Liver, Digestive and Metabolic Diseases, University Medical Centre Groningen (UMCG), \\ University of Groningen, P.O. Box 30.001, 9700 RB Groningen, the Netherlands; ${ }^{6}$ INSERM U1213, Faculté de Médecine \\ Laennec, University of Lyon, 7-11 Rue Guillaume Paradin, 69372 Lyon, France; ${ }^{7}$ FrieslandCampina, P.O. Box 1551, 3800 \\ BN Amersfoort, the Netherlands; ${ }^{8}$ The Rowett Institute, University of Aberdeen, Aberdeen, AB25 2ZD, United Kingdom; \\ ${ }^{9}$ Danone Nutricia Research, Uppsalalaan 12, 3584 CT, Utrecht, the Netherlands; ${ }^{10}$ Department of Chemical Biology E Drug \\ Discovery, Utrecht Institute for Pharmaceutical Sciences, Utrecht University, Universiteitsweg 99, 3584 CG Utrecht, the \\ Netherlands; ${ }^{11}$ Reckitt Benckiser/Mead Johnson Nutrition, Middenkampweg 2, 6545 CJ Nijmegen, the Netherlands; ${ }^{12}$ Sensus \\ (Royal Cosun), Borchwerf 3, 4704 RG Roosendaal, the Netherlands; ${ }^{13}$ Translational Research Center for Gastrointestinal \\ Disorders (TARGID), KULeuven, Herestraat 49, 3000 Leuven, Belgium; publications@ilsieurope.be
}

Received: 31 March 2020 / Accepted: 1 July 2020

(c) 2020 Wageningen Academic Publishers

OPEN ACCESS (c) (1)(2) REVIEW ARTICLE

\section{Abstract}

Evidence is accumulating that short chain fatty acids (SCFA) play an important role in the maintenance of gut and metabolic health. The SCFA acetate, propionate and butyrate are produced from the microbial fermentation of indigestible carbohydrates and appear to be key mediators of the beneficial effects elicited by the gut microbiome. Microbial SCFA production is essential for gut integrity by regulating the luminal $\mathrm{pH}$, mucus production, providing fuel for epithelial cells and effects on mucosal immune function. SCFA also directly modulate host metabolic health through a range of tissue-specific mechanisms related to appetite regulation, energy expenditure, glucose homeostasis and immunomodulation. Therefore, an increased microbial SCFA production can be considered as a health benefit, but data are mainly based on animal studies, whereas well-controlled human studies are limited. In this review an expert group by ILSI Europe's Prebiotics Task Force discussed the current scientific knowledge on SCFA to consider the relationship between SCFA and gut and metabolic health with a particular focus on human evidence. Overall, the available mechanistic data and limited human data on the metabolic consequences of elevated gut-derived SCFA production strongly suggest that increasing SCFA production could be a valuable strategy in the preventing gastro-intestinal dysfunction, obesity and type 2 diabetes mellitus. Nevertheless, there is an urgent need for well controlled longer term human SCFA intervention studies, including measurement of SCFA fluxes and kinetics, the heterogeneity in response based on metabolic phenotype, the type of dietary fibre and fermentation site in fibre intervention studies and the control for factors that could shape the microbiome like diet, physical activity and use of medication.

Keywords: prebiotics, SCFA, dietary fibre, gut health, metabolic health 


\section{Introduction}

There is accumulating evidence that the gut microbiome is of importance in mucosal immunity, barrier integrity and gut health as well in the regulation of host metabolic health. The gut microbiota is able to ferment indigestible food components such as prebiotics and soluble dietary fibres. Prebiotic consumption can result in the microbial production of short-chain fatty acids (SCFA), including acetate, butyrate and propionate, as major end products. These metabolites emerge as one of the key mechanism by which prebiotics exert their beneficial health effects (Gibson et al., 2017; Koh et al., 2016). These include health effects that are attributed to increased microbial SCFA formation including an improved gut barrier function and reduced intestinal inflammation. In addition, the SCFA butyrate is an important fuel for the colonocytes and impairment in fuel supply may play a role in a reduced gastro-intestinal functioning. Additionally, SCFA may affect gastro-intestinal transit and motility. Besides effects on gastro-intestinal health, SCFA may play a role in the pathophysiology of obesity and related diseases such as type 2 diabetes mellitus (T2DM) by affecting body weight control through effects on energy intake and energy expenditure, as well as insulin sensitivity and systemic low-grade (Canfora et al., 2015; Chambers et al., 2018c; Rios-Covian et al., 2016).

Increasing SCFA production and a more saccharolytic fermentation may in that context be considered as a health benefit, but data are mostly based on animal studies and human studies are limited. Additionally, the majority of mechanistic evidence from animal studies used different routes to administer SCFA (e.g. oral vs intragastric infusions vs colonic infusions vs gut microbial fermentation), which may not all directly translate to the human situation. Consequently, a thorough review of the available evidence is required, with a particular focus on human clinical interventions or on human ex vivo studies such as human gut microbiota colonic models.

Therefore, an expert group has been set up by ILSI Europe's Prebiotics Task Force, investigating and reviewing the current scientific knowledge on SCFA to consider the relationship between SCFA and human health as well as whether an increased gut-derived SCFA production can be regarded as a biomarker of gut and metabolic health. The manuscript and its conclusions have been refined in a workshop with scientific experts, industrial representatives and policy makers.

In the review, we present current scientific evidence on health effects of gut-derived SCFA with a focus on evidence from human studies and interventions and only from in vitro or animal research where almost no human research is available. We first provide an overview of intestinal SCFA production, metabolism as well as rate of absorption, which is followed by an overview of SCFA in relation to gastrointestinal health. Subsequently, effects on metabolic health are addressed, including effects on energy balance, substrate metabolism and low-grade inflammation.

\section{Method section}

The search strategy conducted was developed through internal discussion within the research team, and deployed within the PubMed and/or SCOPUS bibliographic database. The search used a combination of terms targeting title headings, keywords or free-text words, with specific filters finally applied.

With respect to all topics on physiological effects the following search terms for SCFA was used: (short chain fatty acid"[TI] OR SCFA[TI] OR butyrate[TI] OR butanoate[TI] OR butyric acid[TI] OR butanoic acid[TI] OR acetate[TI] OR ethanoate[TI] OR acetic acid[TI] OR ethanoic acid[TI] OR propionate[TI] OR propanoate[TI] OR propanoic acid[TI] OR propionic acid[TI]).

This search string was combined with other specific search terms as detailed in the supplementary data. References cited in this review include primarily English language original research and some specific reviews by experts in the field.

The focus was on studies in humans, but important mechanistic insights from animal or 'in vitro' studies were included. For the parts on body weight control and metabolic health a systematic narrative approach was used. No protocol for this review has been published. Detailed information on the applied search can be found in the supplementary data.

\section{Short chain fatty acid metabolism}

\section{Human gut microbiota generate short chain fatty acids}

The human large intestine is home to a large and diverse population of microbial species, with particularly large numbers of bacteria. The phylogenetic core, dynamics and stability of this ecosystem have been intensively studied by high throughput $16 \mathrm{~S}$ ribosomal RNA gene sequencingbased technologies (see recent reviews (Almeida et al., 2019; Falony et al., 2016; Hornung et al., 2018; Shetty et al., 2017). Briefly, the dominant bacterial phyla are Bacteroidetes and Firmicutes, while minor phyla include Actinobacteria, Proteobacteria and Verrucomicrobia, and methanogens are dominant amongst the Archaea. Notably eight abundant genera, namely Bacteroides, Eubacterium, Faecalibacterium, Alistipes, Ruminococcus, Clostridium, Roseburia and Blautia, were identified in more than 1000 humans (Shetty et al., 2017). These microbes utilise a diverse range of dietary substrates to produce an array of 
metabolites, many of which are important for the health of the host. Since the majority of gut microbes are bacteria, here we focus mainly on bacterial metabolism of dietary substrates to SCFA. Such substrates include carbohydrates, prebiotics, plant material and proteins that are not digested in the small intestine, either because they are non-digestible or bypass the host's enzymatic/absorptive capacity (due to overload or disease).

Under the anaerobic conditions prevailing in the colon, the carbohydrate material will be preferentially fermented in the proximal colon, where they will be degraded into monosaccharides by microbial hydrolysis and subsequently fermented to phosphoenolpyruvate via the EmbdenMeyerhof pathway. The phosphoenolpyruvate intermediate will then be used to produce the SCFA via different reactions.

Production of acetate may occur via acetyl-coenzyme A to acetyl-CoA and then to acetate by numerous anaerobic gut bacteria or via the Wood-Ljungdahl pathway. Acetate can be produced by most gut microbiota species and generally reaches the highest levels in the colon as compared to other SCFA as described below.

Propionate can be produced via the succinate, acrylate or propanediol pathways. The phylogenetic distribution of these three routes used for propionate formation within the human gut bacteria was studied using genomic and metagenomic analyses, and by designing primer sets for the detection of diagnostic genes for these pathways (Reichardt et al., 2014). These researchers showed that the dominant route for propionate production from hexose sugars was determined to be the succinate pathway, as indicated by the widespread distribution of the $m m d A$ gene that encodes methylmalonyl-CoA decarboxylase in Bacteroidetes and in many Negativicutes. The acrylate pathway, based on detection of the $l c d A$ gene, encoding lactoyl-CoA dehydratase, was restricted to a few species within the Lachnospiraceae and Negativicutes. Support for the latter was obtained by stable isotope probing for lactate utilisation in Coprococcus catus (Lachnospiraceae). The propanediol pathway detected, using the $p d u P$ gene encoding propionaldehyde dehydrogenase, that processes deoxy sugars such as fucose and rhamnose was more prevalent within the Lachnospiraceae occurring in relatives of Ruminococcus obeum and in Roseburia inulinivorans (Reichardt et al., 2014).

Butyrate is generally formed by condensation of two molecules of acetyl-CoA via either butyrate kinase or butyryl-CoA:acetate CoA-transferase. Study of the human gut microbiota via primers for the genes encoding these enzymes showed that in most cases butyryl-CoA:acetate CoA-transferase, rather than butyrate kinase, appears to perform the final step in butyrate synthesis and is possible only in the presence of acetate (Louis et al., 2004). Butyrate production is widely distributed among phylogenetically diverse human colonic Gram-positive Firmicutes. Two abundant groups are related to Eubacterium rectale/ Roseburia spp. and to Faecalibacterium prausnitzii (Louis et al., 2010). While most species have the capacity for either propionate or butyrate production from hexose sugars, some species of Lachnospiraceae (C. catus and R. inulinivorans) have been demonstrated to switch from butyrate to propionate production on different substrates (Reichardt et al., 2014; Scott et al., 2006). Besides these pathways for SCFA production, there will be numerous other routes to SCFA as some microbes grow on intermediate products of fermentation, such as hydrogen gas $\left(\mathrm{H}_{2}\right)$, lactate, succinate, formate and ethanol, and convert these to end products including SCFA. Other microbes, particularly Archaea species can metabolise carbon dioxide $\left(\mathrm{CO}_{2}\right)$ either yielding methane $\left(\mathrm{CH}_{4}\right)$ or acetate.

\section{Short chain fatty acid concentrations in the colon}

During production in the colon, SCFA are rapidly and almost completely absorbed in colonocytes, or through the portal vein into the liver, or into systemic circulation. Thus only a minor part (approximately 5-10\%) is excreted in faeces. Consequently, faecal measurements are not considered as accurate representative for in vivo colonic production and should be interpreted with caution (Alles et al., 1996; Boets et al., 2015). Recently, it was shown that longer rectosigmoid transit time was associated with low concentrations of faecal SCFA (Muller et al., 2020). The data suggest that faecal SCFA should be considered as most representative for the SCFA production and/or absorption in the very distal colon and not necessarily other or more proximal colonic sites. Nevertheless, there have been numerous studies that measure SCFA concentrations in faeces upon supplementation with different substrates such as dietary fibres, prebiotics, specific foods and diets, or in comparing certain health and lifestyle conditions. Occasionally, the concentrations of (certain) SCFA in faeces have been correlated with specific gut bacterial types, such as reduction of butyrate-producing bacteria abundance with decline in faecal butyrate on a low carbohydrate weight loss diet (Duncan et al., 2007).

Gaining accurate knowledge on in vivo production and absorption kinetics of (individual) SCFA and their relative proportions is challenging due to the inaccessibility of the colon and the rapid absorption by the colonocytes. Human colonic in vitro gut models are widely used to estimate levels and ratios of SCFA production from different substrates, but they cannot account for in vivo absorption (Aguirre et al., 2016; Grootaert et al., 2009). In this review we focus on the available in vivo studies. 
While there were several lines of evidence that microbial fermentation of polysaccharides and fibres in the human gut resulted in SCFA formation as detected in faeces, a landmark study confirmed this in human sudden death victims examined within $4 \mathrm{~h}$ of death (Cummings et al., 1987). Analysis of the intestinal contents of the victims showed low SCFA concentrations (acetate, propionate, butyrate) in the terminal ileum $(13 \pm 6 \mathrm{mmol} / \mathrm{kg})$, which dramatically increased in the ascending colon (137-197 $\mathrm{mmol} / \mathrm{kg}$ ) and decreased towards the descending colon (86-97 mmol/kg) (Cummings et al., 1987; MacFarlane et al., 1992). A molar ratio of acetate:propionate:butyrate:valerate: caproate was estimated at 54:20:21:4:1 in these initial studies (Figure 1) (MacFarlane and Gibson, 1995; MacFarlane et al., 1992). Higher SCFA concentrations in the proximal colon are the result of greater production in combination with relatively less absorption having occurred. As the luminal colonic contents move through the colon, SCFA absorption across the epithelium and bacterial utilisation reduce the measurable concentrations. The rate of transit through the colon affects the amount of absorption, and has been shown to correlate with detectable concentrations of SCFA in faeces (Lewis and Heaton, 1997). In contrast, end products of protein fermentation increase from the proximal to distal colon (MacFarlane et al., 1992). Increased fermentation also reduces the $\mathrm{pH}$, which in turn affects the microbial composition and SCFA production. Based on various studies, approximately 100-400 mmol SCFA can be theoretically produced within the human colon upon a daily ingestion of around $10 \mathrm{~g}$ of fibres (Cummings and MacFarlane, 1997; McBurney and Thompson, 1989).

A non-invasive methodology to measure SCFA production in the human colon is stable isotope technology, in which labelled carbohydrates are consumed and metabolites monitored in blood or expired air. One of the first studies was in premature infants to determine if lactose fermentation occurred in the colon (Kien et al., 1992). A $\left[1-{ }^{13} \mathrm{C}\right]$-acetate orogastric infusion technique was used during constant orogastric feeding, which gave an estimated mean rate of entry of acetic acid of $64.3 \pm 38.6 \%(24 \%-136 \%)$ of the potential two carbon units from dietary lactose in the infants.

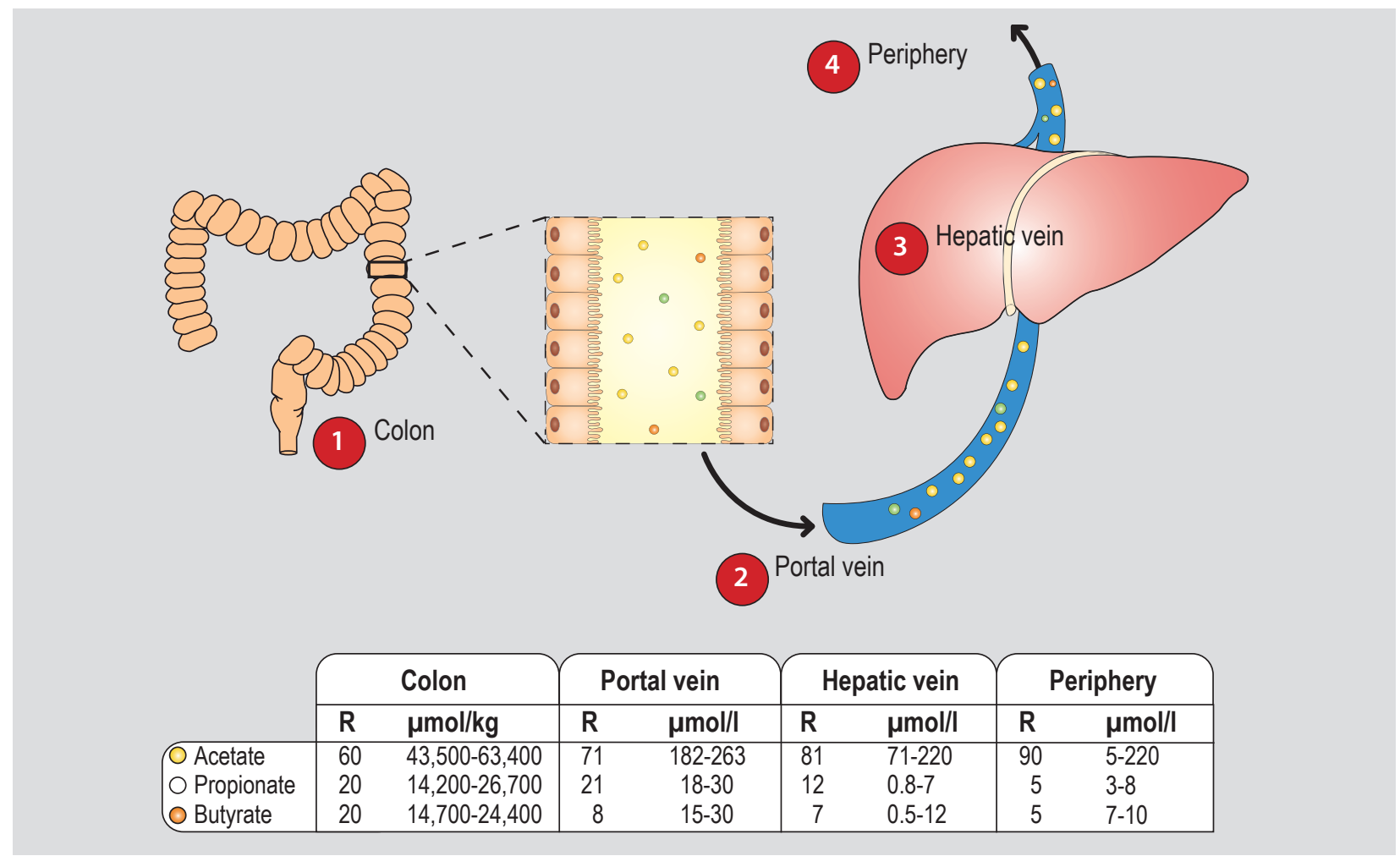

Figure 1. Short chain fatty acid (SCFA) molar ratio and concentration. Data derived from victims who suddenly died and/or from patients undergoing major upper abdominal surgery. Data are expressed as $\mu \mathrm{mol}$ per $\mathrm{kg}$ of luminal content in the colon and $\mu \mathrm{mol} / \mathrm{l}$ of blood in the portal and hepatic veins and in peripheral blood. Acetate is the most abundant SCFA in the large intestine, portal vein, hepatic vein and peripheral circulation and concentrations decrease, respectively. Note that if one approximates that $1 \mathrm{~kg}$ of luminal matter is equivalent to $1 \mathrm{I}$, the drop in concentration from the colon to the portal vein indicates that about $99.5 \%$ of each of the three SCFAs is used by the gut mucosa. The subsequent drop in concentrations between the portal and the hepatic veins further indicates that the remaining low level of propionate and butyrate are mainly extracted by the liver. Note this occurs to a lesser extent for acetate which remains in reasonable levels in the hepatic vein. 
More recently a stable-isotope dilution method was used to quantify the in vivo colonic production of SCFA in healthy humans after consumption of 15 gram prebiotic inulin (Boets et al., 2015). Primed continuous intravenous infusion with ${ }^{13} \mathrm{C}$-SCFA were applied while breath and blood samples were collected; it was estimated that $137 \pm 75$ mmol acetate, $11 \pm 9 \mathrm{mmol}$ propionate, and $20 \pm 17 \mathrm{mmol}$ butyrate were produced over a $12 \mathrm{~h}$ period. Comparison of this study outcome to in vitro human colonic gut models showed slightly different production ratios for the three SCFA. Although stable isotope dilution technology is the preferred way to estimate rates of SCFA appearance and disposal, the rapid turnover of the different SCFA may complicate interpretation of the data. Reappearance of label after metabolism inside peripheral cells may also lead to underestimation of the actual fluxes.

Breath gas $\left(\mathrm{H}_{2}\right.$ or $\left.\mathrm{CH}_{4}\right)$ are used to estimate fermentation to SCFA, but these markers only give a global indication of fermentation. New approaches for sampling SCFA directly in the gut are being investigated such as the IntelliCap system (Maurer et al., 2015), which would help alleviate the current issues with faecal samples only representing the balance between production, utilisation and absorption.

\section{Regulation of short chain fatty acid production and cross-feeding}

Besides production of butyrate, propionate and acetate, bacteria also produce intermediary SCFAs like formate, succinate and lactate in pure culture which are detected only in very small amounts in faeces, primarily due to bacterial cross-feeding (Figure 2). The diverse community structure in the large intestine means that bacteria do not act in isolation, and bacterial interactions, notably crossfeeding, i.e. the utilisation of substrates or metabolites released by other bacteria, are crucial in determining the levels of final SCFA in the colon. Moreover, bacterial crossfeeding plays a key role in maintaining the diversity and stability of this complex ecosystem. Bacteria can crossfeed on both SCFA products and/or smaller carbohydrate moieties released from the initial degradation of complex carbohydrates. For effective cross-feeding, bacteria have to be in close proximity. Hence, the spatial organisation and niche occupation of the bacterial community is important. Bacterial cross-feeding also drives biofilm formation where bacterial symbiosis is particularly important (MacFarlane and MacFarlane, 1997). Due to the limited amount of in vivo studies on cross-feeding, the phenomenon of cross-feeding is described below with examples of in vitro studies using gut models or specific co-cultures and supported when possible by the available in vivo studies.

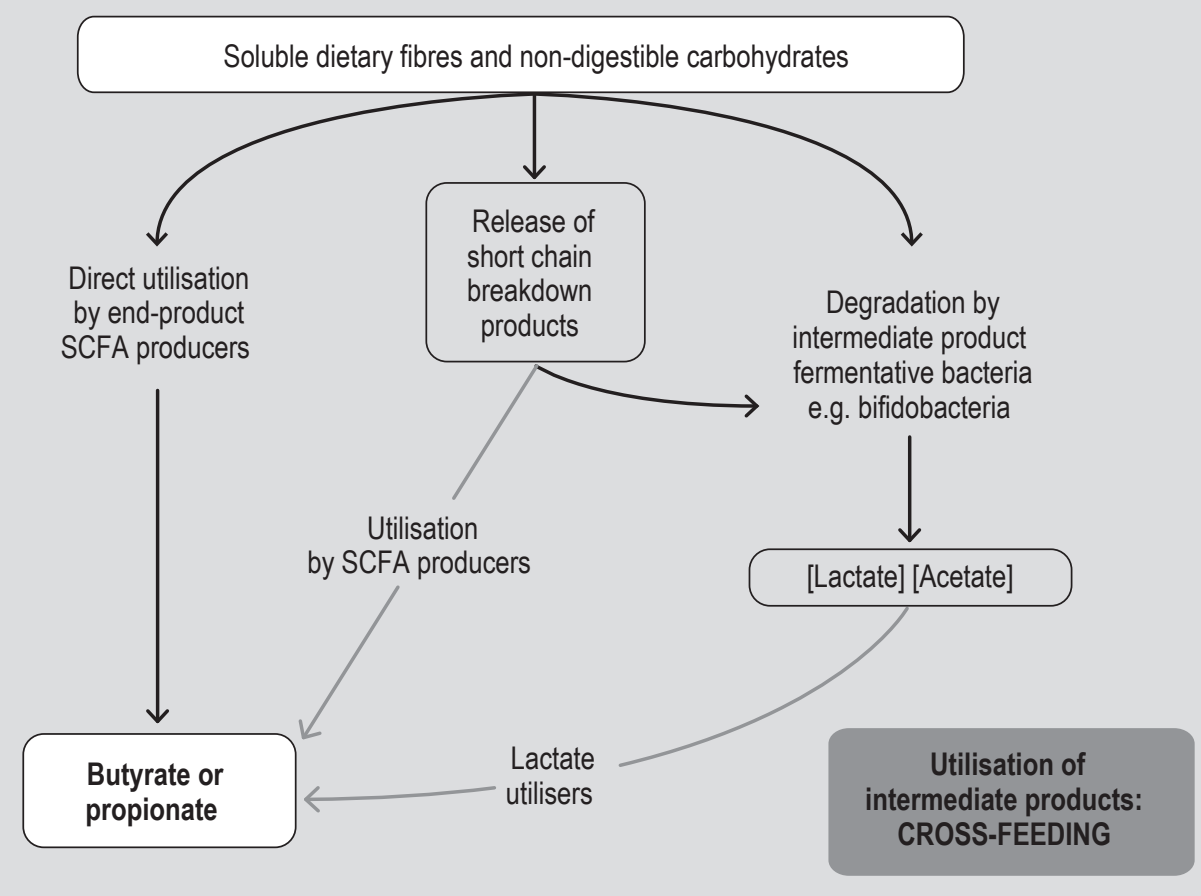

Figure 2. Bacterial cross-feeding. Schematic illustration of the direct fermentation of substrates (non-digestible carbohydrates, soluble fibres and specific prebiotics), or the cross-feeding on intermediate products, to produce the short chain fatty acids (SCFA) end-products propionate and butyrate. 
Some of the early work establishing bacterial cross-feeding mechanisms was triggered by the 'prebiotic conundrum. Specifically, the inulin-type-fructan prebiotics enhance the growth of bifidobacteria, yet also stimulate butyrate production, while bifidobacteria produce lactate, acetate, formate and ethanol, but never butyrate. Lactate is in fact only detected at low concentrations $(<5 \mathrm{mM})$ in faeces from healthy humans. Several studies revealed that lactate-utilising, butyrate-producing bacteria, including Eubacterium hallii and Anaerostipes species, removed lactate from laboratory media in co-cultures with Bifidobacterium adolescentis, thereby producing butyrate (Duncan et al., 2004). Isotope studies using ${ }^{13}$-C labelled lactate and $\left[\mathrm{U}-{ }^{13} \mathrm{C}\right]$ glucose confirmed the stimulatory effect of prebiotic fructans on the carbon flow from lactate or acetate into butyrate (Belenguer et al., 2006; Morrison et al., 2006). Detailed co-culture experiments of bifidobacteria strains with other human gut bacterial strains, which are able to use different carbohydrate growth substrates, demonstrated that two types of cross-feeding occur during prebiotic degradation: (1) conversion of the lactate and acetate produced by bifidobacteria during growth into butyrate; and (2) direct utilisation of released complex carbohydrate breakdown products by butyrateproducing bacteria (Belenguer et al., 2006; Falony et al., 2006; Morrison et al., 2006).

The substrate complexity, including chain length, is important in determining which bacteria can utilise which complex carbohydrates for growth. Only a few gut bacteria can use long-chain or complex carbohydrates, with many more microbes benefiting from release of short-chain length intermediary products by these primary degraders. Therefore, bacterial scavenging and fermentation of released mono- and oligo-saccharide products is an effective cross-feeding strategy.

It is beyond the scope of this review to cover the crossfeeding identified for all these complex substrates but a few examples for prebiotics, starch and intestinal mucin are discussed below. The impact of a range of prebiotics, non-digestible oligosaccharides and soluble fibres on the human stool microbiota composition from clinical studies was recently reviewed, which largely supports the in vitro studies and identifies some further potential cross-feeding interactions (Swanson et al., 2020).

The key starch utilising bacteria were identified by introducing radio-labelled starch into a colonic fermenter system and tracking the ${ }^{13-} \mathrm{C}$ incorporation into $16 \mathrm{~S}$ rRNA (Kovatcheva-Datchary et al., 2009). Several bacterial species namely Ruminococcus bromii, Eubacterium rectale, $B$. adolescentis and Prevotella species contributed to starch degradation, and R. bromii has been identified as a keystone starch degrader, releasing oligo- and mono-saccharides that can be used by other bacteria for growth by cross- feeding (Ze et al., 2012). Human studies with starch supplementation supported the key role of $R$. bromii and $E$. rectale in starch degradation (Martínez et al., 2010; Walker et al., 2011). The main fermentation products of $R$. bromii are acetate and formate whilst $E$. rectale produces butyrate.

Within the inulin-type fructans, there are a range of degradation capabilities by members of the gut microbiota and even a few bifidobacterial species have the capacity to grow on long-chain inulin (Rossi et al., 2005; Scott et al., 2013). The different abilities of bifidobacteria to utilise different chain lengths of inulin means that within-species cross-feeding occurs. In both co-cultures and animal models introduction of (multiple) Bifidobacterium species led to induction of genes involved in carbohydrate metabolism and increased SCFA production (Turroni et al., 2016; Turroni et al., 2015). The release of acetate by bifidobacteria was shown to stimulate the growth of $F$. prausnitzii on oligofructose. However, this only happened when slow preferential degradation of oligofructose occurred by $B$. adolescentis internally, and not during rapid efficient degradation of all chain lengths by other bifidobacteria species (Moens et al., 2016). Some butyrate producing bacteria such as F. prausnitzii are able to utilise oligofructose directly for growth (Scott et al., 2013). Such in vitro mechanistic studies investigating inulin-type-fructans are supported by human studies following dietary consumption and subsequent analyses of the faecal microbiota by molecular technologies such as $16 \mathrm{~S}$ rRNA sequencing or real-time PCR (Dewulf et al., 2013; Healey et al., 2018; Ramirez-Farias et al., 2009).

The intestinal mucus layer is also a carbohydrate source utilised to generate SCFA, although few gut anaerobes can use mucin directly for growth. Akkermansia muciniphila specialises in the degradation of host mucus and resides within the mucin layer (Van Herreweghen et al., 2017). Co-culture of $A$. muciniphila with butyrate-producing bacteria such as $E$. hallii showed that the release of oligosaccharides and production of acetate by $A$. muciniphila stimulated $E$. hallii growth and led to the synthesis of propionate, butyrate, vitamin B12, and 1,2-propanediol production (Belzer et al., 2017). Transcription of various A. muciniphila genes, including those involved in mucin degradation, were differentially regulated in co-culture with A. caccae (Chia et al., 2018). These studies clearly showed that bi-directional syntrophy is important in the complex gastrointestinal ecosystem. Bifidobacterium bifidum is also able to utilise mucin as a growth substrate, releasing monosaccharides and lactate. In co-culture experiments the growth of E. hallii and other bifidobacteria species on mucin were enabled by B. bifidum, resulting in altered SCFA profiles, including the utilisation of lactate by the $E$. hallii (Bunesova et al., 2018). The latter interaction may be particularly important in the early colonisation of the infant gut, and the removal of potentially damaging lactate. 
In silico models are developing in complexity and are now proving useful in unravelling the bacterial interactions in the gut ecosystem. Bacterial cross-feeding on both SCFA and carbohydrate degradation products are essential parameters to include in such models to obtain realistic outputs (Hoek and Merks, 2017). In silico models are initially validated by comparison with results from in vitro models. Thus, the flow of ${ }^{13-} \mathrm{C}$ labelled starch to propionate via succinate, with the remainder found in acetate and butyrate, could be accurately demonstrated. In addition, it was demonstrated that butyrate is mainly synthesised through cross-feeding on acetate (Binsl et al., 2010). The key role of lactate-utilising bacteria in converting lactate and acetate into butyrate in the human colon was also confirmed in silico, with findings replicating those from the batch culture experiments (Muñoz-Tamayo et al., 2011). Substrate preferences of bacteria have also been replicated using mathematical models, verifying the relative importance of cross-feeding on SCFA and carbohydrate degradation products (Van Wey et al., 2016). Moving forward, such models need to consider not only the presence and activity of different bacterial species, but also the relative abundance and competitive abilities of bacteria within the complex community for the different substrates, and the spatial organisation of bacteria within the ecosystem (Henson and Phalak, 2017; Rosendale et al., 2017). The more knowledge we have about bacterial interactions in vitro, the more accurate such in silico models can be in mimicking the gut ecosystem and thus the more knowledge we can gain about the impact of specific dietary substances on bacterial cross-feeding and metabolic outputs.

\section{Apical and basolateral short chain fatty acid transport}

Research on mechanisms involved in trans-epithelial transport of SCFA has been mostly carried out using isolated colonocytes. Both apical and basolateral transport have been studied. Apical transport has been proposed to follow separate routes. Depending on the $\mathrm{pH}$ prevailing in the intestinal milieu the SCFA can be protonated and diffuse across the membrane, but since the $\mathrm{pKa}$ of the different SCFA is around 4.8 and the luminal $\mathrm{pH}$ around 6 , most of the SCFA are in the dissociated form and are transported into enterocytes by active transport systems (Sellin, 1999). Three types of transporters have been found: (1) SCFA-bicarbonate co-transport: the activity of this system has been demonstrated though the proteins responsible have not yet been identified (Harig et al., 1996; Mascolo et al., 1991; Vidyasagar et al., 2005); (2) the monocarboxylate transporter (MCT)1-4, with most work done on MCT1 (SLC16A1) (Teramae et al., 2010) which also transports lactate and pyruvate in a proton co-dependent way (Teramae et al., 2010); and (3) the sodium dependent monocarboxylate transporter (SMCT, SLC5A8). SMCT1 has a preference for butyrate and transports propionate and acetate at a slower rate, although it is probably still the main transporter for them (Gupta et al., 2006; Takebe et al., 2005). Disruption of MCT1 in mice has been shown to be lethal. Experiments in the heterozygous mice showed a distinct intestinal phenotype pointing to an important role for this protein (Lengacher et al., 2013). In view of the fact that MCT1 expression is ubiquitous we will have to wait until intestinal models will be generated to understand the specific role of MCT1.

Since the $\mathrm{pH}$ in the cytosol of the enterocytes is higher than in the intestinal lumen, all SCFA will be ionised and cannot diffuse back to the intestinal lumen or out of the basolateral side of the cells. Therefore, on the basolateral side an active SCFA transport is required. Both SCFA/ $\mathrm{HCO}_{3}$ antiport and SCFA/cation symport have been suggested to be involved. The affinity of the basolateral SCFA/ $\mathrm{HCO}_{3}$ antiporter for butyrate is much lower compared to the apical transporter $(\mathrm{Km}=17.5 \mathrm{vs} 1.5 \mathrm{mM})$ suggesting that two different proteins are involved (Halestrap and Meredith, 2004; Harig et al., 1996). MCT4 and MCT5 have been found at the basolateral side of the membrane (Gill et al., 2005) and could be involved in transport but the importance of their role is as yet unknown. Clearly more work has to be carried out before we really understand the molecular mechanisms of, in particular, basolateral SCFA transport.

\section{Systemic concentrations of short chain fatty acids}

Compared to colonic levels, the plasma concentrations of the three main SCFA are very low: $5-220 ;<8 ;<10 \mu \mathrm{M}$ for acetate, propionate and butyrate, respectively (Bouter et al., 2018; Kootte et al., 2017; Neis et al., 2018; Van der Beek et al., 2015).

The acute SCFA profiles in the systemic circulation derived from the colonic fermentation of ${ }^{13} \mathrm{C}$-barley meals (Verbeke et al., 2010) or, ${ }^{13}$ C-inulin (Deroover et al., 2017) were determined using a stable isotope approach, which demonstrated that SCFA profiles in blood could change following intake of different dietary fibres. Several studies noted that there were large inter- and intra-individual variations in plasma SCFA concentrations, which may be due to differences in diet, gut microbiota, SCFA absorption and metabolism (Deroover et al., 2017; Peters et al., 1992).

Although portal concentrations of SCFA could be two times higher compared to the periphery blood (Cummings et al., 1987; Neis et al., 2018), there is a massive concentration gradient between the intestinal lumen and the blood compartment. Apparently, intestinal uptake is slower than either colonocyte metabolism or removal from the blood by other organs. This suggests that the transporters at the apical side of the colonocytes are important rate controlling steps for SCFA metabolism by the host. Since the lumen-blood gradient is higher for propionate and butyrate compared to acetate this may be particularly true for these two SCFAs (Figure 1). As discussed in the section 
on gluconeogenesis below, colonocytes actively metabolise butyrate, which may explain the low concentration of this SCFA in the blood.

\section{Short chain fatty acids in gut health}

Gut health is most often described by a combination of characteristics including: (1) an adequate production of gastrointestinal secretions leading to appropriate digestion and absorption of food, minerals and water; (2) a predictable and regular stool pattern and stool consistency; (3) a balanced intestinal microbiota; (4) an adequately functioning intestinal barrier; and (5) a status of well-being and absence of gastrointestinal diseases (Bischoff, 2011). In the following paragraphs, we provide an overview of how SCFA may impact the different aspects of gut health.

\section{Short chain fatty acids, gut permeability and tight junctions}

Interventions that modulate the human intestinal microbiota and thus likely SCFA production, yielded mixed results with respect to gut permeability (Reijnders et al., 2016; West et al., 2012). Most studies either did not measure SCFA or only measured faecal SCFA, which hampers drawing correlations between SCFA and intestinal permeability. In children with persistent diarrhoea, supplementation with green bananas (containing resistant starch) and pectin for 1 week significantly reduced intestinal permeability and stool output (Rabbani et al., 2004). Small intestinal permeability was also improved in healthy subjects after consumption of inulin-enriched pasta for 8 weeks compared to control pasta (Russo et al., 2012a). In contrast, 2 weeks of probiotics/FOS $\left(1.5 \times 10^{10} \mathrm{cfu}\right.$ probiotic mixture $+10 \mathrm{~g}$ fructo-oligosaccharides (FOS)) supplementation to healthy subjects did not affect intestinal permeability (Wilms et al., 2016). Similarly, prebiotic supplementation (galactooligosaccharides (GOS), $5.5 \mathrm{~g} / \mathrm{d}$ for 12 weeks) had no significant effect on intestinal permeability in 29 men with well-controlled type 2 diabetes (Pedersen et al., 2016). Finally, no effect on intestinal permeability was observed after administration of prebiotics to critically ill patients (Jain et al., 2004), burn patients (Olguin et al., 2005) or preterm infants (Westerbeek et al., 2011).

The connection between the epithelial cells is formed by tight junctions (TJ), adherent junctions and desmosomes, which consist of specific transmembrane proteins that are intracellularly connected. As the epithelial cells proliferate rapidly and renew quickly, tight junction proteins need to be strictly regulated to avoid detrimental effects on membrane integrity. The impact of SCFA, in particular of butyrate, on tight junctions has mainly been studied in in vitro studies and in various experimental animal models.
In monolayers of differentiated intestinal epithelial cells (cdx2-IEC), butyrate contributed to the intestinal barrier function by increasing the expression of the TJ protein claudin-1 (Wang et al., 2012). Furthermore, butyrate mitigated the negative effects of lipopolysaccharides (LPS) on epithelial integrity concurrent with a selective upregulation of expression of TJ proteins in an in vitro model using porcine intestinal epithelial cell line (IPEC-J2) (Yan and Ajuwon, 2017). The effect of butyrate on tight junction protein complex integrity in colonic epithelial cells includes the activation of AMP-activated protein kinase (AMPK) activity (Peng et al., 2009). Phosphorylation of AMPK was increased in cells after incubation with SCFA and inhibition of AMPK phosphorylation prevented the effects on permeability. In addition, butyrate also induced the redistribution of the TJ proteins occludin and zonula occludens-1 (ZO-1) in the cellular membrane (Elamin et al., 2013; Miao et al., 2016; Peng et al., 2009). These protective effects seem largely concentration dependent, with higher doses causing epithelial barrier disruption. The protective effect of butyrate on tight junction protein expression may also depend on stimulation of interleukin (IL)10-RA (Zheng et al., 2017). IL10-RA inhibits the claudin-2 TJ protein, known to increase intestinal permeability. Furthermore, butyrate may improve the barrier function by stabilising the transcription factor hypoxia-inducible factor (HIF). Intracellular oxidation of butyrate results in depletion of oxygen and stabilisation of HIF, which targets genes in the intestinal cells that are critical for microbial defence, barrier production and mucin production (Kelly et al., 2015).

Animal studies mostly use interventions with prebiotics of fermentable fibre and presume that the effects on barrier integrity are mediated by an increase in SCFA production. In mice, navy and black beans supplementation altered the microbial community structure resulting in enhanced SCFA production. Multiple aspects of mucus and epithelial barrier integrity were enhanced (Monk et al., 2017). Similarly, feeding fermentable dietary fibre to mice increased faecal SCFA and protected the colonic barrier by increased expression of TJ proteins (ZO-1 and ZO-2, occluding, junctional adhesion molecule A (JAMA) and claudin-7) (Hung and Suzuki, 2018). When genetically obese mice $(o b / o b)$ were fed a prebiotic-enriched diet, intestinal permeability was reduced and tight-junction integrity (expression of ZO-1 and occludin) was increased. The effects were mediated by endogenous production of glucagon-like peptide 2 (GLP-2) as administration of a GLP-2 antagonist abolished and pharmacological GLP-2 treatment mimicked the prebiotic effect (Cani et al., 2009b). Since SCFA concentrations were not measured, it is not clear whether the increased GLP-2 concentrations were mediated by prebiotic-induced SCFA production.

In IL-10 knock-out mice which spontaneously develop chronic colitis, multi-fibre feeding also increased epithelial 
expression and correct localisation of $\mathrm{TJ}$ proteins occludin and ZO-1 (Wang et al., 2016). Also in mice with experimentally induced autoimmune hepatitis that were fed a high fibre diet, expression of occludin, ZO-1 and claudin-1 was significantly increased ( $\mathrm{Hu}$ et al., 2018). Administration of (partially hydrolysed) guar gum to dextran sodium sulphate (DSS)-treated mice resulted in doubling of the total faecal SCFA concentrations compared to controls concomitantly with $60-120 \%$ increases in expression of occludin and claudin-3, 4 and 7 (Hung and Suzuki, 2016). Furthermore, oral administration of butyrate $(9 \mathrm{mM}$ in drinking water) but not a mixture of SCFA (35 mM acetate, $15 \mathrm{mM}$ propionate and $9 \mathrm{mM}$ butyrate) prevented a reduction in small intestinal permeability induced by the chemotherapeutic drug 5-fluorouracil (Ferreira et al., 2012).

In weaned piglets, administration of encapsulated sodium butyrate allowed halving the dose of antibiotics for preventing diarrhoea (Huang et al., 2015). Compared to control animals, functional permeability measures (urinary lactulose mannitol ratios) and occludin protein expression were significantly increased. In an animal model of impaired intestinal barrier function, oral administration of butyrate not only improved intestinal histology, but also reduced increased gut permeability, resulting in lowered mortality (Han et al., 2015).

In conclusion, although there is mechanistic support for effects of SCFA on TJ and barrier function, evidence in humans for effects of microbial modulation or SCFA on gut permeability is mixed.

\section{Short chain fatty acids affect mucus production}

Mucus is secreted by specialised Goblet cells of the intestinal mucosa. It forms an essential layer that varies in thickness and chemical composition along the gastrointestinal (GI) tract. Mucus is a biological lubricant, but also serves as a nutrient source for specialised gut microbes. Most importantly, mucus acts as a chemical-physical barrier that contributes to the protection against luminal agents such as chemicals, toxins, pathogens and allergens (for review see Pelaseyed et al., 2014).

An increase in mucus production is often deduced from increased expression of the MUC2 gene that codes for mucin 2 , the most prominent mucin secreted by intestinal epithelial cells. SCFA, in particular butyrate, stimulate MUC2 gene expression via selective acetylation/methylation of histones of the MUC2 gene (Burger-van Paassen et al., 2009; Hatayama et al., 2007) or through the synthesis of prostaglandin E1 as shown in in vitro co-culture model of functionally interacting intestinal epithelial and mesenchymal cells (Willemsen et al., 2003). Administration of butyrate enemas to mice stimulated the expression of MUC1, 2, 3 and 4 in different ways along the colon. In the proximal colon, MUC2 was preferentially increased by butyrate although the number of MUC2 positive cells was not changed. Surprisingly, upregulation of MUC2 expression resulted in a decrease in thickness of the adherent mucus layer (Gaudier et al., 2009). Nevertheless, MUC2 expression was not affected in rectal biopsies from healthy subjects and patients with ulcerative colitis (UC) in remission after daily administration of butyrate enemas (60 ml, 100 mM butyrate) for two weeks (Hamer et al., 2010).

Other studies directly measured mucus production. Ex vivo experiments using colonic tissue biopsies from colitis and cancer patients showed that physiological concentrations of butyrate stimulate mucin synthesis as demonstrated by increased incorporation of $\left[{ }^{3} \mathrm{H}\right]-$ labelled $\mathrm{N}$-acetylglucosamine into mucin (Finnie et al., 1995). Furthermore, in an isolated perfused rat colon loop model, luminal administration of acetate and butyrate, but not propionate, enhanced mucin secretion in a dose dependent manner. The increased secretion of mucin was accompanied by histological changes of goblet cells that reflected increased activation of mucin exocytosis (Barcelo et al., 2000).

Increased mucin synthesis was also supported by oral administration of prebiotics that stimulate luminal SCFA production through microbial metabolism. In a humanised rodent model, oral administration of two prebiotic fibres increased mucin concentration in caecum and faeces. Interestingly, the elevated mucin production was associated with a lower abundance of mucin-degrading bacteria in the caecum, whereas mucin degradation seemed more prominent in the colon (Van den Abbeele et al., 2011).

Besides affecting mucin production, butyrate may also affect its quality. Via posttranslational modification, carbohydrate side chains of varying length and sequence are added to the protein backbone of the mucins. In this way, mucins can be modified by sialylation, sulphation, acetylation, and fucosylation resulting in different proportions of neutral, acidic and sulphated mucins. Highly glycosylated structures of mucins give the mucus gel its physico-chemical properties (i.e. viscosity, hydrophobicity). Treatment of human intestinal goblet cells with butyrate mainly upregulated galectin-1 gene expression (Gaudier et al., 2004). Galection-1 is a regulatory glycosylation enzyme with a protective role in experimental colitis. Moreover, the sugar chains are involved in the interactions between the luminal microbiota and the epithelial cells since bacteria use these sugars not only as growth substrates, but also as adhesion sites. In vitro studies using LS174T colonic epithelial cells indicated that butyrate also improved the adherence of beneficial microbes such as Lactobacillus and bifidobacteria, whereas it prevented the adherence and potential translocation of pathogenic Escherichia coli bacteria (Jung et al., 2015). 


\section{Short chain fatty acids and immune reactivity}

\section{Short chain fatty acids affect mucosal immune function}

SCFA may have a versatile role in supporting immune homeostasis (Davie, 2003; McKenzie et al., 2017; McNabney and Henagan, 2017; Schilderink et al., 2016). Human evidence for effects of SCFA on intestinal immune function or inflammation is limited. The anti-inflammatory effects of butyrate have mainly been investigated in patients with UC where the impact of topical butyrate application using enemas on intestinal inflammation was evaluated (for a review, see Hamer et al., 2008). Such direct intestinal butyrate administration reduced the intestinal inflammatory status in colitis patients (Vernia et al., 1995). Moreover, the clinical anti-inflammatory activity of butyrate in UC patients was demonstrated through oral intake of fermentable dietary fibres (60 g oat bran/d corresponding to $20 \mathrm{~g}$ of dietary fibre) (Hallert et al., 2003). Although most studies contained relatively low numbers of participants and not all were placebo-controlled, there is a cautious optimism in favour of butyrate treatment. Nevertheless, butyrate treatment has not entered clinical application. A possible explanation is the difficulty to administer butyrate in the distal colon and the availability of effective alternative treatment options. Hence, both luminal administration and endogenous stimulation of butyrate production through microbial fermentation of dietary fibres seems to prevent pathological conditions of intestinal inflammation.

There is mechanistic evidence for an effect of SCFA on mucosal immune and inflammatory status, mainly from cell line and small animal models. SCFA, in particular butyrate, alter the secretion of pro-inflammatory mediators (e.g. interferon (IFN)- $\gamma$ IL-1, IL-2, IL-6, IL-8, tumour necrosis factor (TNF)- $\alpha$ ), as well as molecules involved in the homing of inflammatory cells and cell interactions (e.g. intercellular adhesion molecule 1 (ICAM-1), vascular cell adhesion molecule 1 (VCAM-1), T-cell receptors). Basically, these effects occur through inhibition of mitogen-activated protein kinases (MAPK) pathways and inhibition of nuclear factor $\mathrm{\kappa B}(\mathrm{NF}-\mathrm{\kappa B})$ in intestinal epithelial cells (Inan et al., 2000; Schwab et al., 2007). Activation of the G-protein-coupled receptors (GPRs) GPR41 and GPR43 (also known as free fatty acid receptor (FFARs) FFAR3 and FFAR2, respectively) on the immune cell membranes by butyrate results in decreased cAMP levels and increased cytoplasmic calcium levels leading to activation of MAPK, which transfers a signal from the cell surface to the nucleus (Li et al., 2017). The increased intracellular calcium concentrations also result in activation of the NLRP3 inflammasome and subsequent activation of caspase-1. Activated caspase-1 in turn converts pro-IL-18 into IL-18, which promotes epithelial repair (Macia et al., 2015). Inhibition of NF-KB is mediated by activation of $\beta$-arrestin 2 and results in decreased transcription of genes encoding many pro-inflammatory genes. Furthermore, the production of reactive oxygen species (ROS) during oxidative stress and involved in inflammatory processes, can be mitigated by SCFA (e.g. butyrate) through stimulation of antioxidant glutathion (GSH) (Russo et al., 2012b). At physiological dose, SCFA also inhibit pro-inflammatory cytokine release by intestinal epithelial cells induced by toll-like receptor (TLR) activators such as LPS (Iraporda et al., 2015).

Furthermore, SCFA modulate the function of dendritic cells (DCs). DCs are unique, not only because they are able to access the luminal content, but also because they either induce immune responses or maintain tolerance, depending on their stage of maturation.

Whereas incubation of human monocyte-derived DCs with acetate did not elicit significant changes in the transcriptome, butyrate and propionate reduced the release of several pro-inflammatory chemokines and inhibited the expression of LPS-induced cytokines (Nastasi et al., 2015). Incubation of DCs with butyrate in an early stage interfered with the maturation of the cells and kept them in an immature state. Major histocompatibility complex molecules, co-stimulatory molecules and classical DCassociated molecules were downregulated and the major T helper1-skewing factors IL-12 and IFN- $\gamma$ were substantially suppressed whereas the anti-inflammatory cytokine IL-10 was increased (Liu et al., 2012). Similarly, DCs exposed to butyrate expressed the immunosuppressive enzymes indoleamine 2,3-dioxygenase 1 (IDO1) and the vitamin A-converting enzyme aldehyde dehydrogenase 1A2 (Aldh1A2), promoted conversion of naive T-cells into immunosuppressive FoxP3+ $\mathrm{T}_{\text {regs }}$ and suppressed conversion of naive T-cells into pro-inflammatory IFN- $\gamma$ producing cells (Gurav et al., 2015). Moreover, all SCFA restored colonic $\mathrm{T}_{\text {reg }}$ population and function in germfree and SPF-mice thus protecting against colitis in an activated T-cell transfer model (Arpaia et al., 2013; Smith et al., 2013).

The impact of butyrate on differentiation and phenotypical changes of DCs was further reflected in functional assays revealing increased phagocytic activity and reduced T-cell stimulatory capacity (Millard et al., 2002). The induction of IL-10 producing $\operatorname{Tr} 1$ regulatory $\mathrm{T}$ cells by butyrate depended on the induction of retinoic acid producing enzymes (Kaisar et al., 2017; Schilderink et al., 2016).

Humoral immune responses are an important element of immune surveillance in the gut. Secretory $\operatorname{IgA}(\operatorname{SIgA})$ is the most prominent antibody produced in the intestinal mucosa that protects the intestines against bacterial and viral infections. Microbiota plays a role in supporting SIgA production. Acetate, but not butyrate, increased faecal IgA and IgA-positive B-cells in the lamina propria of wildtype mice but had no effect in GPR43 knockout (KO) mice, 
indicating that the process was mediated through specific SCFA receptor interaction. Retinoic acid, which can be stimulated by butyrate (Schilderink et al., 2016), played an important role in the increased production of IgA by B-cells (Wu et al., 2017). The role of retinoic acid was confirmed in vivo. Here, dietary fibre intake stimulated SCFA production, which was linked to an increased expression of vitamin A converting enzymes, a higher production of luminal IgA and increased presence of regulatory $\mathrm{T}$ cells in the intestinal mucosa (Goverse et al., 2017). Increasing colonic SCFA production by high-fibre feeding also increased IgA production and generation of $\mathrm{T}_{\text {reg }}$ cells in a mouse model of food allergy. The protective effect of SCFA on allergic sensitisation was further supported by the observation that mice lacking key SCFA receptors (GPR43 or GPR109A) exhibited aggravated allergic symptoms (Tan et al., 2016).

\section{SCFA and antimicrobial proteins}

The two major families of mammalian anti-microbial proteins are defensins and cathelicidins. They have the capacity to kill and/or inactivate bacteria, fungi, and enveloped viruses in vitro and also contribute to host defence in vivo (Zasloff, 2006). LL-37 is the only cathelicidin host defence peptide in humans. In addition to its bactericidal activities against gram-positive and gramnegative bacteria, LL-37 can neutralise bacterial LPS and is chemotactic for human peripheral monocytes, neutrophils, and CD4+ T lymphocytes (Hase et al., 2002). Butyrate is a potent inducer of cathelicidin expression when incubated in vitro with colonic carcinoma cell lines (Schauber et al., 2006). Moreover, synthesis of LL-37 was enhanced with butyrate in the presence of exogenously added purified MUC2, indicating regulatory mechanisms between MUC2 and cathelicidins in the colonic mucosa (Cobo et al., 2017).

\section{Short chain fatty acids provide energy to the colonocytes}

In contrast to small intestinal epithelial cells that primarily use glucose and glutamine as energy substrates (Mithieux, 2001), SCFA constitute the major energy source of colonocytes. Already in 1980, Roediger demonstrated that $70 \%$ of the total amount of oxygen consumed by human colonocytes in vitro was used for butyrate oxidation (Roediger, 1980). SCFA oxidation has been estimated to recover 600-750 kJ of energy per day from undigested carbohydrate, corresponding to approximately $8 \%$ of the daily recommended energy needs (Bergman, 1990; McNeil, 1984). After absorption into the cells, SCFA diffuse through the inner mitochondrial membrane and enter the citric acid cycle to generate ATP. Complete oxidation of one mole acetate, propionate and butyrate provides 10, 18 and 27 mole ATP, respectively (Clausen and Mortensen, 1995). Butyrate is oxidised at a faster rate compared to acetate and propionate, as demonstrated in in vitro experiments by measuring ${ }^{14} \mathrm{CO}_{2}$ production after incubation of human colonocytes with ${ }^{14} \mathrm{C}$-labelled acetate, propionate and butyrate (Clausen and Mortensen, 1995). Half of the maximal oxidation rate was obtained for butyrate at a concentration of $82 \mu \mathrm{M}$ whereas higher concentrations were required for acetate $(565 \mu \mathrm{M})$ and propionate $(369 \mu \mathrm{M})$.

Both in vitro and in vivo (animal and human) studies have indicated that butyrate oxidation is impaired in UC resulting in a state of energy deficiency ultimately leading to a reduction in sodium absorption and mucin secretion and a shorter life of the colonocytes (De Preter et al., 2011). These results confirm that a certain level of butyrate oxidation is vital for a healthy colonic epithelium. Yet, it remains unclear whether levels above normal provide additional benefits.

\section{Short chain fatty acids affect motility and transit}

Experimental studies in rats have shown that SCFA affect colonic motility although results are contradictory and appear to depend on luminal SCFA concentrations. Infusion of physiological SCFA concentrations (100 mM) into the rat colon did not affect colon motility whereas high concentrations $(500 \mathrm{mM})$ significantly reduced colon contractility (Cherbut et al., 1998). Also the mechanism of action is not clear and may involve secretion of peptide YY (PYY) (Cherbut et al., 1998), interaction with GPR41 and GPR43 (Dass et al., 2007) or stimulation of the efferent vagal nerves by serotonin released from enterochromaffin cells (Fukumoto et al., 2003). Furthermore, the effects of SCFA on motility might differ among species and there is not yet direct evidence that SCFA influence colon motility in humans (Cherbut, 2003; Jouet et al., 2013).

\section{Short chain fatty acids and mineral absorption}

There is compelling data that prebiotics, such as inulin-type fructans and GOS lead to increased mineral absorption, in particular enhancing calcium absorption (Coxam, 2007). Moreover, effects have also been proposed for the absorption of other minerals such as magnesium and phosphorus. SCFA generated from the colonic fermentation of prebiotic fibres are the proposed main protagonist contributing to this effect, with several mechanisms of actions suggested.

Due to technical and logistic difficulties in analysing the effects of SCFA on mineral absorption in vivo, data from human studies is scarce. A trial with six healthy male volunteers investigated the effects of SCFA on calcium absorption in the distal colon with rectal infusions (Trinidad et al., 1993). $30 \mathrm{mmol}$ of calcium were infused together with different amounts of SCFA $(0,22.5$ or $45 \mathrm{mmol}, 3: 1$ mixture of acetate and propionate). Infusion of SCFA together with calcium led to dose-dependent increases in serum calcium concentrations. Follow-on studies demonstrated that propionate exhibited a greater effect 
than acetate at higher doses of calcium (Trinidad et al., 1993, 1997, 1999). Moreover, an increase in the absorption of the SCFA acetate and propionate at higher doses of calcium was demonstrated. Therefore, the hypothesis of a calcium-hydrogen exchange similar to that proposed by Lutz and Scharrer (1991) was supported. Comprehensive data is available from in vitro studies, which support the mechanism of action. The production of SCFA led to a decreased $\mathrm{pH}$ of the colonic contents and thereby may reduce the complexation of minerals like calcium (Weaver, 2015), resulting in more calcium being available for uptake in the colon. However, the decreased colonic $\mathrm{pH}$ might not be the only mechanism by which SCFA enhance calcium absorption. In a series of in vitro experiments, SCFA were added to Caco-2 human intestinal epithelial cells and resulted in an increase in mRNA expression of proteins involved in paracellular calcium uptake (Fukushima et al., 2009, 2012). Transcription of transient receptor potential vanilloid type 6 (TRPV6/CaT1/ECaC2), which is located in small intestinal mucosal epithelial cells on the luminal side where it promotes transcellular calcium uptake, was elevated in Caco2-cells upon stimulation with sodiumbutyrate and sodium-propionate (Fukushima et al., 2009). Moreover, mRNA expression of calbindin-D9k, a calciumbinding protein that transports intracellular calcium to the basolateral membrane of mucosal epithelial cells, was upregulated (Fukushima et al., 2012). Furthermore, in experiments with rat cecum and colon explants in an Ussing chamber it has been demonstrated that the presence of SCFA increased transepithelial calcium transport (Mineo et al., 2001; Raschka and Daniel, 2005). Similar results were reported by Kashimura et al. (1996) who used hindgut segments from rats to analyse the stimulatory effects of SCFA on the absorption of calcium, magnesium and phosphorus. They also showed an increase in absorption of these minerals upon addition of acetic and butyric acid. These findings support the concept of additional stimulatory effects of SCFA on mineral, particularly calcium, uptake. Hence, stimulatory effects of SCFA on mineral absorption go beyond the effect of lowering $\mathrm{pH}$ as the sole underlying mechanism.

Three animal experiments attempting to directly determine the effect of SCFA on mineral absorption were identified. In a luminal perfusion experiment with rats, Lutz and Scharrer (1991) demonstrated in an in vivo setting that acetate and butyrate caused an increase in calcium absorption in the distal colon. In the proximal colon, this calcium absorption enhancing effect was not observed (Lutz and Scharrer, 1991). The authors hypothesised that a calciumhydrogen exchanger located in the apical membrane of the epithelium might be involved in calcium absorption by the distal colon (Lutz and Scharrer, 1991). In accordance with the mechanistic in vitro and ex vivo studies described above, Kashimura et al. (1996) demonstrated that the intake of different substrates increased mineral absorption and retention in rats corresponding to the fermentability of these substrates. Furthermore, Fukushima et al. (2009) found changes in gene expression in rat colorectal mucosa cells in response to a diet containing FOS, which were in accordance to those observed in vitro in Caco- 2 cells. Namely, TRPV6 and calbindin-D9k mRNA expression were increased after the FOS diet, indicating that SCFA are the mediators of this calcium absorption enhancing effect (Fukushima et al., 2009).

In summary (Figure 3), there is consistent mechanistic evidence that SCFA, in particular butyrate, are important regulators of intestinal barrier function through mechanisms that include stimulation of mucin synthesis and quality, the synthesis of antimicrobial peptides as well as reducing epithelial permeability targeting tight junction complex integrity. Furthermore, SCFA may regulate mucosal immunity, luminal administration and endogenous stimulation of butyrate production seem to benefit pathological conditions of intestinal inflammation. Nevertheless, human intervention studies are limited and report mixed results of SCFA on gut permeability as well as mucosal immunity and inflammation. Finally, a consistent effect of SCFA on colonic calcium absorption has been demonstrated in vitro, ex vivo and confirmed by rectal infusion experiments in rats and humans.

\section{Short chain fatty acids in metabolic health}

\section{Body weight control}

This part of the review aims to provide an integrated view on the impact of SCFA on energy homeostasis by collating and examining the recent evidence around (1) the effect of increasing the provision of SCFA on body weight, energy intake and energy expenditure, and (2) the effect of SCFA receptors, through rodent GPR41 and GPR43 knockout studies, on body weight, energy intake and energy expenditure (Figure 4).

\section{Body weight: selected studies}

In total, 19 studies reporting a body weight outcome that met inclusion criteria were identified. Fourteen studies reported the effect of increasing the provision of SCFA on body weight. Of these, 10 studies were conducted in mice (8 in C57BL/6 mice, 1 in E3LCETP mice and 1 in LDLr $\mathrm{KO}$ mice) and 3 in rats ( 2 in non-described rats and 1 in OLETF/LETO rats) and only a single study was conducted in humans (overweight/obese adults). Within the rodent studies, the SCFA investigated were acetate in 6 studies, butyrate in 10 studies, propionate in 4 studies and a mixture of acetate, butyrate and propionate in 1 study. Acetate was administered orally via diet in 3 studies, oral injection in 1 study, intraperitoneal injection in 1 study and intragastric infusion in 1 study. Butyrate was administered orally via diet 


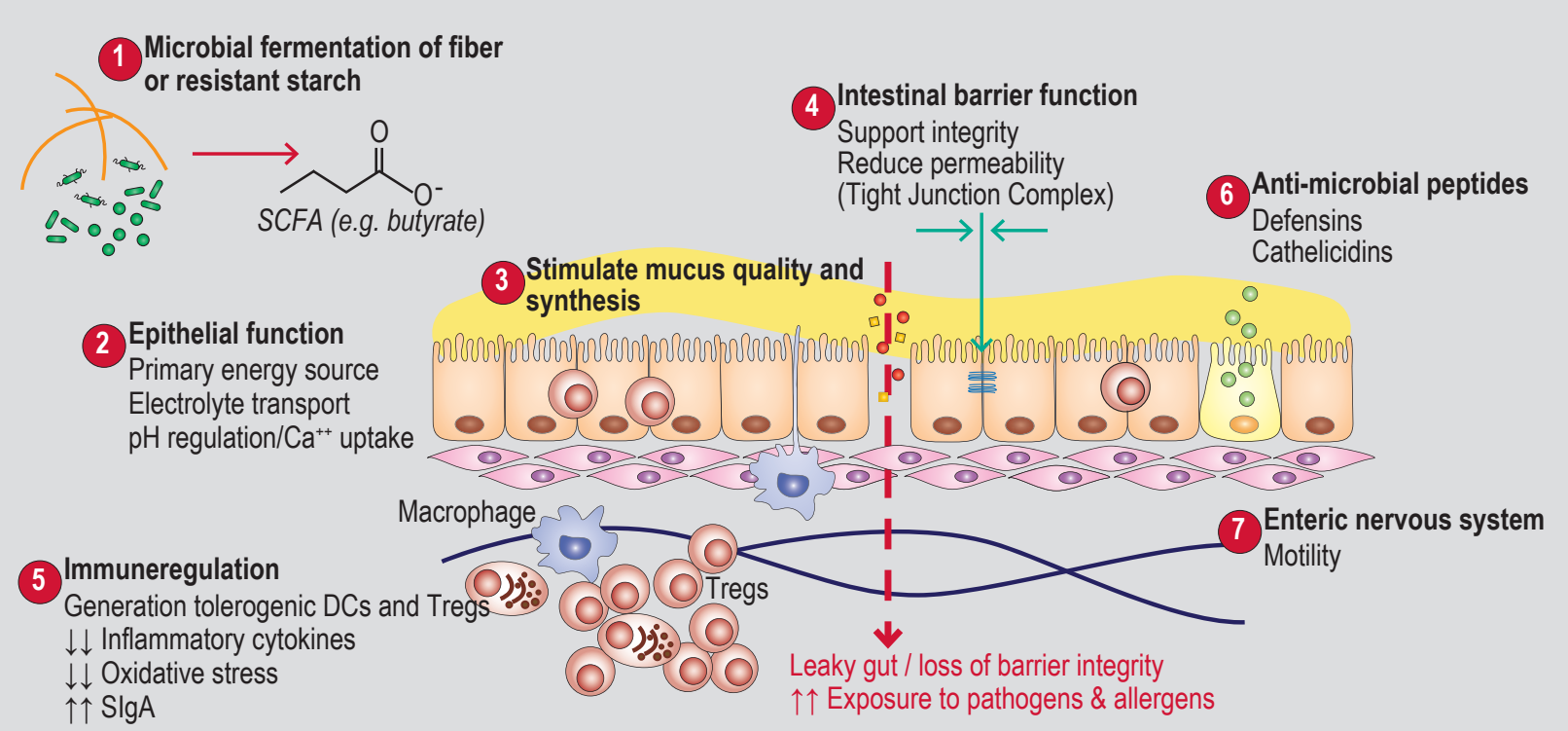

Figure 3. Effects of short chain fatty acids (SCFA) on intestinal mucosal homeostasis. Bacteria inhabiting the gastrointestinal tract can ferment fibres and oligosaccharides to produce SCFAs, e.g. acetate, propionate and butyrate (1). These metabolites play an important role in the microbiome-host interface, and maintain intestinal homeostasis through supporting epithelial cell function (2), strengthening intestinal barrier integrity $(3,4)$ and affecting immunoregulatory processes, e.g. the generation of tolerogenic DC and T cells and anti-inflammatory processes (5). SCFA also support the innate immune defence against pathogenic bacteria through the stimulation of antimicrobial molecules (6). Moreover, they can act on the enteric nervous system (7) affecting gut motility and the gut-brain axis, the latter substantiating their potential beneficial role in certain neurological disorders.

in 8 studies, oral gavage in 1 study and intragastric gavage in 1 study. Propionate was administered orally via diet in all 4 studies. The mixture of SCFA was administered orally via diet. In the human study, the SCFA investigated was propionate, which was administered orally via diet. Five studies reporting the effect of SCFA receptor knockout on body weight were identified, of which 2 studies investigated GPRR41-KO and 3 study investigated GPR43-KO.

\section{Short chain fatty acids and body weight}

The investigation into the effect of SFCA supplementation and body weight in humans is at present limited with only one study reporting body weight change (Table 1 , human), with the majority of the current literature focussing mainly on fibre supplementation and endogenous SCFA production rather than supplementation. Chambers et al. (2015) demonstrated that propionate supplementation to human subjects protected against weight gain as part of a habitual diet. A $10 \mathrm{~g}$ a day supplementation of an inulinpropionate ester, delivering additional 2.36 g propionate into the colon, for 24 weeks resulted in a significantly reduced weight gain compared to control. Only $4 \%$ of the participants in the inulin-propionate ester group gained greater or equal to $3 \%$ body weight, compared with $25 \%$ in the control group, with an additional $17 \%$ in the control group gaining at least $5 \%$ body weight. Currently, the evidence that SCFA supplementation in humans influences body weight is limited to this single study investigating propionate supplementation, and thus generalising the result in the context of human body weight effect is not currently possible.

Thirteen studies were identified (Table 1, rodents), which have recorded the impact of SCFA administration on body weight in rodents, and 12 of the 13 showed a beneficial effect of SCFA administration on weight loss, prevention of weight gain or attenuation of weight gain. Ten studies investigated the effects of butyrate administration on body weight in rodents, of which all reported improvements in body weight compared to control. Li et al. (2017) showed butyrate, incorporated into a high fat diet (HFD) for 9 weeks reduced diet induced obesity in mice by $27 \%$ compared with no butyrate in a HFD control group. Similar results were observed by Gao et al. (2009), who showed that butyrate supplementation within a HFD significantly reduced HFDinduced body weight gain over a 16 week period, compared to control. Following an additional 5 weeks of butyrate supplementation, a $10.2 \%$ reduction in body weight was observed. A further study by Arnoldussen et al. (2017), showed that 2 months of butyrate supplementation on a HFD in mid-adult mice tended to reduce body weight by $16 \%$, but this was not significantly different. However, in late-adult mice ( $>10$ months old) there was a $23 \%$ reduction in body weight $(P<0.001)$ in diet induced obese mice fed a HFD at 12 months, highlighting the longer-term effect of 


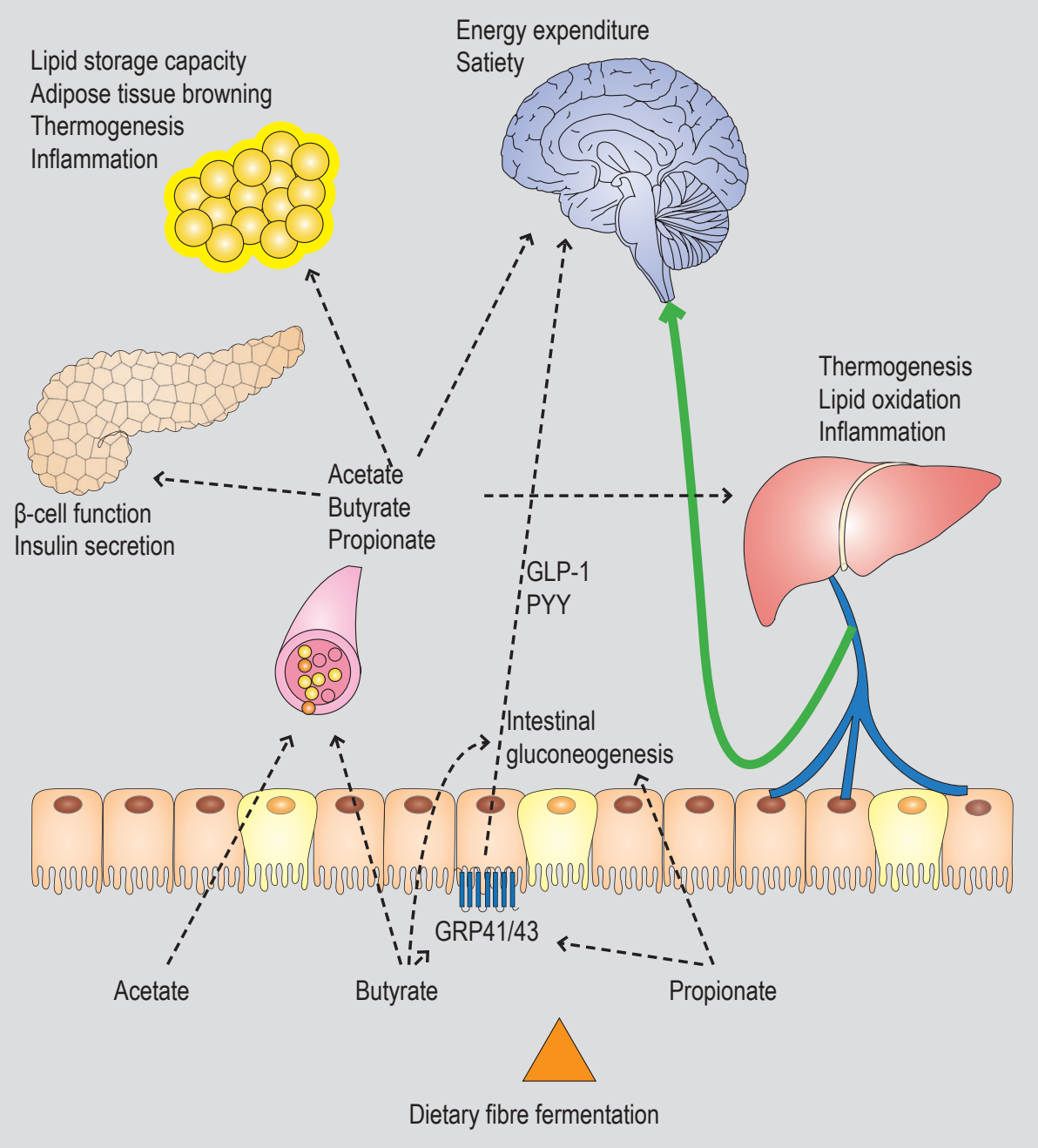

Figure 4. Short chain fatty acids (SCFA) and metabolic health. The best studied mechanism include the capability of mainly propionate and butyrate bind to G-protein-coupled receptors (GPR41 and GPR43) in the colon leading to the production of the gut hormones peptide YY (PYY) and glucagon-like peptide 1 (GLP-1), thereby affecting satiety and glucose homeostasis. Propionate and butyrate activate intestinal gluconeogenesis by several complementary mechanisms. Released glucose initiates a neural signal conveyed by portal nerves (in green) to the brain, resulting in metabolic benefits (satiety, insulin sensitivity). SCFA can also reach the circulation and can, thereby, directly affect peripheral tissue substrate metabolism and function. In the adipose tissue, acetate and propionate might attenuate intracellular lipolysis and affect the lipid buffering capacity. Acetate, and especially propionate and butyrate might reduce the secretion of proinflammatory cytokines and chemokines, thereby possibly reducing local macrophage infiltration. Mainly acetate and butyrate may increase thermogenesis and browning in adipose tissue. Acetate and butyrate increase liver lipid oxidation and decrease inflammation. Propionate may improve $\beta$-cell function and SCFA may affect glucose-stimulated insulin secretion.

butyrate on attenuating weight gain on HFD. Additional animal studies have also reported an attenuation of body weight gain with butyrate administration (De Vadder et al., 2014; Den Besten et al., 2015; Dutzan et al., 2017; Guo et al., 2016; Henagan et al., 2015; Hong et al., 2016; Kang et al., 2017; Lim et al., 2012; Lu et al., 2016; Zhou et al., 2017).

The role of acetate supplementation in body weight regulation appears to be less clear with both positive and negative effects. Acetate supplementation has been shown to attenuate HFD associated weight gain (Den Besten et al., 2015; Guo et al., 2016; Kimura et al., 2013; Lim et al., 2012; Lu et al., 2016; Yamashita et al., 2007). In the studies by Guo et al. (2016) and Lu et al. (2016) it was shown that dietary supplementation of acetate, propionate, butyrate or a mixture of the three SCFA significantly suppressed HFD induce weight gain, with acetate having the greatest overall effect $(\approx 72 \%)$. However, an investigation by Perry et al. (2016) reported that chronic intragastric infusion of acetate for 10 days promoted an increase in body weight compared 
Table 1. Tabulated summary of the effects of increasing the provision of short chain fatty acids (SCFA) on body weight in humans and rodents. ${ }^{1}$

\section{Reference Sample characteristics}

\section{Humans}

Chambers et

al., 2015

\section{Rodents}

$\begin{array}{ccl}\text { Arnoldussen et } & \text { LDLr KO male mice }(\mathrm{n}=30) \text {, age } 3 \text { or } 6 \mathrm{~m} \\ \text { al., } 2017 & \text { SCFA: } & \text { butyrate } \\ & \text { Dose: } & 5 \% \mathrm{w} / \mathrm{w} \\ & \text { Administered via: } & \text { Oral; HFD or HFD + butyrate } \\ \text { Duration: } & \text { Age } 3 \mathrm{~m} \text { mice }=4 \mathrm{~m} \text { on HFD }+2 \mathrm{~m} \mathrm{HFD}+\text { butyrate; age } \\ & & 6 \mathrm{~m} \text { mice }=6 \mathrm{~m} \text { on HFD + } 2 \mathrm{~m} \text { HFD + butyrate }\end{array}$

\section{Den Besten et $\quad$ C57BI/6J male mice ( $\mathrm{n}=6-8)$, age $2 \mathrm{~m}$}

$$
\text { al., } 2015
$$

SCFA:

acetate, butyrate, and propionate

Dose: $5 \% \mathrm{w} / \mathrm{w}$

Administered via: oral; HFD or HFD + acetate, butyrate or propionate Duration: 12 wk

De Vadder et Sprague-Dawley male rats $(n=6)$, age 6-8 wk, BW 275-300 g

$\begin{array}{lll}\text { al., } 2014 & \text { SCFA: } & \text { butyrate and propionate } \\ & \text { Dose: } & 5 \% \mathrm{w} / \mathrm{w}\end{array}$

Administered via: oral; standard diet or standard diet + butyrate or propionate

Duration: $\quad$ 10-14 d

Gao et al., 2009 Dietary-obese C57BL/6J male mice ( $n=10)$, age 4 wk

$\begin{array}{ll}\text { SCFA: } & \text { butyrate } \\ \text { Dose: } & 5 \% \mathrm{w} / \mathrm{w}\end{array}$

Administered via: oral; HFD or HFD + butyrate

Duration: $\quad 16$ and $21 \mathrm{wk}$

Hong et al., $\quad$ C57BL/6 male mice $(n=8)$ on HFD diet 2016

SCFA: butyrate

Dose: $\quad 80 \mathrm{mg}$

Administered via: oral; HFD or HFD + butyrate gavage dosing

Duration: $\quad 5$ doses in $10 \mathrm{~d}$

Henagan et al., C57BL/6J male mice ( $n=10$ per group), age 5 wk

2015

SCFA: butyrate

Administered via: oral; LFD, HFD or HFD + butyrate

Duration: $\quad 10 \mathrm{wk}$

Li et al., 2018 E3L.CETP male mice ( $n=8-10)$, age 10-12 wk

$\begin{array}{ll}\text { SCFA: } & \text { butyrate } \\ \text { Dose: } & 5 \% \mathrm{w} / \mathrm{w}\end{array}$

Administered via: oral; HFD or HFD + butyrate

Duration: $\quad 9 \mathrm{wk}$

Lin et al., 2012 C57BL/6N male mice $(n=8)$, age $3 \mathrm{~m}$

SCFA: acetate, butyrate, and propionate

Dose: $\quad$ acetate $(3.74 \%)$, butyrate $(5 \%)$, propionate $(4.3 \%)$

Administered via: oral; HFD or HFD + acetate, butyrate or propionate

Duration:

\section{Outcome}

Significant reduction in $\mathrm{BW}$ gain $(\sim 5 \%)$ $(P=0.033)$, and prevention of increase in BW $(\sim 3 \%)(P=0.036)$, with habitual diet + propionate compared to habitual diet.

In baseline age $3 \mathrm{~m}$ mice, no-significant effect of HFD + butyrate compared to HFD ( $P>0.05)$. In baseline age $6 \mathrm{~m}$ mice, significant reduction in $\mathrm{BW}(23 \%)$ with HFD + butyrate compared to HFD $(P<0.001)$.

Significant reduction in BW gain ( -8 g) with HFD + either SCFA compared to HFD $(P<0.05)$.

Significant prevention of BW gain $(\sim-5 \mathrm{~g})$ with standard diet + butyrate or propionate compared to standard diet $(P<0.05)$.

At 16 wk, significant reduction in BW gain $(\sim-17 \mathrm{~g})$ with HFD + butyrate compared to HFD $(P<0.05)$. At 21 wk, further significant reduction in BW gain (10.2\%) with HFD + butyrate compared to HFD $(P<0.05)$.

Significant reduction in $\mathrm{BW}$ gain $(\sim-3 \mathrm{~g})$ with HFD + butyrate gavage dosing compared to HFD $(P<0.05)$.

Significant prevention of BW gain ( -8 g) with HFD + butyrate compared to HFD. ${ }^{2}$

Significant prevention of BW gain ( $27 \%$ / $\sim-10 \mathrm{~g})$ with HFD + butyrate compared to HFD $(P<0.001)$.

Significant suppression of BW gain ( 40\%) with HFD + acetate compared to HFD $(P<0.001)$. Significant prevention of BW gain $(\sim 40 \%)$ with HFD + butyrate and propionate compared to HFD $(P<0.0001)$. 
Table 1. Continued.

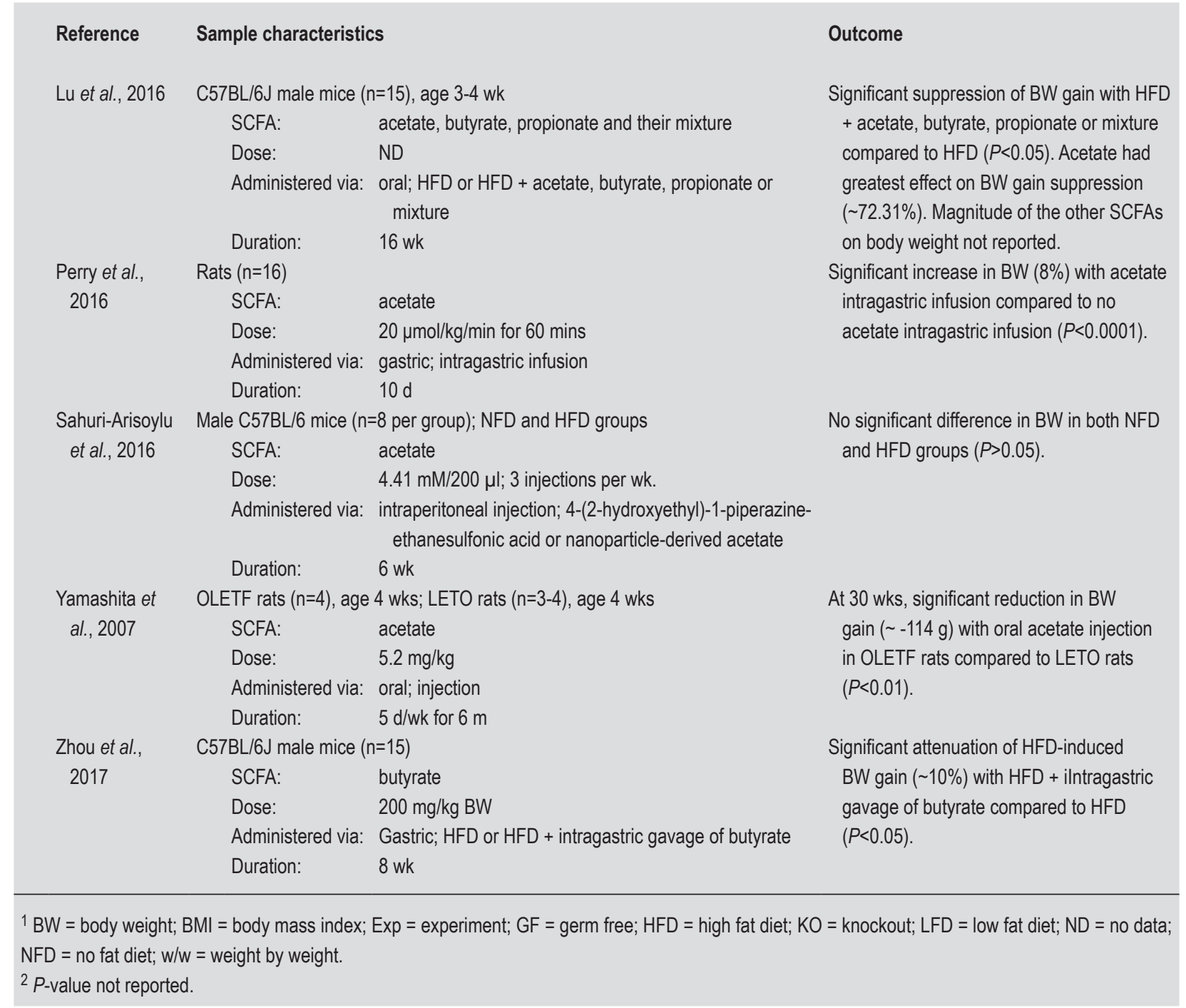

to control treated rodents. Similarly, Sahuri-Arisoylu et al. (2016) found that intraperitoneal injection of nanoparticlederived acetate for 6 weeks increased body weight when on a normal chow diet, although such difference was not observed in mice fed a high fat diet.

Although it is the least studied out of the three SCFA in rodents, propionate has shown to directly attenuate high fat diet weight gain in all 4 studies identified with a 10-14 day up to 12 week duration (De Vadder et al., 2014; Den Besten et al., 2015; Guo et al., 2016; Lim et al., 2012; Lu et al., 2016). Two separate studies have looked at the combination of all three SCFA on body weight, demonstrating that there was a significant reduction in body weight gain (Den Besten et al., 2015; Guo et al., 2016; Lu et al., 2016). In general, rodent studies highlight that oral SCFA supplementation attenuates weight gain associated with a high fat diet. However, there is currently a lack of evidence to suggest that SCFA supplementation results in direct weight loss or prevents weight gain when added to normal chow.

Mechanistically, five studies were identified (Table 2) that investigated the impact of either GPR43 or GPR41 KO on body weight in rodents, 4 of which have found body weight difference between GPR-KO mice and there control. The initial work of Samuel et al. (2008) reported the effect of GPR41-KO on weight gain in germ free (GF) raised mice and those colonised with the saccharolytic bacterium, Bacteroides thetaiotamicron and the methanogenic archaeon, Methanobrevibacter smithii (Bt/Ms). GPR41-KO had no effect on weight gain compared to wild types under GF raised conditions, whilst weight gain was significantly lower in GPR-KO mice compared to wild types in the $\mathrm{Bt} / \mathrm{Ms}$ colonised mice, suggesting that GPR41 signalling contributes to body weight gain. This observation is not supported by others who found that GPR41-KO in mice 
Table 2. Tabulated summary of the effects of short chain fatty acid (SCFA) receptor knockout on body weight. ${ }^{1}$

\begin{tabular}{|c|c|c|c|c|}
\hline Reference & $\begin{array}{l}\text { SCFA } \\
\text { receptor }\end{array}$ & Sample characteristics & Duration & Outcome \\
\hline $\begin{array}{l}\text { Bellahcene et } \\
\text { al., } 2013\end{array}$ & GPR41 & $\begin{array}{l}\text { GPR } 41-K O \text { vs wildtype C57BL/6 mice }(n=9) \text {. } \\
\text { HFD }\end{array}$ & 40 wk & No significant difference in $\mathrm{BW}(P>0.05)$. \\
\hline $\begin{array}{l}\text { Bjursell et al., } \\
2011\end{array}$ & GPR43 & $\begin{array}{l}\text { Male GPR43-KO }(n=9) \text { vs wildtype C57BL/6 } \\
\text { mice }(n=7) . \text { Normal chow and HFD groups }\end{array}$ & 35 wk & $\begin{array}{l}\text { Significantly lower BW in GPR43-KO mice compared to } \\
\text { wildtype C57BL/6 mice, when on HFD. }{ }^{2}\end{array}$ \\
\hline $\begin{array}{l}\text { Kimura et al., } \\
2013\end{array}$ & GPR43 & $\begin{array}{l}\text { Male GPR43-KO vs wildtype 129/Sv mice } \\
(n=7) \text {. Normal chow and HFD groups }\end{array}$ & $14-16$ wk & $\begin{array}{l}\text { Significant increase in BW on normal chow }(\sim 8 \mathrm{~g}) \text { and } \\
\text { HFD }(\sim 20 \mathrm{~g}) \text { in GPR43-KO mice compared to wildtype } \\
\text { 129/Sv mice }(P<0.005) \text {. }\end{array}$ \\
\hline Lin et al., 2012 & GPR41 & $\begin{array}{l}\text { Male GPR41-KO mice. Exp } 1 \text { ( } n=8-13) \text {, exp } 2 \\
(n=34-41) . \text { Butyrate }(5 \%) \text {, propionate }(4.3 \%) \\
\text { or acetate }(3.74 \%) \text { in HFD }\end{array}$ & $\begin{array}{r}\operatorname{Exp} 1: 1 w k \\
\exp 2: 8 d\end{array}$ & $\begin{array}{l}\text { Exp 1: no significant difference }(P>0.05) \text {. Acetate result } \\
\text { not reported. Exp 2: significant suppression of BW } \\
\text { gain }(\sim-2 \mathrm{~g}) \text { in HFD + butyrate and HFD + propionate } \\
(P<0.001) \text {. Acetate not reported. }\end{array}$ \\
\hline $\begin{array}{l}\text { Samuel et al., } \\
2008\end{array}$ & GPR41 & $\begin{array}{l}\text { Wildtype vs GPR41-KO mice with and without } \\
\text { a model fermentative microbial community } \\
\text { ( } \mathrm{n}=4-9 \text { per group) }\end{array}$ & 4 wk & $\begin{array}{l}\text { No significant difference in BW between GF wildtype and } \\
\text { GPR41-KO mice }(P>0.05) \text {. Significant reduction in BW } \\
\text { gain in GPR41-KO mice compared to wildtype mice } \\
\text { with model fermentative microbial community }(P<0.05) \text {. }\end{array}$ \\
\hline
\end{tabular}

(Bellahcene et al., 2013; Lim et al., 2012) had no impact on body weight compared to wild-type mice on standard chow diet or HFD. Furthermore, initial work by Bjursell et al. (2011) identified that GPR43-KO mice had lower body weight gain compared to wild type controls after 35 weeks of a HFD. No differences were observed on the normal chow diet. Conversely, Kimura et al. (2013) demonstrated that body weight of both normal chow and high fat diet fed GPR43-KO mice were significantly higher than that of wild-type mice. In summary, the available studies do not report a consistent impact of either GPR43 or GPR41 signalling on weight gain in rodent $\mathrm{KO}$ models.

In summary, the current literature appears to support the preventative effect of butyrate and propionate against HFD-induced weight gain in rodents, although there is conflicting data regarding studies investigating acetate supplementation. The vast majority of this evidence is derived from rodent studies (evidence from a single human study) and further inclusion of a body weight outcome is warranted in human studies to complement work investigating energy intake and/or energy expenditure.

\section{Short chain fatty acids and energy intake}

In total, 16 studies reporting an energy intake outcome were identified, which met inclusion criteria. 12 studies reporting the effect of increasing the provision of SCFA on energy intake were identified, of which 7 studies were conducted in mice, 1 study in Sprague and Dawley rats and
- importantly - 4 studies were conducted in overweight/ obese adult humans. Within the rodent studies, the SCFA investigated were acetate in 4 studies, butyrate in 6 studies and propionate in 3 studies. Acetate was administered orally via diet in 2 studies, and intraperitoneal injection in 2 studies. Butyrate was administered orally via diet in 5 studies and either intragastric gavage or intravenous injection in 1 study. Propionate was administered orally via diet in all 3 studies. Within human studies, the SCFA investigated was propionate in all 4 studies, which was administered orally via diet. Four studies reporting the effect of SCFA receptor knockout on energy expenditure were identified. Of which 2 studies investigated GPR43 and 2 studies investigated GPR41-KO.

Four studies have investigated the impact of SCFA on energy intake in human volunteers, all of which investigate the effect of propionate supplementation on energy intake (Table 3, humans). Darzi et al. (2012) incorporated propionate into sourdough bread and found no difference in energy intake at an ad libitum test meal or over the $24 \mathrm{~h}$ period following consumption. It is likely that the orally supplemented propionate would have been absorbed in the upper gastrointestinal tract, meaning little would reach the colon and the major site of SCFA production. The three other studies have employed methods where propionate is directly delivered to the lower gastrointestinal tract. An example of this being the inulin-SCFA ester, a unique delivery system, whereby SCFA are conjugated by an ester linkage to inulin, a carrier molecule. The ester 
Table 3. Tabulated summary of the effects of increasing the provision of short chain fatty acids (SCFA) on energy intake in humans and rodents. ${ }^{1}$

\section{Reference Sample characteristics}

\section{Humans}

Byrne et al., $\quad$ Male $(n=20)$, age: $26-61$ y, BMI $25.2 \pm 0.5 \mathrm{~kg} / \mathrm{m}^{2}$ 2016 SCFA:

Dose: propionate

$2.6 \mathrm{~g}$ (equivalent in colon)

Administered via: oral; taken at breakfast: propionate or inulin control Duration: $1 d$

Chambers et 19 Male, 30 Female $(n=49)$, age $40-65$ y, BMl $25-40 \mathrm{~kg} / \mathrm{m}^{2}$

$\begin{array}{lll}\text { al., } 2015 & \text { SCFA: } & \text { propionate } \\ & \text { Dose: } & 2.6 \mathrm{~g} \text { (equivalent in colon) }\end{array}$

Administered via: oral; habitual diet or habitual diet + propionate

Duration: 24 wk

Darzi, Frost and 11 Male, 9 Female $(n=20)$, age $25.1 \pm 4.6$ y, BMl $23.1 \pm 2.4 \mathrm{~kg} / \mathrm{m}^{2}$

Robertson, SCFA: propionate

$2012 \quad$ Dose: $6 \mathrm{mmol}$

Administered via: oral; taken at breakfast: bread + propionate or bread Duration: $\quad 1 d$

Polyviou et al., Overweight healthy males $(n=9)$, age $38 \pm 9$ y, BMl $29.8 \pm 1.5 \mathrm{~kg} / \mathrm{m}^{2}$ 2016

SCFA

Dose: propionate $10 \mathrm{~g} / \mathrm{d}$

Administered via: oral; propionate or inulin control

Duration:

$7 d$

\section{Rodents}

Den Besten et $\quad$ C57BI/6J male mice $(n=6-8)$, age $2 \mathrm{~m}$ al., 2015 SCFA: acetate, butyrate, and propionate

Dose: $5 \% \mathrm{w} / \mathrm{w}$

Administered via: oral; HFD or HFD + acetate, butyrate or propionate Duration: 12 wk

De Vadder et Sprague-Dawley male rats $(n=6)$, age $6-8 w k$ al., 2014 SCFA butyrate and propionate Dose: $5 \% \mathrm{w} / \mathrm{w}$

Administered via: oral; standard diet or standard diet + butyrate or propionate

Duration: $\quad$ 10-14 d

Frost et al., $\quad$ C57BL/6 male mice $(n=7-22)$, age 6-8 wk 2014 SCFA acetate Dose: $\quad 500 \mathrm{mg} / \mathrm{kg}$ (intraperitoneal injection); $2.5 \mu \mathrm{mo}$ (intracerebroventricular administration)

Administered via: injection; intraperitoneal injection or intraperitoneal injection + acetate or intracerebroventricular administration or intracerebroventricular administration + acetate

Duration $4 \mathrm{~h}$

Gao et al., 2009 Dietary-obese C57BL/6J male mice ( $n=10)$, age 4 wk

SCFA: butyrate

Dose: $\quad 5 \% \mathrm{w} / \mathrm{w}$

Administered via: oral; HFD or HFD + butyrate

Duration:

\section{Outcome}

Significant reduction in El with propionate compared to Inulin control $(P=0.03)$.

Acute phase, significant reduction in El with habitual diet + propionate compared to habitual $\operatorname{diet}(P<0.01)$. No significant difference at 24 wks $(P>0.05)$.

No significant difference in El $(P>0.05)$.

Significant reduction in El during ad libitum test meal compared to inulin $(P=0.025)$.

No significant difference in El between HFD or HFD + either SCFA $(P>0.05)$.

No significant difference in food intake between HFD or HFD + either SCFA $(P>0.05)$.

Significant suppression in food intake at $1-2 \mathrm{~h}$ and reduction in cumulative food intake $2-4 \mathrm{~h}$ with intracerebroventricular administration + acetate compared to intracerebroventricular administration.

No significant difference in food intake between HFD or HFD + butyrate $(P>0.05)$. 
Table 3. Continued.

\begin{tabular}{|c|c|c|c|}
\hline Reference & \multicolumn{2}{|l|}{ Sample characteristics } & Outcome \\
\hline $\begin{array}{l}\text { Henagan et al., } \\
2015\end{array}$ & $\begin{array}{l}\text { C57BL/6J male mice ( } \\
\text { SCFA: } \\
\text { Dose: } \\
\text { Administered via: } \\
\text { Duration: }\end{array}$ & $\begin{array}{l}n=10 \text { per group), age } 5 \text { wk } \\
\text { butyrate } \\
5 \% \text { w/w } \\
\text { oral; LFD, HFD or HFD + butyrate } \\
10 \text { wk }\end{array}$ & $\begin{array}{l}\text { No significant difference in food intake with HFD } \\
\text { + butyrate compared to HFD }(P>0.05) \text {. }\end{array}$ \\
\hline Li et al., 2018 & $\begin{array}{l}\text { E3L.CETP male mice } \\
\text { SCFA: } \\
\text { Dose: } \\
\text { Administered via: } \\
\text { Duration: }\end{array}$ & $\begin{array}{l}\text { ( } \mathrm{n}=8-10) \text {, age } 10-12 \mathrm{wk} \\
\text { butyrate } \\
6 \mathrm{M} \text { in } 0.15 \mathrm{ml} \text { (intra-gastric gavage); } 15 \mathrm{mM} \text { or } 150 \\
\mathrm{mM} \text { in } 0.1 \mathrm{ml} \text { (intravenous injection); } 5 \% \mathrm{w} / \mathrm{w} \text { (diet) } \\
\text { intragastric gavage or intravenous injection or HFD } \\
\text { or HFD + butyrate } \\
1 \mathrm{~h} \text { and } 9 \text { wk }\end{array}$ & $\begin{array}{l}\text { After } 1 \mathrm{~h} \text {, significant reduction in food } \\
\text { intake with intragastric gavage + butyrate } \\
\text { compared to HFD }(P<0.05) \text {. No significant } \\
\text { difference with intravenous injection or HFD } \\
\text { + butyrate compared to HFD }(P>0.05) \text {. After } \\
9 \text { wk, significant reduction in food intake } \\
\text { with intragastric gavage + butyrate }(\sim-22 \%) \\
\text { compared to HFD ( } P<0.01) \text {. No significant } \\
\text { difference with intravenous injection or HFD + } \\
\text { butyrate compared to HFD }(P>0.05) \text {. }\end{array}$ \\
\hline Lin et al., 2012 & $\begin{array}{l}\text { C57BL/6N male mice } \\
\text { SCFA: } \\
\text { Dose: } \\
\text { Administered via: } \\
\text { Duration: }\end{array}$ & $\begin{array}{l}(n=8) \text {, age } 3 \mathrm{~m} \\
\text { acetate, butyrate, and propionate } \\
\text { acetate }(3.74 \%) \text {, butyrate }(5 \%) \text {, propionate }(4.3 \%) \\
\text { oral; HFD or HFD + acetate, butyrate or propionate } \\
4 \text { wk }\end{array}$ & $\begin{array}{l}\text { Significant reduction in 9-day cumulative food } \\
\text { intake }(\sim-22 \%) \text { with HFD + acetate compared } \\
\text { to HFD }(P<0.05) \text {. No significant with HFD } \\
\text { + butyrate or propionate compared to HFD } \\
(P>0.05) \text {. }\end{array}$ \\
\hline \multirow[t]{2}{*}{$\begin{array}{l}\text { Sahuri-Arisoylu } \\
\text { et al., } 2016\end{array}$} & $\begin{array}{l}\text { Male C57BL/6 mice ( } \mathrm{n} \\
\text { SCFA: } \\
\text { Dose: } \\
\text { Administered via: }\end{array}$ & $\begin{array}{l}=8 \text { per group); NFD and HFD groups } \\
\text { acetate } \\
4.41 \mathrm{mM} / 200 \mu \mathrm{ll}, 3 \text { injections per wk } \\
\text { intraperitoneal injection; } 4 \text {-(2-hydroxyethyl)-1- } \\
\text { piperazineethanesulfonic acid or nanoparticle- } \\
\quad \text { derived acetate }\end{array}$ & $\begin{array}{l}\text { No significant difference in El in both NFD and } \\
\text { HFD }(P>0.05) \text {. }\end{array}$ \\
\hline & Duration: & 6 wk & \\
\hline
\end{tabular}

linkage can only be broken down via bacterial fermentation meaning a known amount of SCFA is delivered directly to the colon and released upon microbiota fermentation. A number of feeding studies have been carried out in humans using the inulin-propionate ester added to a standard food product using a dose of $10 \mathrm{~g}$, which results in a 2.5 -fold increase in daily propionate production based on UK nonstarch polysaccharide (NSP) intake. It has been shown that an acute increase in colonic propionate production using inulin-propionate ester reduces ad libitum energy (Chambers et al., 2015). Similarly, ad libitum energy intake was reduced following a 7-day supplementation (Polyviou et al., 2016). The effect of increased colonic propionate on reward-based eating behaviour was further investigated by assessing brain anticipatory reward responses during a food picture evaluation task following the consumption of inulin-propionate ester by Byrne et al. (2016). Elevated colonic propionate reduced activation in brain regions associated with reward-processing during a food picture evaluation task and reduced the appeal of high-energy foods and ad libitum energy intake. While there are a number of studies investigating the effect of propionate on food intake in humans, there are no known studies that have investigated the effects of acetate or butyrate.

Five studies have reported the effects of incorporating SCFA into the diet of rodents (Table 3, rodents), with four observing no effects on energy intake (De Vadder et al., 2014; Den Besten et al., 2015; Gao et al., 2009; Henagan et al., 2015). However, Lim et al. (2012) reported a significant reduction in cumulative energy intake following acetate supplementation to a high fat diet. Two further studies in mice have used different routes of administration, and suggest SCFA supplementation can suppress energy intake. Li et al. (2017) reported a reduction in energy intake following both the acute and chronic intragastric administration of butyrate. Interestingly, this acute reduction in energy intake was not present following the intravenous administration of butyrate. This disparity in results may be due to the fact that intragastric 
administration allows butyrate to reach its natural site of production and therefore interact with intestinal receptors and/or metabolism, which is not achieved with peripheral administration. Frost et al. (2014) investigated the effect of acetate on energy intake. While colonic delivery of encapsulated acetate did not change food intake, intraperitoneal and central brain administration of acetate in mice was found to acutely $(4 \mathrm{~h})$ reduce food intake. Longer-term intraperitoneal administration of acetate (6 weeks), however, found no difference in mice on no fat and high fat diets (Sahuri-Arisoylu et al., 2016). Acetate, the SCFA that circulates at the highest concentrations, has been detected at concentrations of $30-40 \mu \mathrm{M}$ in cerebrospinal fluid (Nagashima and Morio, 2010) and can be used as an energy source by the brain (Bhatt et al., 2013; Jiang et al., 2013). Frost et al. (2014) also confirmed that colonic acetate crosses the blood brain barrier, absorbed by the brain and reduces food intake. Furthermore, acetateinduced neuronal activation in the hypothalamus following intraperitoneal administration was observed by Frost et al. (2014), suggesting that acetate plays a direct role in central appetite regulation.

The available rodent and human studies therefore suggest that oral SCFA supplementation does not modulate energy intake, whilst administering SCFA to the lower gut may reduce energy intake. The SCFA receptors GPR43 and GPR41 are co-expressed in glucagon-like peptide 1 (GLP1) and PYY expressing cells (Karaki et al., 2006), which led to the suggestion that SCFA might reduce food intake via stimulating the release of these hormones. The distal ileum and colon contain a high number of enteroendocrine
L-cells, which release the anorectic hormones GLP-1 and PYY. Several studies in in vitro models of enteroendocrine cell lines have probed this effect of SCFA in gut hormone release, (Psichas et al., 2014; Tolhurst et al.). These studies suggest that SCFA can stimulate anorectic gut hormone release via GPR43. It has also been suggested that high levels of SCFA in the lower gut could modulate energy intake via gut-brain neural circuits. For example, De Vadder et al. (2014) reported that elevated colonic propionate production could induce vagal signalling in the gut or portal vein via GPR41. Similarly, Li et al. (2017) found that the decrease in food intake following intragastric administration of butyrate in mice, was blocked after vagotomy. As previously mentioned, there is also evidence to suggest that large increases in circulating acetate may having a direct effect on the brain leading to a suppression in appetite (Frost $e t$ al., 2014). In regard to identified studies in this area, four studies (Table 4) investigated the impact of either GPR43- or GPR41-KO on energy intake while two studies assessed the role of GPR43 in energy intake in GPR43-KO mice. Bjursell et al. (2011) reported a significant increase in energy intake relative to body weight, in GPR43-KO mice fed a high fat diet for 38 weeks. However, there was no difference in food intake in mice fed normal chow. Similarly, Kimura et al. (2013) reported a significant increase in food intake in GPR43-KO mice fed a high fat diet, but not when fed normal chow. The other two studies investigated the role of GPR41 in food intake in GPR41-KO mice. Lin et al. reported a significant increase in food intake in GPR41 KO mice fed a high fat diet (Lin et al., 2012). However, Bellahcene et al. (2013) reported no significant effect of genotype on food intake in both low fat and high fat diet mice. In summary,

Table 4. Tabulated summary of effects of short chain fatty acid (SCFA) receptor knockout on energy intake.

\begin{tabular}{|c|c|c|c|c|}
\hline Reference & $\begin{array}{l}\text { SCFA } \\
\text { receptor }\end{array}$ & Sample characteristics & Duration & Outcome \\
\hline $\begin{array}{l}\text { Bellahcene et } \\
\text { al., } 2013\end{array}$ & GPR41 & $\begin{array}{l}\text { GPR41-KO vs wildtype C57BL/6 mice ( } n=9) \text {. } \\
\text { LFD and HFD }\end{array}$ & $40 w k$ & No significant difference in food intake $(P>0.5)$. \\
\hline $\begin{array}{l}\text { Bjursell et al., } \\
2011\end{array}$ & GPR43 & $\begin{array}{l}\text { Male GPR43-KO ( } n=9) \text { vs wildtype C57BL/6 } \\
\text { mice }(n=7) \text {. Normal chow and HFD groups }\end{array}$ & $\begin{array}{l}14-15 w k \\
37-35 w k\end{array}$ & $\begin{array}{l}\text { Significant increase in absolute food intake with GPR43- } \\
\text { KO mice compared to wildtype C57BL/6 mice, when } \\
\text { on normal chow }(P<0.05) \text {. Significant increase in } \\
\text { relative food intake at } 38 \text { wks, and absolute food intake } \\
\text { at } 15 \text { and } 38 \text { wks with GPR43-KO mice compared to } \\
\text { wildtype C57BL/6 mice, when on HFD }(P<0.05) \text {. }\end{array}$ \\
\hline $\begin{array}{l}\text { Kimura et al., } \\
2013\end{array}$ & GPR43 & $\begin{array}{l}\text { Male GPR43-KO vs wildtype } 129 / \text { Sv mice } \\
(n=7) . \text { Normal chow and HFD groups }\end{array}$ & $14-16$ wk & $\begin{array}{l}\text { Significant increase in food intake with GPR43-KO mice } \\
\text { compared to wildtype } 129 / \text { Sv mice, when on HFD } \\
(P<0.05) \text {. No significant difference in food intake on } \\
\text { LFD }(P>0.05) \text {. }\end{array}$ \\
\hline Lin et al., 2012 & GPR41 & $\begin{array}{l}\text { Male GPR41-KO mice vs wildtype C57BL/6 } \\
\text { mice ( } n=34-41) \text {. Butyrate }(5 \%) \text {, propionate } \\
(4.3 \%) \text { or acetate }(3.74 \%) \text { in HFD }\end{array}$ & $8 d$ & $\begin{array}{l}\text { Significant increase in food intake }(\sim-9 \%) \text { with } \\
\text { GPR41-KO mice compared to wildtype C57BL/6 mice } \\
(P<0.05) \text {. }\end{array}$ \\
\hline
\end{tabular}

${ }^{1} \mathrm{HFD}=$ high fat diet; LFD = low fat diet; $\mathrm{KO}=$ knockout. 
the majority of current studies suggest that GPR43 and GPR41 have stimulatory effects on energy intake, with as 3 of the 4 identified studies showing $\mathrm{KO}$ of these receptors increases energy intake in mice fed a high fat diet.

In summary, studies observing the impact of oral SCFA administration have repeatedly failed to demonstrate an impact on energy intake, which may be related to the absorption of the exogenous SCFA in the upper GI tract. Investigations that have targeted delivery of SCFA to the lower GI tract have shown reductions in energy intake, which may be related to anorectic gut hormone release and/or direct neural gut-brain signalling via GPR43 and GPR41 receptors.

\section{Short chain fatty acids and energy expenditure}

In total, 14 studies assessing energy expenditure outcome were identified which met inclusion criteria. Ten studies studying the effect of provision of SCFA on energy expenditure were identified. Of which, 6 studies were conducted in mice ( 5 in C57BL/6 mice and 1 in E3LCETP mice), 1 study in OLETF rats, and 3 studies were conducted in adult humans ( 2 in overweight/obese and 1 in body mass index (BMI) $18-35 \mathrm{~kg} / \mathrm{m}^{2}$ ). Within the rodent studies, the SCFA investigated were acetate in 4 studies, butyrate in 3 studies and propionate in 2 studies. Acetate was administered orally via diet in 3 studies and by intraperitoneal injection in 1 study. Butyrate was administered orally via diet in all 3 studies. Propionate was administered orally via diet in 1 study and by intraperitoneal injection in 1 study. Within human studies, the SCFA's investigated were acetate in 1 study, propionate in 1 study and mixtures of acetate, propionate and butyrate in 1 study. Acetate was administered in distal and proximal colon in 1 study. SCFA mixtures were administered in distal colon in 1 study. Propionate was administered orally via diet in 1 study.

Four studies reporting the effect SCFA receptor knockout on energy expenditure were identified. Of which 2 studies investigated GPR43 knockout and 2 studies investigated GPR41 knockout mice. Data from the rodent studies are summarised in Table 5 (rodents). Three studies have quantified the impact of SCFA on energy expenditure in human volunteers (Table 5, humans). These studies have only recorded the acute impact over $2-3 \mathrm{~h}$ and the potential chronic effects of SCFA on energy expenditure remain untested. Van der Beek et al. (2016) first investigated the impact of infusing sodium acetate to either the proximal or distal colon in overweight and obese humans. The authors report no significant effect of colonic acetate infusion in either the overnight fasted state or after volunteers ingested an oral glucose load. The same authors, however, report positive effects of infusing a SCFA mixture, high in either acetate or propionate, to the distal colon. These effects in overweight and obese males were only observed in the overnight fasted state and not following ingestion of a glucose load. The impact of oral SCFA supplementation on energy expenditure in humans has only been assessed by Chambers et al. (2018b). The investigation reported that oral supplementation with sodium propionate increased energy expenditure in overnight fasted volunteers. In summary, the available data suggests that SCFA supplementation in humans acutely increases energy expenditure; however, future work is needed to clarify if this effect is only observed in fasted conditions or other physiological states. Similarly, to the rodent data, the available studies have not compared the SCFA intervention vs an energy-matched control. Consequently, the increase in energy expenditure above basal fasting level reported by Canfora et al. (2017a) and Chambers et al. (2018b) maybe a response to the energy content of the SCFA, rather than any unique stimulatory effect of the SCFA on energy metabolism.

Hattori et al. (2010) reported that oral acetate supplementation in mice acutely stimulates energy expenditure compared to a water control, whilst Kimura et al. (2011) described that intraperitoneal injection of propionate increased oxygen consumption compared to phosphate buffered saline. These studies would indicate that SCFA supplementation acutely increases energy expenditure in rodents, however, in both studies the control intervention was not energy matched. As gut-derived SCFA play important roles as substrates in host carbohydrate and lipid metabolism (Den Besten et al., 2013), within these studies it is presently unclear if the observed increase in energy expenditure in response to acute SCFA provision, is simply a result of metabolic handling stimulated by the energy content of the SCFA rather than a unique stimulatory effect of the SCFA themselves.

The impact of chronic SCFA administration on energy expenditure in rodents has been reported in five studies. An investigation by Li et al. (2017) observed that incorporating sodium butyrate to a HFD had no effect on energy expenditure after 1 week in mice, despite an elevation in whole-body lipid oxidation rates. Conversely, Gao et al. (2009) demonstrated that supplementing a high fat diet with sodium butyrate enhanced energy expenditure recorded after 1 and 10 week. This stimulatory effect on energy expenditure was only observed during the $12 \mathrm{~h}$ night cycle, with no differences observed during the $12 \mathrm{~h}$ light phase. Yamashita et al. (2009) reported a similar outcome in rats orally administered acetate over a 20-week period, as acetate only increased energy expenditure in the $12 \mathrm{~h}$ 'active' night period and not during the $12 \mathrm{~h}$ 'resting' phase. However, the observation that SCFAs only increase energy expenditure during the night period is not supported by more investigations by Den Besten et al. (2015) and SahuriArisoylu et al. (2016). Den Besten et al. (2015) reported that incorporating either sodium acetate, sodium propionate or sodium butyrate into a high fat diet enhanced energy 
Table 5. Tabulated summary of the effects of increasing the provision of short chain fatty acids (SCFA) on energy expenditure in humans and rodents. ${ }^{1}$

\section{Reference Sample characteristics}

\section{Humans}

Canfora et al., Overweight/obese males $(n=12)$ 2017

SCFA:

Dose:

acetate, butyrate and propionate

Placebo ( $40 \mathrm{mM}$ sodium chloride); high acetate (24 mM sodium acetate, $8 \mathrm{mM}$ sodium propionate, $8 \mathrm{mM}$ sodium butyrate); high propionate ( $18 \mathrm{mM}$ sodium acetate, $14 \mathrm{mM}$ sodium propionate, $8 \mathrm{mM}$ sodium butyrate); high butyrate ( $18 \mathrm{mM}$ sodium acetate, $8 \mathrm{mM}$ sodium propionate, $14 \mathrm{mM}$ sodium butyrate)

Administered via: distal colon; placebo or high acetate or high propionate or high butyrate

Duration: $\quad$ EEx measured after infusions for $2 \mathrm{~h}$ following overnight fast and $2 \mathrm{~h}$ after $75 \mathrm{~g}$ oral glucose load

Chambers et Males and females ( $n=18)$, BMl $18-35 \mathrm{~kg} / \mathrm{m}^{2}$

al., 2018

SCFA:

propionate

Dose: control (4,164 mg sodium chloride); propionate $(6,845 \mathrm{mg}$ sodium propionate)

Administered via: oral; capsules ingested over $2 \mathrm{~h}$ in overnight fasted state: control or propionate

Duration: $\quad$ EEx measured for $3 \mathrm{~h}$

Van der Beek et Overweight/obese males $(n=6)$

$\begin{array}{lll}\text { al., } 2016 & \text { SCFA: } & \text { acetate } \\ & \text { Dose: } & 100 \text { and } 180 \mathrm{mmol} / /\end{array}$

Administered via: proximal and distal colon; placebo (sodium chloride) or acetate

Duration: $\quad$ EEx measured after infusions for $2 \mathrm{~h}$ following overnight fast and $2 \mathrm{~h}$ after $75 \mathrm{~g}$ oral glucose load

Rodents

Den Besten et C57BI/6J male mice ( $n=6-8)$, age $2 \mathrm{~m}$ al., 2015

SCFA

acetate, butyrate, and propionate

Dose: $5 \% \mathrm{w} / \mathrm{w}$

Administered via: oral; HFD or HFD + acetate, butyrate or propionate Duration: $\quad 12 \mathrm{wk}$

Gao et al., 2009 Dietary-obese C57BL/6J male mice ( $n=10)$, age 4 wk

SCFA: butyrate

Dose: $\quad 5 \% \mathrm{w} / \mathrm{w}$

Administered via: oral; HFD or HFD + butyrate

Duration: $\quad$ EEx measured after $1 \mathrm{wk}$ and $10 \mathrm{wk}$.

Hattori et al., C57BL/6 male mice $(n=9)$, age 9 wk

2010

SCFA

acetate

Dose: $\quad 1.5 \%$ in $10 \mathrm{ml} / \mathrm{kg}$ water

Administered via: oral; acetate or water

Duration: $\quad 3 \mathrm{~h}$ post administration

Kimura et al., $\quad$ C57BL/6 male mice $(n=8)$, age 4-16 wk 2011
SCFA: propionate

Dose: $\quad 1 \mathrm{~g} / \mathrm{kg}$

Administered via: intraperitoneal injection; PBS or propionate

Duration: $\quad 40$ min post administration

\section{Outcome}

Significant increase in EEx with high acetate and high propionate compared to placebo in overnight fasted state $(P<0.05)$. No significant difference in $\mathrm{EEx}$ in postprandial state $(P>0.05)$.

Significant increase in EEx with propionate compared to control.

No significant increase in EEx in either proximal or distal colon or fasted or postprandial states $(P>0.05)$.

Significant enhancement of EEx overall, and in both 'day' (06:30 to 18:00) and 'night' (18:00 to 06:30) periods with HFD + SCFA compared to HFD $(P<0.05)$.

Significant increase in EEx after both 1 and $10 \mathrm{wk}$ of supplementation in $12 \mathrm{~h}$ 'night' phase $(P<0.05)$ in HFD + butyrate compared to HFD. No significant difference in $12 \mathrm{~h}$ 'day' phase $(P>0.05)$. Significant increase in EEx with acetate compared to water $(P<0.05)$.

Significant increase in oxygen consumption with propionate compared to PBS $(P<0.05)$. 
Table 5. Continued.

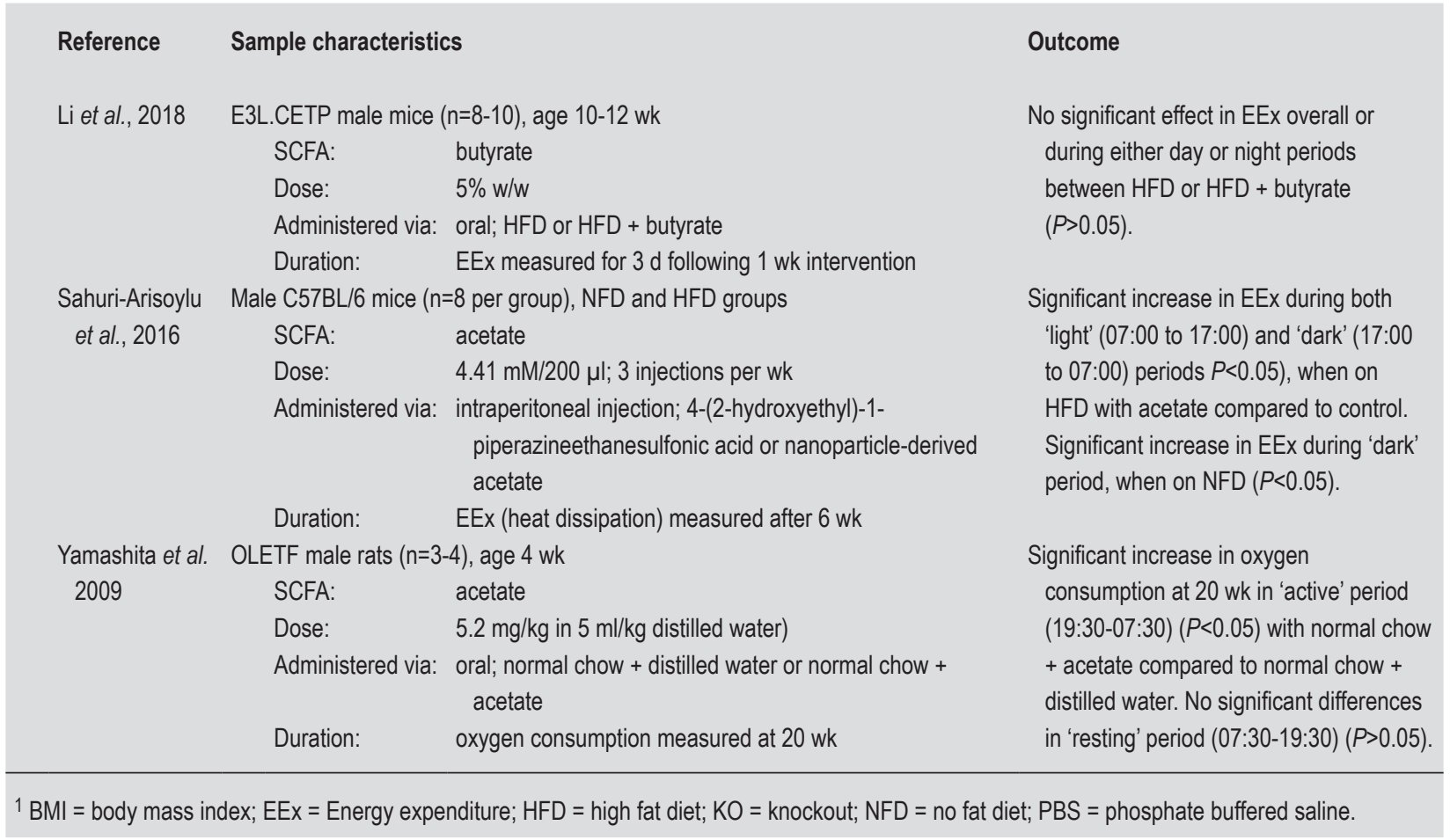

expenditure after 10 weeks in mice during both 12 h day and night periods. In addition, Sahuri-Arisoylu et al. (2016) found that Intraperitoneal injection of nanoparticle-derived acetate for 6 weeks increases energy expenditure on a high fat diet during both $12 \mathrm{~h}$ day and night periods. In summary, the majority of studies have reported that chronic administration of SCFA promotes energy expenditure in rodents, but within the current literature discrepancy exists as to whether these effects are observed during the active/ night and/or the resting/light periods.

Mechanistically, the positive effect of SCFA on energy expenditure could be due to stimulation of GPR43 and GPR41. Four studies were identified (Table 6) which have investigated the impact of either GPR43 or GPR41 knockout on energy expenditure in rodents. The initial work of Bjursell et al. (2011) identified that GPR43-KO promoted energy expenditure in mice. No differences were reported between GPR43-KO and wild-type mice fed a normal fat chow diet, however in mice fed HFD, GPR43-KO was associated with higher energy expenditure when mice were studied at 34-35 weeks. Three subsequent studies reported opposite effects and demonstrated that mice lacking either GPR43 or GPR41 have lower energy expenditure compared to wild-type controls. Kimura et al. (2011) reported that oxygen consumption was significantly lower at 14-16 weeks in GPR41-KO mice fed a normal chow diet. However, this effect was not observed when mice had been starved for $48 \mathrm{~h}$. Later work by the same research group (Kimura et al., 2013) described that GPR43-KO lowers energy expenditure in 16-week old mice fed a high fat diet. Furthermore, Bellahcene et al. (2013) reported that male GPR41-KO mice fed a high fat diet had lower energy expenditure at 15, 27 and 40 weeks of age compared to wild-type controls. This study suggests gender differences in GPR41-KO mice, as these differences were not recorded in female mice. In summary, the majority of current studies suggest that GPR43 and GPR41 have stimulatory effects on energy expenditure, as $\mathrm{KO}$ of these receptors lowers measured rates of energy expenditure in rodents. These effects have predominantly been tested in male mice. Interestingly, the only study that investigated gender differences suggested that GPR41-KO only influences energy expenditure in males. Future work is needed to clarify the possible differential effects of GPR43 and GPR41 $\mathrm{KO}$ on males and females.

It has consistently been reported that the increase in energy expenditure stimulated by SCFA is associated with a promotion in whole-body lipid oxidation (Den Besten et al., 2015; Gao et al., 2009; Hattori et al., 2010; Li et al., 2017). All three human studies also support the observations in rodent models that administration of SCFA stimulates whole-body lipid oxidation (Canfora et al., 2017b; Chambers et al., 2018b; Van der Beek et al., 2016). The increase in energy expenditure and lipid oxidation by SCFA administration has been postulated to be due to stimulation of sympathetic nervous system (SNS) activity, via GPR41 expressed at the 
Table 6. Tabulated summary of effects of short chain fatty acid (SCFA) receptor knockout on energy expenditure. ${ }^{1}$

\begin{tabular}{|c|c|c|c|c|}
\hline Reference & $\begin{array}{l}\text { SCFA } \\
\text { receptor }\end{array}$ & Sample characteristics & Duration & Outcome \\
\hline $\begin{array}{l}\text { Bellahcene et } \\
\text { al., } 2013\end{array}$ & GPR41 & $\begin{array}{l}\text { GPR41-KO vs wildtype C57BL/6 mice } \\
(\mathrm{n}=9) . \mathrm{HFD}\end{array}$ & $\begin{array}{l}\text { EEx measured } \\
\text { at } 15,27 \text { and } \\
40 \mathrm{wk}\end{array}$ & $\begin{array}{l}\text { Significant reduction in } 24 \mathrm{~h} \text { EEx in male GPR41-KO mice } \\
\text { at } 15,27 \text { and } 40 \text { wk compared to wildtype } C 57 \mathrm{BL} / 6 \\
\text { mice }(P<0.05) \text {. No significant difference in female mice } \\
(P>0.05) \text {. }\end{array}$ \\
\hline $\begin{array}{l}\text { Bjursell et al., } \\
2011\end{array}$ & GPR43 & $\begin{array}{l}\text { Male GPR43-KO }(n=9) \text { vs wildtype } \\
\text { C57BL/6 mice }(n=7) \text {. Normal chow and } \\
\text { HFD groups }\end{array}$ & $\begin{array}{l}\text { EEx measured } \\
\text { at } 11-12 \text { and } \\
34-35 \text { wk }\end{array}$ & $\begin{array}{l}\text { Significant increase in EEx at } 34-35 \text { wk with GPR43-KO } \\
\text { mice at } 15,27 \text { and } 40 \text { wk compared to wildtype } \mathrm{C} 57 \mathrm{BL} / 6 \\
\text { mice, when on HFD }(P<0.05) \text {. No significant difference in } \\
\text { EEx on normal chow or at } 11-12 \text { wk on HFD ( } P>0.05) \text {. }\end{array}$ \\
\hline $\begin{array}{l}\text { Kimura et al., } \\
2011\end{array}$ & GPR41 & $\begin{array}{l}\text { Male GPR41-KO vs wildtype C57BL/6 } \\
\text { mice }(n=5-7) \text {. }\end{array}$ & $\begin{array}{l}\text { oxygen } \\
\text { consumption } \\
\text { measured at } \\
14-16 \text { wk }\end{array}$ & $\begin{array}{l}\text { Significant reduction in oxygen consumption during } \\
\text { feeding in GPR41-KO mice compared to wildtype } \\
\text { C57BL/6 mice }(P<0.05) \text {. }\end{array}$ \\
\hline $\begin{array}{l}\text { Kimura et al., } \\
2013\end{array}$ & GPR43 & $\begin{array}{l}\text { Male GPR43-KO vs wildtype 129/Sv mice } \\
(n=7) \text {. Normal chow and HFD groups }\end{array}$ & $\begin{array}{l}\text { EEx measured } \\
\text { at } 16 \text { wk }\end{array}$ & $\begin{array}{l}\text { Significant reduction in } 24 \mathrm{~h} \text { EEx in GPR43-KO mice } \\
\text { compared to wildtype } 129 / \text { Sv mice }(P<0.05) \text {. }\end{array}$ \\
\hline
\end{tabular}

level of the sympathetic ganglion (Kimura et al., 2011), an increase in brown adipose tissue (BAT) activity (Li et al., 2017; Sahuri-Arisoylu et al., 2016) and via suppression of PPAR $\gamma$ in peripheral tissues, which upregulates lipid oxidation (Den Besten et al., 2015).

\section{Conclusion body weight control}

Based on the balance of the available data we can conclude that: (1) SCFA supplementation appears to prevent weight gain associated with HFD in rodents, while human studies are limited. (2) SCFA supplementation is not associated with reductions in energy intake. The route of administration of exogenous SCFA may impact on the observed appetitesuppressive effect. Oral delivery of SCFA has consistently been shown not to modulate energy intake, whilst methods that target delivery of SCFA to the lower gut have been shown to reduce energy intake. (3) SCFA administration has been shown to stimulate energy expenditure by promoting lipid oxidation. At present, the vast majority of the available evidence has been obtained from animal models. Direct translation into humans may be limited, thus future translational work should support the development of novel interventions to increase SCFA production to improve long-term energy homeostasis.

\section{Short chain fatty acids and glucose homeostasis, including insulin secretion and insulin sensitivity}

Disturbances in substrate metabolism and inter-organ crosstalk between gut-adipose tissue, liver and skeletal muscle may play an important role in the aetiology of ectopic fat accumulation and insulin resistance. In this section, a systematic review, using defined search strings is done on human studies relating SCFA administration or dietary fibres-related SCFA production to glycaemic control, insulin sensitivity and insulin secretion. Second, we summarise studies on the effect of SCFA on factors that contribute to the progression of insulin resistance such as adipose tissue dysfunction, characterised by a reduced lipid storage capacity and low-grade inflammation, as well as impairments in substrate handling and oxidation in metabolically active tissues (DeFronzo et al., 1981). The aforementioned effects of SCFA on gut barrier function and gut integrity can also contribute, to the development of insulin resistance and impairments in glucose homeostasis (Cani et al., 2007; Henao-Mejia et al., 2012; Tremaroli and Bäckhed, 2012). In this section the focus is on the effects of SCFA on adipose tissue, liver and skeletal muscle and $\beta$-cell function and metabolism as well as on low-grade inflammation (summarised in Figure 4).

\section{Human data on effects of short chain fatty acids on glucose homeostasis and insulin sensitivity}

\section{Acute studies}

Six intervention studies focused on the acute effects of SCFA administration on parameters of glucose homeostasis and insulin sensitivity (for more details see Table 7). Wolever et al. (1989) found no effects on blood glucose and insulin levels after rectal administration of acetate and propionate within $30 \mathrm{~min}$. However, both mixtures decreased circulating fatty acid (FA) concentrations. In 
Table 7. Short chain fatty acid (SCFA) intervention studies in humans and glucose homeostasis. ${ }^{1}$

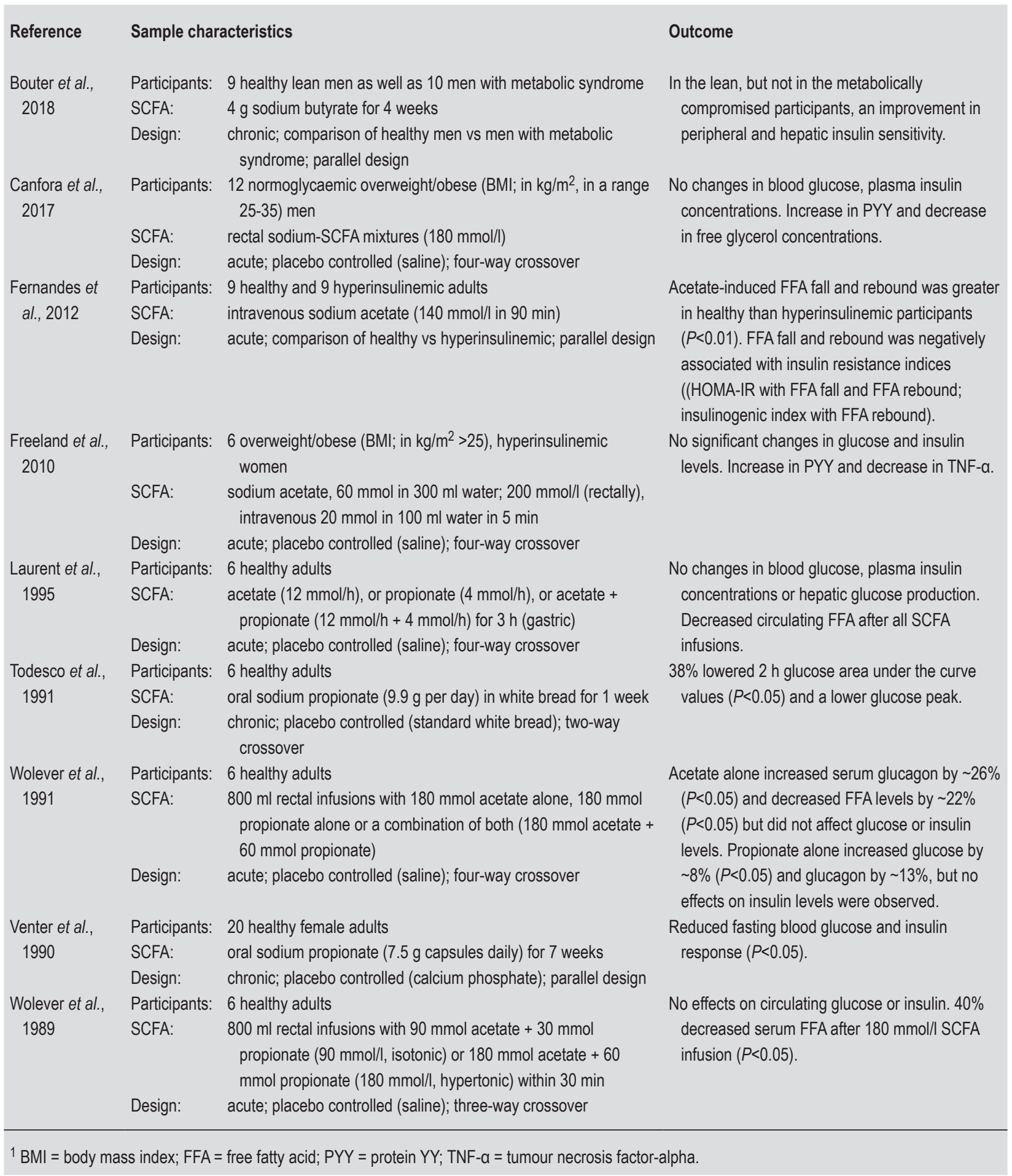

a subsequent acute study by Wolever et al. (1991) rectal acetate infusions increased circulating glucagon and decreased circulating FA levels, but did not affect blood glucose or insulin levels. Rectal propionate infusions increased glucose and glucagon levels, but did not affect FA or insulin concentrations, suggesting a putative role of gut-derived propionate as a substrate for gluconeogenesis. Laurent et al. (1995) found no effects of $3 \mathrm{~h}$ gastric infusions of acetate and/or propionate on glucose metabolism, whilst all infusions reduced circulating FA concentrations. Also, Freeland and Wolever (2010) found no effects of acute intravenously and rectally infused sodium acetate on 
glucose and insulin levels, whilst intravenous and rectal acetate infusions lowered plasma TNF- $\alpha$ and rectal acetate infusions increased PYY levels. Furthermore, Fernandes et al. (2012) found no differences in acetate clearance when acetate was infused intravenously in hyperinsulinaemic (HI) and healthy (NI) adults, but found a greater FA rebound in the NI group when compared to HI, which was correlated with IR indices, indicating a relation between the decreased lipolysis and improved insulin sensitivity. Canfora et al. (2017b) rectally infused mixtures of SCFA in overweight to obese men. The SCFA administration did not affect fasting or postprandial (after a $75 \mathrm{~g}$ glucose load) plasma glucose or insulin concentrations but increased fasting PYY and decreased fasting free glycerol concentrations.

\section{Longer-term short chain fatty acid administration}

We identified three human studies of longer-term (chronic) SCFA administration with outcomes on glucose homeostasis and insulin sensitivity (Table 8). In a study of Venter et al. (1990) propionate supplementation for 7 weeks resulted in decreased fasting glucose level and increased maximum insulin increments during an oral glucose tolerance test in healthy females. Todesco et al. (1991) showed that the

\section{Table 8. Long-term dietary intervention studies with effects on glucose homeostasis and insulin sensitivity. ${ }^{1}$}

\begin{tabular}{|c|c|c|c|}
\hline Reference & Sample characteristics & & Outcome \\
\hline $\begin{array}{l}\text { Robertson et } \\
\text { al., } 2005\end{array}$ & $\begin{array}{l}\text { Participants: } \\
\text { Nondigestible carbohydrate: } \\
\text { Design: }\end{array}$ & $\begin{array}{l}10 \text { healthy adults } \\
30 \mathrm{~g} \text { resistant starch ( } 10 \mathrm{~g} \text { three times) per day } \\
4 \text { wk placebo controlled ( } 20 \mathrm{~g} \text { digestible starch); two- } \\
\text { way crossover }\end{array}$ & $\begin{array}{l}\text { Improved whole-body insulin sensitivity } \\
\text { (euglycemic-hyperinsulinaemic clamp) by } \\
\sim 13 \%(P<0.05) \text {. }\end{array}$ \\
\hline Cani et al., 2009 & $\begin{array}{l}\text { Participants: } \\
\text { Nondigestible carbohydrate: } \\
\text { Design: }\end{array}$ & $\begin{array}{l}10 \text { healthy adults } \\
16 \mathrm{~g} \text { oligofructose ( } 8 \mathrm{~g} \text { twice) per day } \\
2 \text { wk placebo-controlled ( } 16 \mathrm{~g} \text { dextrin maltose); } \\
\text { parallel design }\end{array}$ & $\begin{array}{l}\text { 2h postprandial glucose AUC was reduced by } \\
\sim 17 \%(P<0.05) \text {. Increased plasma GLP-1 } \\
\text { and PYY levels and increased breath- } \\
\text { hydrogen excretion. }\end{array}$ \\
\hline $\begin{array}{l}\text { Parnell et al., } \\
2009\end{array}$ & $\begin{array}{l}\text { Participants: } \\
\text { Nondigestible carbohydrate: } \\
\text { Design: }\end{array}$ & $\begin{array}{l}48 \text { overweight/obese adults; BMl >25 kg/m² } \\
21 \mathrm{~g} \text { oligofructose }(7 \mathrm{~g} \text { three times) per day } \\
12 \text { wk placebo-controlled }(7.89 \mathrm{~g} \text { isocaloric } \\
\text { maltodextrin); parallel design }\end{array}$ & $\begin{array}{l}\text { Absolute } 6 \mathrm{~h} \text { postprandial plasma glucose } \\
\text { and insulin concentrations were reduced } \\
\text { by } 5 \%(P<0.01) \text { and } \sim 10 \%(P<0.01) \text {, } \\
\text { respectively. }\end{array}$ \\
\hline $\begin{array}{l}\text { Dewulf et al., } \\
2013\end{array}$ & $\begin{array}{l}\text { Participants: } \\
\text { Nondigestible carbohydrate: } \\
\text { Design: }\end{array}$ & $\begin{array}{l}30 \text { women with obesity; BMI }>30 \mathrm{~kg} / \mathrm{m}^{2} \\
16 \mathrm{~g} \text { inulin/oligofructose mix }(8 \mathrm{~g} \mathrm{twice}) \text { per day } \\
3 \text { mo placebo-controlled ( } 16 \mathrm{~g} \text { maltodextrin); parallel } \\
\text { design }\end{array}$ & $\begin{array}{l}\text { Reduced post-OGTT glucose response }(7 \% \\
(P<0.01) \text {. No effects on HOMA, fasting } \\
\text { glucose and insulin and HbA1c. }\end{array}$ \\
\hline $\begin{array}{l}\text { Vulevic et al., } \\
2013\end{array}$ & $\begin{array}{l}\text { Participants: } \\
\text { Nondigestible carbohydrate: } \\
\text { Design: }\end{array}$ & $\begin{array}{l}45 \text { overweight/obese adults, } B M I>25 \mathrm{~kg} / \mathrm{m}^{2} \\
5.5 \mathrm{~g} \text { galactooligosaccharide mixture once a day } \\
12 \text { wk placebo-controlled ( } 5.5 \mathrm{~g} \text { maltodextrin); two- } \\
\text { way crossover }\end{array}$ & $\begin{array}{l}\text { Decreased fasting insulin }(\sim 14 \%(P<0.01) \text {, } \\
\text { triglyceride and } C \text {-reactive protein plasma } \\
\text { concentrations. }\end{array}$ \\
\hline $\begin{array}{l}\text { Dewulf et al., } \\
2013\end{array}$ & $\begin{array}{l}\text { Participants: } \\
\text { Nondigestible carbohydrate: } \\
\text { Design: }\end{array}$ & $\begin{array}{l}30 \text { obese women, BMI }>35 \mathrm{~kg} / \mathrm{m}^{2} \\
\text { Inulin/oligofructose mixture ( } 16 \mathrm{~g} / \text { day) } \\
12 \text { wk placebo-controlled ( } 16 \mathrm{~g} \text { maltodextrin); parallel } \\
\text { design }\end{array}$ & $\begin{array}{l}\text { Improved postprandial glucose response. } \\
\text { However, no effects were found on HbA1c, } \\
\text { HOMA and fasting insulin and glucose } \\
\text { levels. }\end{array}$ \\
\hline $\begin{array}{l}\text { Canfora et al., } \\
2017\end{array}$ & $\begin{array}{l}\text { Participants: } \\
\text { Nondigestible carbohydrate: } \\
\text { Design: }\end{array}$ & $\begin{array}{l}44 \text { prediabetic overweight/obese adults, BMl range } \\
25-35 \mathrm{~kg} / \mathrm{m}^{2} \\
15 \mathrm{~g} \text { of galacto-oligosaccharide }(3 \times 5 \mathrm{~g}) \text { per day } \\
12 \text { wk placebo-controlled (isocaloric maltodextrin); } \\
\text { parallel design }\end{array}$ & $\begin{array}{l}\text { No effects on glucose or insulin homeostasis. } \\
\text { No increases in fasting SCFA plasma } \\
\text { concentrations or faecal SCFA. }\end{array}$ \\
\hline $\begin{array}{l}\text { Zhao et al., } \\
2018\end{array}$ & $\begin{array}{l}\text { Participants: } \\
\text { Nondigestible carbohydrate: } \\
\text { Design: }\end{array}$ & $\begin{array}{l}43 \text { adults with type } 2 \text { diabetes mellitus } \\
\text { high-fibre diet; composed of whole grains, traditional } \\
\text { Chinese medicinal foods, and prebiotics } \\
12 \text { weeks; isocaloric low fibre diet; parallel design }\end{array}$ & $\begin{array}{l}\text { Complex fibre mixtures for } 12 \text { wk promoted } \\
\text { SCFA producing bacteria and decreased } \\
\text { haemoglobin A1c levels and fasting } \\
\text { blood glucose and glucose tolerance by } \\
\text { approximately } 20 \%(P<0.05) \text {. }\end{array}$ \\
\hline
\end{tabular}


daily propionate supplementation in bread for one week decreases glucose values, when compared to propionate-free bread. However, the glucose lowering effects were related to lower digestion of the bread-derived starch, since a higher faecal bulk was found in the propionate treated group. In a pilot study by Bouter et al. (2018), healthy lean men as well as men with metabolic syndrome were treated with $4 \mathrm{~g}$ of sodium butyrate daily for 4 weeks. Interestingly, in the lean, but not in the metabolically compromised participants, an improvement in peripheral and hepatic insulin sensitivity (determined via hyperinsulinaemic-euglycaemic clamp) was observed. This pilot data suggests a disturbed SCFA handling/signalling in individuals with metabolic syndrome. However, the data should be confirmed in a larger cohort and underlying mechanisms need to be investigated.

\section{Dietary fibre/prebiotic studies}

Further indications for a beneficial effect of SCFA on insulin sensitivity and glucose homeostasis are derived from eight human dietary intervention studies using fermentable polysaccharides. Robertson et al. (2005) showed that 30 g per day resistant starch supplementation for 4 weeks enhanced whole-body and skeletal muscle insulin sensitivity in healthy subjects, which was accompanied by increased systemic acetate and propionate levels and an increase in adipose tissue and skeletal muscle acetate uptake. Cani et al. (2009a) showed that a 2-week treatment with oligofructose (16 g/day) decreased postprandial glucose levels, which was associated with plasma GLP-1 levels and an increased breath-hydrogen excretion (increased microbial fermentation) in healthy adults. In line, Parnell and Reimer (2009) found reduced postprandial glucose and insulin levels and increased PYY levels after oligofructose ( $21 \mathrm{~g} /$ day) intake for 12 weeks in overweight adults. Pouteau et al. (2010) investigated the effects of 5-week supplementation of the acetogenic fibres acacia gum and pectin ( $28 \mathrm{~g} /$ day) on glucose turnover and insulin sensitivity in 21 men with metabolic syndrome. Fasting glucose turnover improved compared to control. However, peripheral insulin sensitivity (measured via hyperinsulinaemic-euglycaemic clamp) did not change. In addition, Vulevic et al. (2013) found that a 12-week supplementation of a GOS mixture in overweight subjects beneficially altered faecal microbiota, fasting insulin and TAG concentrations. An elegant study of Dewulf et al. (2013) found an improved postprandial glucose response, and a shift towards a butyrate-producing gut microbiota composition after 3 months intake of an inulin/oligofructose mixture (16 g/day) in obese women. However, no effects were found on HbA1c, HOMA and fasting insulin and glucose levels. Canfora et al. (2017a) investigated the effect of the acetogenic fibre galactooligosaccharide ( $15 \mathrm{~g} /$ day) on insulin sensitivity in obese, pre-diabetic individuals. Besides 5-fold increases in Bifidobacterium spp., neither effects on SCFA plasma and faecal concentrations nor on peripheral and adipose tissue insulin sensitivity (as measured via hyperinsulinaemic-euglycaemic clamp technique) were found. A study by Zhao et al. (2018) showed that a diet rich in complex fibre mixtures for 12 weeks decreased haemoglobin A1c levels and fasting blood glucose and improved glucose tolerance by approximately $20 \%$ in T2DM individuals. A metagenomics analysis of the faecal microbiota revealed that the microbial pathways for acetate and butyrate production were significantly increased. There was also a trend for increased faecal acetate and butyrate concentrations, which coincided with increased circulating levels of fasting PYY and postprandial GLP-1. Interestingly, when a responder analyses was performed the microbiome of the positive responders showed a higher genetic microbial capacity to ferment fibres and to produce SCFA.

Together, these data provide direct and indirect evidence for a beneficial role of SCFA in glucose control and insulin sensitising. However, it has to be mentioned that recent well-controlled longer-term studies using fermentable dietary fibres failed to show beneficial effects on glucose homeostasis and insulin sensitivity. Interestingly, in these studies mainly individuals with a metabolically disturbed phenotype (metabolic syndrome, obesity or prediabetes) were included, which suggests a disturbed SCFA handling/ signalling in these individuals. These controversial outcomes indicate the urgent need for well-controlled longer-term human SCFA intervention studies investigating effects on glucose homeostasis and insulin sensitivity in different metabolic phenotypes.

\section{Short chain fatty acids affect adipose tissue metabolism}

SCFA have been shown to affect adipose tissue metabolism. In particular, the systemically most abundant SCFA acetate might affect the adipocyte intracellular lipolysis. A decreased phosphorylation of hormone-sensitive lipase in a GPR-dependent manner might underlie this antilipolytic effect, as demonstrated by Aberdein et al. (2014) in 3T3L1 rodent cell lines and by Jocken et al. (2017) in a human adipocyte model. Several in vivo studies also have shown that acetate can inhibit whole-body lipolysis in humans. For instance, Canfora et al. (2017b) demonstrated that rectal administrations of SCFA mixtures high in sodium acetate decreased circulating glycerol concentrations. Furthermore, Fernandes et al. (2012) showed that acute intravenouslyadministered acetate decreased plasma FFA levels in healthy and hyperinsulinaemic individuals with obesity. In contrast, butyrate seems to have pro-lipolytic properties as shown by Jocken et al. (2017) in a human adipocyte model and by Rumberger et al. (2014) and Jia et al. (2016) in rodent cell lines. The underlying mechanism might be an increase in histone hyperacetylation-associated $\beta_{3}$-adrenergic receptor activation and increased activity of the key lipolytic enzymes adipose triglyceride lipase (ATGL) and hormone-sensitive lipase (HSL). However, human in vivo data demonstrating 
an increased lipolytic activity after butyrate administration are currently not available, which might be related to the low systemic abundance of butyrate.

Besides lipolysis, also adipogenesis may be affected by SCFA. Hong et al. (2005) demonstrated that treatment of 3T3-L1 preadipocytes with acetate and propionate for seven days increased adipogenesis. The increments in adipogenesis were related to an increased expression of GPR43 and peroxisome proliferator-activated receptor gamma 2 (PPAR 2 ), which is a transcription factor involved in early adipogenic differentiation. Of note, these the adipogenic effects of SCFA were completely abolished when GPR43 expression was blocked using siRNA, indicating that the GPR43 receptor is of major importance in the adipogenic potential of SCFA.

In summary, SCFA, in particular acetate, may affect adipose tissue function by increasing the lipid buffering capacity and preventing chronic low-grade inflammation, which may in the end positively affect insulin sensitivity. Potential mechanisms involved are the modulation of intracellular and extracellular lipolysis and PPAR $\gamma /$ GPR43-mediated adipogenesis.

\section{Short chain fatty acids affect skeletal muscle metabolism}

SCFA may improve skeletal muscle functioning by increasing the skeletal muscle lipid oxidative capacity as demonstrated in rodents. Yamashita et al. (2009) treated obese rats for a period of 6 months with acetate (5.2 $\mathrm{mg} / \mathrm{kg}$ body weight) and found increased expression of genes involved in oxidative and glucose metabolism (i.e. myoglobin, glucose transporter type 4, pAMPK). Next, Fushimi et al. (2001) showed that six days dietary acetate supplementation in rats increased glycogen storage and decreased glycolysis in the gastrocnemius muscle. Gao et al. (2009) demonstrated that of a sodium butyrate enriched high-fat diet for 16 weeks enhanced the proportion of type 1 oxidative muscle fibres and expression of PPAR- $\delta$ resulting in enhanced mitochondrial fat oxidation in C57BL/6J mice. Together, these data indicate that SCFA may affect skeletal muscle glucose and oxidative metabolism and may increase muscle lipid turnover, thereby contributing to improved insulin sensitivity. Future investigation should focus on skeletal muscle SCFA uptake and their contribution to muscle oxidative metabolism in humans.

\section{Short chain fatty acids affect liver metabolism}

SCFA may affect hepatic glucose and lipid metabolism. Li et al. (2013) showed that bovine hepatocytes cultured with acetate in concentrations of $1.8 \mathrm{mmol} / \mathrm{l}$ to $7.2 \mathrm{mmol} / \mathrm{l}$ for $3 \mathrm{~h}$ increased the AMP/ATP ratio and AMPKo phosphorylation, which subsequently increased the expression of PPAR $\alpha$ target genes involved in lipid oxidation. Moreover, oral and intravenous administration of acetate (Kondo et al., 2009; Sakakibara et al., 2006; Yamashita et al., 2007) and all three SCFA (Den Besten et al., 2015) in animal models of obesity and T2DM demonstrated a decreased liver lipid accumulation and improved glucose homeostasis. The related mechanisms include an increased hepatic AMPK activity, and increased expression of PPAR $\alpha$ target genes involved in, fat oxidation, thermogenesis, gluconeogenesis and lipogenesis. However, human studies focusing on SCFA effects on parameters of liver metabolism are currently lacking.

\section{Short chain fatty acids affect $\beta$-cell function and insulin secretion}

Rodent as well as human pancreatic $\beta$-cells express the SCFA receptors GPR41 and GPR43 (McNelis et al., 2015; Priyadarshini et al., 2015). Priyadarshini et al. (2015) demonstrated in obese and insulin resistant mice that SCFA have the capacity to increase glucose-stimulated insulin secretion via GPR43. McNelis et al. (2015) showed that depletion of GPR43 in mice with diet-induced obesity deteriorated $\beta$-cell function and increased $\beta$-cell mass. Moreover, Veprik et al. (2016) indicated that SCFA/ GPR41 signalling is of particular importance in controlling pancreatic $\beta$-cell insulin secretion, since GPR41 knockout or overexpression in mice resulted in impairments in glucose control without effects on insulin sensitivity. By using a propionate-inulin-ester in a human in vivo study, Pingitore et al. (2017) demonstrated that propionate has beneficial effects on $\beta$-cell function and insulin secretion, which was independent of GLP-1. They also performed an in vitro follow-up experiment using human islets, which showed that propionate increased glucose-stimulated insulin release and maintained $\beta$-cell mass through inhibition of apoptosis. Thus, the SCFA/GPR axis is emerging as an important regulator of pancreatic insulin secretion and $\beta$-cell functioning.

\section{Short chain fatty acids affect low-grade inflammation}

Chronic low-grade (or systemic) inflammation results from the chronic activation of the immune system and the release of pro-inflammatory mediators such as TNF- $\alpha$, IL like IL- 6 and IL-1 $\beta$ and eicosanoids (McLoughlin et al., 2017). These mediators are mainly produced in the cells of the immune system, but additionally, the adipose tissue serves as an endocrine organ secreting hormones (adipokines) involved in the regulation of energy metabolism (Roelofsen et al., 2010). Dysregulation of adipokine production is regarded as one factor contributing to the chronic inflammatory state often accompanying obesity. Chronic low-grade inflammation is associated with the development of a variety of health impairments like diabetes, cardiovascular disease and cancer (McLoughlin et al., 2017) and it has been shown that intake of prebiotics, i.e. fermentable dietary 
fibre is inversely associated with inflammatory markers (McLoughlin et al., 2017). This has been attributed to SCFA produced during their fermentation as mediators of the anti-inflammatory properties.

Only a few human studies have been identified analysing the effect of SCFA on low-grade chronic or systemic inflammation. Not addressed here are the series of human studies examining SCFA topical therapy as a promising option in distinct forms of inflammatory bowel disease (Harig et al., 1989; Scheppach, 1996). The effects of colonic administration of physiologically relevant SCFA mixtures was examined in a study in overweight and obese subjects. After colonic infusions of physiologically relevant SCFA mixtures, in concentrations and ratios reached after fibre intake, fasting circulating levels of the pro-inflammatory cytokine IL- $1 \beta$ decreased with a high acetate (60\%) containing SCFA mixture compared to placebo, and was significantly lower compared to a high propionate (35\%) SCFA mixture. Postprandial IL-1 $\beta$ levels did not differ between treatment groups. In addition, no significant differences between groups were reported in other proinflammatory cytokines such as TNF- $\alpha$, IL-6 and IL- 8 neither in the fasting nor in the postprandial period (Canfora et al., 2017b). In the study by Van der Beek et al. (2016) a tendency for lower fasting plasma TNF- $\alpha$ concentrations was found after distal colonic acetate infusion with a $100 \mathrm{mmol} / \mathrm{l}$ yet not with a $180 \mathrm{mmol} / \mathrm{l}$, as well as after proximal colonic acetate infusion Other inflammatory markers were not influenced. In two studies by Hamer et al. (2009; 2010) in patients with UC and healthy volunteers, butyrate (60 ml of a $100 \mathrm{mM}$ solution) was administered via rectal enema once daily prior to sleeping. While a significant increase in mucosal IL-10/IL-12 was found in UC patients, no significant change of plasma C-reactive protein or other markers were found within the butyrate group. In females with high fasting plasma insulin levels, acetate was found to significantly decrease plasma TNF- $\alpha$, while a suppressing effect was only confirmed after intravenous infusion of $20 \mathrm{mmol} / \mathrm{l}$ acetate (corresponding to an amount that would be produced in 1-4 h) yet not rectal acetate infusions of $60 \mathrm{mmol} / \mathrm{l}$ (Freeland and Wolever, 2010).

Different routes have been proposed by which microbiotagenerated prebiotic fibre derived SCFA can modulate inflammatory processes. SCFA can bind to the G protein coupled receptors GPR41 and GPR43 and elicit intracellular signalling cascades like mitogen-activated protein kinases (MAPKs), protein kinase $\mathrm{C}$ (PKC) and transcription factors. Furthermore, SCFA act as histone deacetylase inhibitors, thereby altering the acetylation state of histones and other proteins and consequently leading to changes in the transcription of genes (Vinolo et al., 2011). An influence on cyclooxygenase enzyme and thereby on eicosanoid production has also been proposed (Al-Lahham et al., 2010a; Nurmi et al., 2005).

Mechanistic insight into the direct effects of SCFA on inflammation comes mainly from in vitro and ex vivo experiments with isolated cells or tissues (Vinolo et al., 2011). During inflammation, neutrophils are recruited into the inflamed tissues where they exert antibacterial actions by releasing ROS and granule enzymes and phagocytosis of bacteria (Aoyama et al., 2010). However, excess proinflammatory mediators released by the neutrophils can also lead to damage of healthy host tissues if their apoptosis is delayed. In isolated human neutrophils, butyrate and propionate increased apoptosis via a caspase-dependent pathway (Aoyama et al., 2010). In rat neutrophils, a decrease in ROS production was measured in response to butyrate treatment while propionate had no effect and acetate even increased ROS production (Vinolo et al., 2009).

In a co-culture experiment with adipocytes and macrophages, Ohira et al. (2013) found significant dosedependent decreases of the inflammatory markers TNF- $\alpha$, monocyte chemoattractant protein 1 (MCP-1) and IL-6 after treatment with butyrate. In experiments using human omental adipose tissue (OAT) explants, Al-Lahham et al. $(2012 ; 2010 \mathrm{~b})$ demonstrated that propionate inhibited secretion of inflammatory mediators like TNF- $\alpha$ and resistin. Since resistin is a marker for insulin resistance in humans and acts pro-inflammatory, its reduction is in agreement with the anti-inflammatory properties of SCFA.

The concentrations of the SCFA that were required to exert a specific action in the experiments reported above were often different. Furthermore, acetate, butyrate and propionate sometimes exhibit contrasting effects (e.g. Cavaglieri et al., 2003). Thus, diverse statements can be found in the literature. However, it is possible that the amount of SCFA required to elicit an anti-inflammatory response indeed varies with different underlying causes of inflammation (Al-Lahham et al., 2010a). Furthermore, the cell type used for the experiments might influence the outcome. Accordingly, Huuskonen et al. (2004) showed that butyrate has anti-inflammatory properties in primary, brain-derived microglial cells, but exerts pro-inflammatory effects in transformed, proliferating N9 microglial cells. According to the authors, this effect could be involved in the colon cancer protective role of butyrate. In T-cells, SCFA promoted differentiation depending on the cytokine milieu (Park et al., 2015).

Confirmation of the anti-inflammatory properties that are often associated with SCFA comes from animal experiments. In ApoE knockout mice, feeding with butyrate reduced atherosclerotic lesions and lowered macrophage migration accompanied by a decrease in pro-inflammatory cytokines (Aguilar et al., 2014). In mice treated intraperitoneally with 
acetate, inflammatory processes after kidney injuries were decreased leading to attenuation of the detrimental effects of inflammation on renal function (Andrade-Oliveira et al., 2015). Conversely, after systemic administration of supraphysiological doses of SCFA, renal tissue inflammation was increased due to dysregulation of $\mathrm{T}$ cell response (Park et al., 2016). In another study with mice it was found that SCFA receptors GPR41 and GPR43 are required for an inflammatory response to bacterial infection and thus, a protective pro-inflammatory response (Kim et al., 2013). In rodent models of colitis oral acetate administration was shown to be protective (Masui et al., 2013).

Based on the totality of available data from in vitro/ex vivo, animal and limited human studies, there is plausible evidence supporting beneficial effects of SCFA generated from fermentation processes by the gut microbiota following prebiotic consumption on modulating and ameliorating low-grade inflammation.

\section{Emerging concept in the gut-brain axis: gluconeogenesis in intestinal epithelium}

Intestinal gluconeogenesis (IGN) is a function recently described in humans and all vertebrates studied up to now, that is able to influence energy homeostasis (for a review, Soty et al., 2017). Basically, major metabolic benefits exerted by the SCFA butyrate and propionate relate to the activation of IGN in enterocytes. IGN releases glucose that is detected by the portal neural system, sending a signal to the brain. This initiates a set of brain-derived metabolic benefits in energy homeostasis, including decreased fat storage and body weight, improved insulin sensitivity and systemic glucose control (Soty et al., 2017). Since butyrate and propionate bind to G protein-coupled receptor (GPR)41 and 43, which are both present in the enterocyte plasma membrane, an attractive hypothesis was that butyrate and propionate may modulate enterocyte metabolism via the activation of GPRs. However, this was not the case relating to IGN. Indeed, both SCFA activate IGN via complementary mechanisms that do not involve enterocyte GPR-41/43.

Instead, butyrate enters the enterocyte and is converted to butyryl-CoA, and subsequently, acetyl-CoA that is oxidised in the Krebs cycle and produces ATP. The ATP increase activates the production of cAMP via an ATP-induced activation of adenylate cyclase, independently of any hormonal stimulation, which finally activates the expression of the regulatory gluconeogenesis genes (glucose- 6 phosphatase, and phosphoenolpyruvate carboxykinasecytosolic form) (De Vadder et al., 2014).

Propionate activates IGN via two distinct processes. Firstly, it binds to and activates neuronal GPR-41 receptors, especially those present in the gastrointestinal nerves surrounding the portal vein. This initiates a neural loop resulting in the release of vasoactive intestinal peptide (VIP) in the submucosal nervous plexus. VIP binds to its receptor VPAC1 in the enterocyte plasma membrane and activates adenylate cyclase, which activates the production of cAMP and the expression of IGN regulatory genes (De Vadder et al., 2015). It is noteworthy that, owing to this neural-mediated relay, IGN gene expression is activated first in the distal gut but also along the whole intestine, even if the initial propionate signal is supposed to start from the colon where the bulk of microbiota resides (De Vadder et al., 2014). Secondly, propionate serves as a glucose precursor for IGN, entering the enterocyte and the enterocyte metabolism via the formation of propionyl$\mathrm{CoA}$. The latter is converted to methylmalonyl-CoA by propionyl-CoA carboxylase, and the methylmalonyl-CoA is then converted to succinyl-CoA by methylmalonyl-CoA mutase (MUT). Succinyl-CoA enters the Krebs cycle to be finally converted to oxaloacetate and glucose via the IGN pathway (De Vadder et al., 2014).

It is noteworthy that these studies have extended the notion of 'gut-brain' axis, classically ascribed until now to gastrointestinal hormones transported to the brain via the blood circulation. Indeed, fibre-derived signalling metabolites (propionate then glucose) are both sensed by the gastrointestinal nervous system locally, e.g. in the portal vein walls, and the signal regulating the hypothalamic homeostatic function is nervous in nature and peripheral in origin. Moreover, inactivating the gastrointestinal sensitive nerves by the neurotoxic agent capsaicin suppresses the metabolic benefits deriving from fibre, propionate or glucose (De Vadder et al., 2014; Soty et al., 2017). Similarly, the beneficial effects of the aforementioned nutrients do not take place in mice with deficient IGN (De Vadder $e t$ al., 2014; Soty et al., 2017).

Of note, the metabolic benefits conferred on the host by butyrate and propionate, via IGN, were deciphered in rat and mice studies. It is noteworthy that, while they are not expressed in the rat colon under normal feeding conditions, the regulatory genes of IGN are rapidly induced upon fibre feeding, via the action of propionate and butyrate (De Vadder et al., 2014). Interestingly, IGN has since been demonstrated in humans under conditions known to be associated with dramatic metabolic benefits, such as after, gastric bypass surgery to treat obesity. The beneficial metabolic outcomes of the latter are very similar as those initiated by dietary fibre (Gutierrez-Repiso et al., 2017; Hayes et al., 2011; Mithieux, 2012). Moreover, it was reported that the outcomes of gastric bypass in obese humans were better when the starting IGN of the individual was high (Gutierrez-Repiso et al., 2017). It was determined that around $6 \%$ of luminal propionate is converted to glucose from a tracer study (Boets et al., 2017). Since SCFA concentrations may reach concentrations around hundreds $\mathrm{mM}$ in the colon lumen, this represents a huge 
flux of propionate to the body glucose pool, while it cannot be estimated from such studies whether the conversion takes place in the intestine or the liver. Interestingly, the importance of normal metabolism by the intestinal mucosa of propionate deriving from gut microbial fermentation was emphasised in patients with MUT deficiency (methylmalonic aciduria), in which methylmalonyl-CoA accumulates and exerts deleterious effects. Indeed, the virtual elimination of gut microbial propionate production by antibiotic treatment decreased methylmalonate production, which substantially ameliorated health in these patients. Specifically, they retrieved appetite and increased food intake, while vomiting was virtually suppressed (Bain et al., 1988).

Finally, these data suggest that IGN and portal to brain glucose signalling could be a key mediator of the metabolic benefits deriving from SCFA (Figure 4). Furthermore, they suggest that a normal propionate metabolism in the colonic mucosa is a requirement for health.

\section{Discussion}

There is mechanistic evidence that SCFA contribute to maintaining the intestinal barrier function and seem to benefit pathological conditions of intestinal inflammation, may prevent weight gain and may have positive effects on glucose homeostasis and insulin sensitivity. Nevertheless, human evidence is more limited and mixed. The question whether an increased microbial SCFA production can be seen as a health benefit as such is addressed in this review. The available evidence will be summarised below, followed by a conclusion under what conditions SCFA can be regarded as a health benefit, addressing the gaps in research and ending with perspectives for future research. This manuscript is the result of the work of an expert group of ILSI Europe's Prebiotics task force. The drafted manuscript, its discussion and conclusions have been refined based on a workshop with participation of scientific experts, industrial representatives as well as policy makers.

SCFA contribute to maintaining the intestinal barrier function through mechanisms that include stimulation of mucus synthesis and quality, and the synthesis of antimicrobial peptides as well as reducing epithelial permeability targeting tight junction complex integrity. Both luminal administration and endogenous stimulation of butyrate production through microbial fermentation of dietary fibres seem to benefit pathological conditions of intestinal inflammation. In human, interventions that modulate the microbiota and presumably also SCFA production yielded mixed results with respect to effects on gut permeability, as well as mucosal immunity and inflammation (Jain et al., 2004; Olguin et al., 2005; Pedersen et al., 2016; Russo et al., 2012a; Westerbeek et al., 2011; Wilms et al., 2016).
Based on the available data and our systemic review of literature, SCFA supplementation appears to prevent weight gain associated with a high HFD in rodents with limited human evidence. With respect to energy intake the balance of available data indicates that the route of SCFA administration may be of importance. Oral SCFA have consistently been shown not to reduce energy intake, which may be related to the absorption of SCFA in the upper GI tract. Targeted delivery to the lower gut may reduce energy intake, which may be related to anorectic gut hormone release and/or indirect neural gut-brain signalling via GPR41 and 43 receptors. There is also human evidence that SCFA administration may affect energy expenditure and fat oxidation. Here, oral propionate (Chambers et al., 2018a) as well as distal colonic SCFA administration (Canfora et al., 2017b) have been shown to increase energy expenditure and fat oxidation in acute settings during overnight fasted conditions.

Human data on effects of acute SCFA administration on metabolic health and glucose homeostasis show that SCFA affect whole lipolysis and hormones like PYY (Canfora et al., 2017b; Van der Beek et al., 2016). There are limited studies investigating the effect of longer term SCFA administration on glucose homeostasis and insulin sensitivity. Oral butyrate administration for 4 weeks improved hepatic and peripheral insulin sensitivity in lean but not in metabolically compromised individuals (Bouter et al., 2018). Additionally, based on the totality of available data from in vitro/ex vivo, animal and limited human studies, there is mechanistic evidence supporting beneficial effects of SCFA generated from fermentation processes by the gut microbiota following prebiotic consumption on modulating and ameliorating low-grade inflammation.

Overall, human studies for health effects of SCFA are limited and in vitro and animal data do often not directly translate into the human condition. Furthermore, human studies are hampered by difficulties in measuring SCFA production, by differences in mode of administration and/ or site of production, by variation in dietary fibres tested as well as diet composition and by variation in metabolic phenotype between individuals. Those factors will be addressed more extensively below.

In many studies, faecal SCFA are used as a biomarker of gut-derived SCFA production. However, concentrations of both faecal and circulating SCFA are the net result of bacterial production, bacterial cross-feeding on different SCFA, and colonocyte absorption. The body rapidly and almost completely absorbs gut microbially produced SCFA. Consequently, faecal measurements are not representative of in vivo colonic production, which is influenced by prebiotics or other colonic substrates, colonic $\mathrm{pH}$ and microbiota composition. Accurate knowledge of in vivo production and absorption kinetics of (individual) SCFA is challenging; 
stable isotope technology is the superior non-invasive methodology to measure SCFA production in humans; however, this is not suitable for routine use. Nevertheless, this technology has been applied to prebiotic inulin which conclusively demonstrated increased SCFA production within the human colon (Boets et al., 2015). Faecal SCFA concentrations are thus a balance of production, utilisation and absorption. Whilst the increases that are observed in human studies supplying more fermentable fibres to the complex microbial ecosystem indicates that faecal samples may be used as a proxy for increased SCFA production, care should be taken interpreting such data.

From an increasing number of studies it is evident that the mode of administration or site of fermentation is an important determinant of the metabolic response. Interestingly, as indicated above, acute human studies demonstrated that infusions of SCFA in the distal, but not proximal, colon modulated whole-body substrate metabolism, with an increased lipid oxidation and PYY concentration, and attenuated lipolysis (Van der Beek et $a l ., 2016)$. Therefore, an interesting future approach might be to increase the availability of dietary fibre in the more distal colonic site. Of note, an increased saccharolytic fermentation in the distal colon may also decrease microbial products derived from proteolytic fermentation (Hald et $a l ., 2016)$, such as the branched SCFA isobutyrate and isovalerate, ammonia and hydrogen sulphide. These products are far less studied, but high concentrations in the colon and systemic circulation of these products are related to adverse effect on gut and metabolic health (Blachier et al., 2019; Canfora et al., 2019; Da Silva et al., 2018; Russell et al., 2011). Additionally, targeted delivery of SCFA to the lower gut may impact energy intake, whilst oral administration has no such effect. Also, health effects may depend on the type of SCFA. Whilst gastro-intestinal health including mucosal immunity, immunity and integrity has been merely related to butyrate, in metabolic health, including body weight regulation and glucose homeostasis, also effects of propionate and acetate have been described in addition to those of butyrate.

Some of the conclusions with respect to SCFA come from prebiotic or dietary fibre studies in which (indicators of) SCFA production or microbial SCFA producers have been measured. The data from those studies are inconsistent which may relate to the characteristics of those fibres, including the site of fermentation, their fermentation type as well as the amount and type of SCFA produced. Notably, one study showed that fermentable oligosaccharides increased the abundance of bifidobacteria, but decreased the abundance of several other butyrate-producing bacteria, and even resulted in adverse effects on glucose homeostasis (Liu et al., 2017). Also, other studies using one specific fibre did not show very pronounced metabolic effects as reviewed by Canfora et al. (2019). Although some studies using specific prebiotic supplements showed promising metabolic effects (Dehghan et al., 2016; Dehghan et al., 2013; Rao et al. 2019), the message may be that it is important to keep the diversity of SCFA-producing bacteria high by providing different microbial substrates instead of stimulating one specific SCFA producing genus (Le Bourgot et al., 2018; Rao et al., 2019).

Besides that, SCFA intervention may not be similarly effective in all individuals. As indicated above, it has been shown that oral butyrate intervention for 4 wk improved insulin sensitivity in lean but not in obese individuals (Bouter et al., 2018). Additionally, acetate infusion led to a greater FFA rebound in normal than in hyperinsulinemic individuals (Fernandes et al., 2012). Thus, one size does not fit all and it may be the case that in metabolically compromised individuals, longer periods of intervention are required ( $>3$ months) to induce physiologically relevant improvements.

\section{Conclusions and perspectives}

In conclusion, the available mechanistic data and limited human data on the metabolic consequences of elevated gutderived SCFA production strongly suggest that increasing SCFA production could be a valuable strategy in the preventing gastro-intestinal dysfunction, obesity and type 2 diabetes mellitus. Nevertheless, there is an urgent need for well controlled longer term human SCFA intervention studies investigating effects on intestinal inflammation, body weight control, glucose homeostasis and insulin sensitivity as well as other parameters of metabolic health, taking the following factors into account:

More information on actual SCFA fluxes and kinetic studies on SCFA metabolism by means of stable isotope methodology, taken into account type of SCFA and site of production. Further, more information is needed on the transport of SCFA into the body as well as small and large intestinal SCFA handling.

There may be responders and non-responders to intervention, depending on initial microbial and/or metabolic profile. Non-responders to intervention may possibly need an intervention of longer duration.

In dietary fibre studies, the type of fibre(s) and site of fermentation, i.e. site of SCFA production may determine the outcome on human health and metabolism.

Controlling for factors that could shape the microbial composition and might directly affect host substrate and energy metabolism is also very important. Such factors include among other factors diet and physical activity, medications, as well as changes in gut transit time. 
Combining in vivo gold-standard clinical techniques with advanced metabolomics, metatranscriptomics and metagenomics approaches will help to further determine the relationship between the microbiome and host gastrointestinal and metabolic health.

\section{References}

Aberdein, N., Schweizer, M. and Ball, D., 2014. Sodium acetate decreases phosphorylation of hormone sensitive lipase in isoproterenol-stimulated 3T3-L1 mature adipocytes. Adipocyte 3: 121.

Aguilar, E.C., Leonel, A.J., Teixeira, L.G., Silva, A.R., Silva, J.F., Pelaez, J.M.N., Capettini, L.S.A., Lemos, V.S., Santos, R.A.S. and AlvarezLeite, J.I., 2014. Butyrate impairs atherogenesis by reducing plaque inflammation and vulnerability and decreasing NFkB activation. Nutrition, Metabolism and Cardiovascular Diseases 24: 606-613. https://doi.org/10.1016/j.numecd.2014.01.002

Aguirre, M., De Souza, C.B. and Venema, K., 2016. The gut microbiota from lean and obese subjects contribute differently to the fermentation of arabinogalactan and inulin. PLoS ONE 11: e0159236. https://doi.org/10.1371/journal.pone.0159236

Al-Lahham, S.a., Roelofsen, H., Rezaee, F., Weening, D., Hoek, A., Vonk, R. and Venema, K., 2012. Propionic acid affects immune status and metabolism in adipose tissue from overweight subjects. European Journal of Clinical Investigation 42: 357-364. https://doi. org/10.1111/j.1365-2362.2011.02590.x

Al-Lahham, S.a.H., Peppelenbosch, M.P., Roelofsen, H., Vonk, R.J. and Venema, K., 2010a. Biological effects of propionic acid in humans; metabolism, potential applications and underlying mechanisms. Biochimica et Biophysica Acta 1801: 1175-1183. https://doi. org/10.1016/j.bbalip.2010.07.007

Al-Lahham, S.a.H., Roelofsen, H., Priebe, M., Weening, D., Dijkstra, M., Hoek, A., Rezaee, F., Venema, K. and Vonk, R.J., 2010b. Regulation of adipokine production in human adipose tissue by propionic acid. European Journal of Clinical Investigation 40: 401-407. https://doi. org/10.1111/j.1365-2362.2010.02278.x

Alles, M.S., Hautvast, J.G.A.J., Nagengast, F.M., Hartemink, R., Van Laere, K.M.J. and Jansen, J.B.M.J., 1996. Fate of fructooligosaccharides in the human intestine. British Journal of Nutrition 76: 211-221. https://doi.org/10.1079/BJN19960026

Almeida, A., Mitchell, A.L., Boland, M., Forster, S.C., Gloor, G.B., Tarkowska, A., Lawley, T.D. and Finn, R.D., 2019. A new genomic blueprint of the human gut microbiota. Nature 568: 499-504. https:// doi.org/10.1038/s41586-019-0965-1

Andrade-Oliveira, V., Amano, M.T., Correa-Costa, M., Castoldi, A., Felizardo, R.J.F., Almeida, D.C.d., Bassi, E.J., Moraes-Vieira, P.M., Hiyane, M.I., Rodas, A.C.D., Peron, J.P.S., Aguiar, C.F., Reis, M.A., Ribeiro, W.R., Valduga, C.J., Curi, R., Vinolo, M.A.R., Ferreira, C.M. and Camara, N.O.S., 2015. Gut bacteria products prevent AKI induced by ischemia-reperfusion. Journal of the American Society of Nephrology 26: 1877-1888. https://doi.org/10.1681/ asn.2014030288
Aoyama, M., Kotani, J. and Usami, M., 2010. Butyrate and propionate induced activated or non-activated neutrophil apoptosis via HDAC inhibitor activity but without activating GPR-41/GPR-43 pathways. Nutrition 26: 653-661. https://doi.org/10.1016/j.nut.2009.07.006 Arnoldussen, I.A.C., Wiesmann, M., Pelgrim, C.E., Wielemaker, E.M., Duyvenvoorde, W.V., Amaral-santos, P.L., Verschuren, L. and Keijser, B.J.F., 2017. Butyrate restores HFD-induced adaptations in brain function and metabolism in mid-adult obese mice. International Journal of Obesity 41: 935-944. https://doi.org/10.1038/ijo.2017.52 Arpaia, N., Campbell, C., Fan, X., Dikiy, S., Van der Veeken, J., deRoos, P., Liu, H., Cross, J.R., Pfeffer, K., Coffer, P.J. and Rudensky, A.Y., 2013. Metabolites produced by commensal bacteria promote peripheral regulatory T-cell generation. Nature 504: 451-455. https:// doi.org/10.1038/nature12726

Bain, M.D., Borriello, S.P., Tracey, B.M., Jones, M., Reed, P.J., Chalmers, R.A. and Stacey, T.E., 1988. Contribution of gut bacterial metabolism to human metabolic disease. The Lancet 331: 1078-1079. https:// doi.org/10.1016/S0140-6736(88)91898-3

Barcelo, A., Claustre, J., Moro, F., Chayvialle, J.A., Cuber, J.C. and Plaisancié, P., 2000. Mucin secretion is modulated by luminal factors in the isolated vascularly perfused rat colon. Gut 46: 218-224. https:// doi.org/10.1136/gut.46.2.218

Belenguer, A., Duncan, S.H., Calder, A.G., Holtrop, G., Louis, P., Lobley, G.E. and Flint, H.J., 2006. Two routes of metabolic cross-feeding between Bifidobacterium adolescentis and butyrate-producing anaerobes from the human gut. Applied and Environmental Microbiology 72: 3593-3599. https://doi.org/10.1128/ AEM.72.5.3593-3599.2006

Bellahcene, M., O’Dowd, J.F., Wargent, E.T., Zaibi, M.S., Hislop, D.C., Ngala, R.A., Smith, D.M., Cawthorne, M.A., Stocker, C.J. and Arch, J.R., 2013. Male mice that lack the G-protein-coupled receptor GPR41 have low energy expenditure and increased body fat content. British Journal of Nutrition 109: 1755-1764. https://doi.org/10.1017/ S0007114512003923

Belzer, C., Chia, L.W., Aalvink, S., Chamlagain, B., Piironen, V., Knol, J. and De Vos, W.M., 2017. Microbial metabolic networks at the mucus layer lead to diet-independent butyrate and vitamin B12 production by intestinal symbionts. mBio 8 . https://doi.org/10.1128/ mBio.00770-17

Bergman, E.N., 1990. Energy contributions of volatile fatty-acids from the gastrointestinal-tract in various species. Physiological Reviews 70: 567-590.

Bhatt, D.P., Houdek, H.M., Watt, J.A. and Rosenberger, T.A., 2013. Acetate supplementation increases brain phosphocreatine and reduces AMP levels with no effect on mitochondrial biogenesis. Neurochemistry International 62: 296-305. https://doi.org/10.1016/j. neuint.2013.01.004

Binsl, T.W., De Graaf, A.A., Venema, K., Heringa, J., Maathuis, A., De Waard, P. and Van Beek, J.H.G.M., 2010. Measuring non-steadystate metabolic fluxes in starch-converting faecal microbiota in vitro. Beneficial Microbes 1: 391-405. https://doi.org/10.3920/ BM2010.0038

Bischoff, S.C., 2011. 'Gut health': a new objective in medicine? BMC Medicine 9: 24. https://doi.org/10.1186/1741-7015-9-24 
Bjursell, M., Admyre, T., Goransson, M., Marley, A.E., Smith, D.M., Oscarsson, J. and Bohlooly, Y.M., 2011. Improved glucose control and reduced body fat mass in free fatty acid receptor 2-deficient mice fed a high-fat diet. American Journal of Physiology and Endocrinology Metabolism 300: E211-220. https://doi.org/10.1152/ ajpendo.00229.2010

Blachier, F., Beaumont, M., Portune, K.J., Steuer, N., Lan, A., Audebert, M., Khodorova, N., Andriamihaja, M., Airinei, G., Benamouzig, R., Davila, A.-M., Armand, L., Rampelli, S., Brigidi, P., Tomé, D., Claus, S.P. and Sanz, Y., 2019. High-protein diets for weight management: interactions with the intestinal microbiota and consequences for gut health. A position paper by the my new gut study group. Clinical Nutrition 38: 1012-1022. https://doi.org/10.1016/j.clnu.2018.09.016

Boets, E., Deroover, L., Houben, E., Verbeke, K., S.V, G. and Delcour, J.A., 2015. Quantification of in vivo colonic short chain fatty acid production from inulin. Nutrients 7: 8916-8929. https://doi. org/10.3390/nu7115440

Boets, E., Gomand, S.V., Deroover, L., Preston, T., Vermeulen, K., De Preter, V., Hamer, H.M., Van den Mooter, G., De Vuyst, L., Courtin, C.M., Annaert, P., Delcour, J.A. and Verbeke, K.A., 2017. Systemic availability and metabolism of colonic-derived short-chain fatty acids in healthy subjects: a stable isotope study. Journal of Physiology 595: 541-555. https://doi.org/10.1113/JP272613

Bouter, K.E.C., Bakker, G.J., Levin, E., Hartstra, A.V., Kootte, R.S., Udayappan, S.D., Katiraei, S., Bahler, L., Gilijamse, P.W. and Tremaroli, V., 2018. Differential metabolic effects of oral butyrate treatment in lean versus metabolic syndrome subjects. Clinical and Translational Gastroenterology 9: 155.

Bunesova, V., Lacroix, C. and Schwab, C., 2018. Mucin cross-feeding of infant bifidobacteria and Eubacterium hallii. Microbial Ecology 75: 228-238. https://doi.org/10.1007/s00248-017-1037-4

Burger-Van Paassen, N., Vincent, A., Puiman, Patrycja, J., Van der Sluis, M., Bouma, J., Boehm, G., Van Goudoever, J.B., Van Seuningen, I. and Renes, I.B., 2009. The regulation of intestinal mucin MUC2 expression by short-chain fatty acids: implications for epithelial protection. Biochemical Journal 420: 211-219.

Byrne, C.S., Chambers, E.S., Alhabeeb, H., Chhina, N., Morrison, D.J., Preston, T., Tedford, C., Fitzpatrick, J., Irani, C., Busza, A., Garciaperez, I., Fountana, S., Holmes, E., Goldstone, A.P. and Frost, G.S., 2016. Increased colonic propionate reduces anticipatory reward responses in the human striatum to high-energy foods. American Journal of Clinical Nutrition 104(1): 5-14. https://doi.org/10.3945/ ajcn.115.126706.1

Canfora, E.E., Jocken, J.W. and Blaak, E.E., 2015. Short-chain fatty acids in control of body weight and insulin sensitivity. Nature Reviews Endocrinology 11: 577-591. https://doi.org/10.1038/ nrendo.2015.128

Canfora, E.E., Meex, R.C.R., Venema, K. and Blaak, E.E., 2019. Gut microbial metabolites in obesity, NAFLD and T2DM. Nature Reviews Endocrinology 15: 261-273. https://doi.org/10.1038/ s41574-019-0156-z
Canfora, E.E., Van der Beek, C.M., Hermes, G.D.A., Goossens, G.H., Jocken, J.W.E., Holst, J.J., Van Eijk, H.M., Venema, K., Smidt, H., Zoetendal, E.G. Dejong, C.H.C., Lenaerts, K. and Blaak, E.E., 2017a. Supplementation of diet with galacto-oligosaccharides increases bifidobacteria, but not insulin sensitivity, in obese prediabetic individuals. Gastroenterology 153: 87-97. https://doi.org/10.1053/j. gastro.2017.03.051

Canfora, E.E., Van der Beek, C.M., Jocken, J.W.E., Goossens, G.H., Holst, J.J., Olde Damink, S.W.M., Lenaerts, K., Dejong, C.H.C. and Blaak, E.E., 2017b. Colonic infusions of short-chain fatty acid mixtures promote energy metabolism in overweight/obese men: a randomized crossover trial. Scientific Reports 7: 2206-2206. https:// doi.org/10.1038/s41598-017-02546-x

Cani, P.D., Amar, J., Iglesias, M.A., Poggi, M., Knauf, C., Bastelica, D., Neyrinck, A.M., Fava, F., Tuohy, K.M. and Chabo, C., 2007. Metabolic endotoxemia initiates obesity and insulin resistance. Diabetes 56: 1761-1772.

Cani, P.D., Lecourt, E., Dewulf, E.M., Sohet, F.M., Pachikian, B.D., Naslain, D., De Backer, F., Neyrinck, A.M. and Delzenne, N.M., 2009a. Gut microbiota fermentation of prebiotics increases satietogenic and incretin gut peptide production with consequences for appetite sensation and glucose response after a meal. American Journal of Clinical Nutrition 90: 1236-1243.

Cani, P.D., Possemiers, S., Van de Wiele, T., Guiot, Y., Everard, A., Rottier, O., Geurts, L., Naslain, D., Neyrinck, A., Lambert, D.M., Muccioli, G.G. and Delzenne, N.M., 2009b. Changes in gut microbiota control inflammation in obese mice through a mechanism involving GLP-2-driven improvement of gut permeability. Gut 58: 1091-1103. https://doi.org/10.1136/gut.2008.165886

Cavaglieri, C.R., Nishiyama, A., Fernandes, L.C., Curi, R., Miles, E.A. and Calder, P.C., 2003. Differential effects of short-chain fatty acids on proliferation and production of pro- and anti-inflammatory cytokines by cultured lymphocytes. Life Sciences 73: 1683-1690.

Chambers, E.S., Byrne, C.S., Aspey, K., Chen, Y., Khan, S., Morrison, D.J. and Frost, G., 2018a. Acute oral sodium propionate supplementation raises resting energy expenditure and lipid oxidation in fasted humans. Diabetes, Obesity and Metabolism 20: 1034-1039. https:// doi.org/10.1111/dom.13159

Chambers, E.S., Preston, T., Frost, G. and Morrison, D.J., 2018b. Role of gut microbiota-generated short-chain fatty acids in metabolic and cardiovascular health. Current Nutrition Reports 7: 198-206. https://doi.org/10.1007/s13668-018-0248-8

Chambers, E.S., Viardot, A., Psichas, A., Morrison, D.J., Murphy, K.G., Zac-varghese, S.E.K., Macdougall, K., Preston, T., Tedford, C., Finlayson, G.S., Blundell, J.E., Bell, J.D., Thomas, E.L., Mt-isa, S., Ashby, D., Gibson, G.R., Dhillo, W.S., Bloom, S.R., Morley, W., Clegg, S. and Frost, G., 2015. Effects of targeted delivery of propionate to the human colon on appetite regulation, body weight maintenance and adiposity in overweight adults. BMJ 64: 1744-1754. https://doi. org/10.1136/gutjnl-2014-307913

Cherbut, C., 2003. Motor effects of short-chain fatty acids and lactate in the gastrointestinal tract. Proceedings of the Nutrition Society 62: 95-99. 
Cherbut, C., Ferrier, L., Roze, C., Anini, Y., Blottiere, H., Lecannu, G. and Galmiche, J.P., 1998. Short-chain fatty acids modify colonic motility through nerves and polypeptide YY release in the rat. American Journal of Physiologyy 275: G1415-1422.

Chia, L.W., Hornung, B.V.H., Aalvink, S., Schaap, P.J., De Vos, W.M., Knol, J. and Belzer, C., 2018. Deciphering the trophic interaction between Akkermansia muciniphila and the butyrogenic gut commensal Anaerostipes caccae using a metatranscriptomic approach. Antonie van Leeuwenhoek 111: 859-873. https://doi. org/10.1007/s10482-018-1040-x

Clausen, M.R. and Mortensen, P.B., 1995. Kinetic studies on colonocyte metabolism of short chain fatty acids and glucose in ulcerative colitis. Gut 37: 684-689.

Cobo, E.R., Kissoon-Singh, V., Moreau, F., Holani, R. and Chadee, K., 2017. MUC2 mucin and butyrate contribute to the synthesis of the antimicrobial peptide cathelicidin in response to Entamoeba histolytica- and dextran sodium sulfate-induced colitis. Infection and Immunity 85: e00905-16.

Coxam, V., 2007. Current data with inulin-type fructans and calcium, targeting bone health in adults. Journal of Nutrition 137: 2527S-2533S. https://doi.org/10.1093/jn/137.11.2527S

Cummings, J.H. and MacFarlane, G.T., 1997. Colonic microflora: nutrition and health. Nutrition 13: 476-478. https://doi.org/10.1016/ S0899-9007(97)00114-7

Cummings, J.H., Pomare, E.W., Branch, H.W.J., Naylor, C.P.E. and MacFarlane, G.T., 1987. Short chain fatty acids in human large intestine, portal, hepatic and venous blood. Gut 28: 1221-1227. https://doi.org/10.1136/gut.28.10.1221

Da Silva, H.E., Teterina, A., Comelli, E.M., Taibi, A., Arendt, B.M., Fischer, S.E., Lou, W. and Allard, J.P., 2018. Nonalcoholic fatty liver disease is associated with dysbiosis independent of body mass index and insulin resistance. Scientific Reports 8: 1466. https:// doi.org/10.1038/s41598-018-19753-9

Darzi, J., Frost, G.S. and Robertson, M.D., 2012. Effects of a novel propionate-rich sourdough bread on appetite and food intake. European Journal of Clinical Nutrition 66: 789-794. https://doi. org/10.1038/ejcn.2012.1

Dass, N.B., John, A.K., Bassil, A.K., Crumbley, C.W., Shehee, W.R., Maurio, F.P., Moore, G.B., Taylor, C.M. and Sanger, G.J., 2007. The relationship between the effects of short-chain fatty acids on intestinal motility in vitro and GPR43 receptor activation. Neurogastroenterology and Motility 19: 66-74. https://doi. org/10.1111/j.1365-2982.2006.00853.x

Davie, J.R., 2003. Inhibition of histone deacetylase activity by butyrate. Journal of Nutrition 133: 2485S-2493S.

De Preter, V., Geboes, K.P., Bulteel, V., Vandermeulen, G., Suenaert, P., Rutgeerts, P. and Verbeke, K., 2011. Kinetics of butyrate metabolism in the normal colon and in ulcerative colitis: the effects of substrate concentration and carnitine on the beta-oxidation pathway. Alimentary Pharmacology \& Therapeutics 34: 526-532.

De Vadder, F., Kovatcheva-Datchary, P., Goncalves, D., Vinera, J., Zitoun, C., Duchampt, A., Bäckhed, F. and Mithieux, G., 2014. Microbiota-generated metabolites promote metabolic benefits via gut-brain neural circuits. Cell 156: 84-96. https://doi.org/10.1016/j. cell.2013.12.016
De Vadder, F., Plessier, F., Gautier-Stein, A. and Mithieux, G., 2015. Vasoactive intestinal peptide is a local mediator in a gut-brain neural axis activating intestinal gluconeogenesis. Neurogastroenterology and Motility 27: 443-448. https://doi.org/10.1111/nmo.12508

DeFronzo, R.A., Jacot, E., Jequier, E., Maeder, E., Wahren, J. and Felber, J.P., 1981. The effect of insulin on the disposal of intravenous glucose: results from indirect calorimetry and hepatic and femoral venous catheterization. Diabetes 30: 1000-1007.

Dehghan, P., Farhangi, M.A., Tavakoli, F., Aliasgarzadeh, A. and Akbari, A.M., 2016. Impact of prebiotic supplementation on T-cell subsets and their related cytokines, anthropometric features and blood pressure in patients with type 2 diabetes mellitus: a randomized placebo-controlled trial. Complementary Therapies in Medicine 24: 96-102. https://doi.org/10.1016/j.ctim.2015.12.010

Dehghan, P., Pourghassem Gargari, B. and Asgharijafarabadi, M., 2013. Effects of high performance inulin supplementation on glycemic status and lipid profile in women with type 2 diabetes: a randomized, placebo-controlled clinical trial. Health Promotion Perspectives 3: 55-63. https://doi.org/10.5681/hpp.2013.007

Den Besten, G., Bleeker, A., Gerding, A., Van Eunen, K., Havinga, R., Van Dijk, T.H., Oosterveer, M.H., Jonker, J.W., Groen, A.K. and Reijngoud, D.-J., 2015. Short-chain fatty acids protect against high-fat diet-induced obesity via a PPAR $\gamma$-dependent switch from lipogenesis to fat oxidation. Diabetes 64: 2398-2408. https://doi. org/10.2337/db14-1213.

Den Besten, G., Lange, K., Havinga, R., Van Dijk, T.H., Gerding, A., Van Eunen, K., Muller, M., Groen, A.K., Hooiveld, G.J., Bakker, B.M. and Reijngoud, D.J., 2013. Gut-derived short-chain fatty acids are vividly assimilated into host carbohydrates and lipids. American Journal of Physiology - Gastrointestinal and Liver Physiology 305: G900-910. https://doi.org/10.1152/ajpgi.00265.2013

Deroover, L., Verspreet, J., Luypaerts, A., Vandermeulen, G., Courtin, C.M. and Verbeke, K., 2017. Wheat bran does not affect postprandial plasma short-chain fatty acids from 13C-inulin fermentation in healthy subjects. Nutrients 9: 83. https://doi.org/10.3390/nu9010083

Dewulf, E.M., Cani, P.D., Claus, S.P., Fuentes, S., Puylaert, P.G.B., Neyrinck, A.M., Bindels, L.B., De Vos, W.M., Gibson, G.R. and Thissen, J.P., 2013. Insight into the prebiotic concept: lessons from an exploratory, double blind intervention study with inulin-type fructans in obese women. Gut 62: 1112-1121.

Duncan, S.H., Belenguer, A., Holtrop, G., Johnstone, A.M., Flint, H.J. and Lobley, G.E., 2007. Reduced dietary intake of carbohydrates by obese subjects results in decreased concentrations of butyrate and butyrate-producing bacteria in feces. Applied and Environmental Microbiology 73: 1073-1078. https://doi.org/10.1128/AEM.02340-06

Duncan, S.H., Louis, P. and Flint, H.J., 2004. Lactate-utilizing bacteria, isolated from human feces, that produce butyrate as a major fermentation product. Applied and Environmental Microbiology 70: 5810-5817. https://doi.org/10.1128/AEM.70.10.5810-5817.2004 
Dutzan, N., Abusleme, L., Bridgeman, H., Greenwell-Wild, T., ZangerleMurray, T., Fife, M.E., Bouladoux, N., Linley, H., Brenchley, L., Wemyss, K., Calderon, G., Hong, B.-Y., Break, T.J., Bowdish, D.M.E., Lionakis, M.S., Jones, S.A., Trinchieri, G., Diaz, P.I., Belkaid, Y., Konkel, J.E. and Moutsopoulos, N.M., 2017. On-going mechanical damage from mastication drives homeostatic Th17 cell responses at the oral barrier. Immunity 46: 133-147. https://doi.org/10.1016/j. immuni.2016.12.010

Elamin, E.E., Masclee, A.A., Dekker, J., Pieters, H.J. and Jonkers, D.M., 2013. Short-chain fatty acids activate AMP-activated protein kinase and ameliorate ethanol-induced intestinal barrier dysfunction in caco-2 cell monolayers. Journal of Nutrition 143: 1872-1881. https:// doi.org/10.3945/jn.113.179549

Falony, G., Joossens, M., Vieira-Silva, S., Wang, J., Darzi, Y., Faust, K., Kurilshikov, A., Bonder, M.J., Valles-Colomer, M., Vandeputte, D., Tito, R.Y., Chaffron, S., Rymenans, L., Verspecht, C., De Sutter, L., Lima-Mendez, G., D’hoe, K., Jonckheere, K., Homola, D., Garcia, R., Tigchelaar, E.F., Eeckhaudt, L., Fu, J., Henckaerts, L., Zhernakova, A., Wijmenga, C. and Raes, J., 2016. Population-level analysis of gut microbiome variation. Science 352: 560-564.

Falony, G., Vlachou, A., Verbrugghe, K. and De Vuyst, L., 2006. Crossfeeding between Bifidobacterium longum BB536 and acetateconverting, butyrate-producing colon bacteria during growth on oligofructose. Applied and Environmental Microbiology 72: 78357841. https://doi.org/10.1128/AEM.01296-06

Fernandes, J., Vogt, J. and Wolever, T.M.S., 2012. Intravenous acetate elicits a greater free fatty acid rebound in normal than hyperinsulinaemic humans. European Journal of Clinical Nutrition 66: 1029-1034.

Ferreira, T.M., Leonel, A.J., Melo, M.A., Santos, R.R., Cara, D.C., Cardoso, V.N., Correia, M.I. and Alvarez-Leite, J.I., 2012. Oral supplementation of butyrate reduces mucositis and intestinal permeability associated with 5 -fluorouracil administration. Lipids 47: 669-678. https://doi.org/10.1007/s11745-012-3680-3

Finnie, I.A., Dwarakanath, A.D., Taylor, B.A. and Rhodes, J.M., 1995. Colonic mucin synthesis is increased by sodium butyrate. Gut 36: 93-99.

Freeland, K.R. and Wolever, T.M., 2010. Acute effects of intravenous and rectal acetate on glucagon-like peptide-1, peptide YY, ghrelin, adiponectin and tumour necrosis factor-alpha. British Journal of Nutrition 103: 460-466.

Frost, G., Sleeth, M.L., Sahuri-arisoylu, M., Lizarbe, B., Cerdan, S., Brody, L., Anastasovska, J., Ghourab, S., Hankir, M., Zhang, S., Carling, D., Swann, J.R., Gibson, G., Viardot, A., Morrison, D., Thomas, E.L. and Bell, J.D., 2014. The short-chain fatty acid acetate reduces appetite via a central homeostatic mechanism. Nature Communications 5: 1-11. https://doi.org/10.1038/ncomms4611

Fukumoto, S., Tatewaki, M., Yamada, T., Fujimiya, M., Mantyh, C., Voss, M., Eubanks, S., Harris, M., Pappas, T.N. and Takahashi, T., 2003. Short-chain fatty acids stimulate colonic transit via intraluminal 5-HT release in rats. American Journal of Physiology - Regulatory, Integrative and Comparative Physiology 284: R1269-R1276. https:// doi.org/10.1152/ajpregu.00442.2002
Fukushima, A., Aizaki, Y. and Sakuma, K., 2009. Short-chain fatty acids induce intestinal transient receptor potential vanilloid type 6 expression in rats and caco-2 cells. Journal of Nutrition 139: 20-25. https://doi.org/10.3945/jn.108.096230

Fukushima, A., Aizaki, Y. and Sakuma, K., 2012. Short-chain fatty acids increase the level of calbindin-D9k messenger RNA in caco-2 cells. Journal of Nutritional Science and Vitaminology 58: 287-291. https://doi.org/10.3177/jnsv.58.287

Fushimi, T., Tayama, K., Fukaya, M., Kitakoshi, K., Nakai, N., Tsukamoto, Y. and Sato, Y., 2001. Acetic acid feeding enhances glycogen repletion in liver and skeletal muscle of rats. Journal of Nutrition 131: 1973-1977.

Gao, Z., Yin, J., Zhang, J., Ward, R.E., Martin, R.J., Lefevre, M., Cefalu, W.T. and Ye, J., 2009. Butyrate improves insulin sensitivity and increases energy expenditure in mice. Diabetes 58: 1509-1509.

Gaudier, E., Forestier, L., Gouyer, V., Huet, G., Julien, R. and Hoebler, C., 2004. Butyrate regulation of glycosylation-related gene expression: evidence for galectin-1 upregulation in human intestinal epithelial goblet cells. Biochemical and Biophysical Research Communications 325: 1044-1051. https://doi.org/10.1016/j.bbrc.2004.10.141

Gaudier, E., Rival, M., Buisine, M.P., Robineau, I. and Hoebler, C., 2009. Butyrate enemas upregulate muc genes expression but decrease adherent mucus thickness in mice colon. Physiological Research 58: 111-119.

Gibson, G.R., Hutkins, R., Sanders, M.E., Prescott, S.L., Reimer, R.A., Salminen, S.J., Scott, K., Stanton, C., Swanson, K.S., Cani, P.D., Verbeke, K. and Reid, G., 2017. Expert consensus document: The International Scientific Association for Probiotics and Prebiotics (ISAPP) consensus statement on the definition and scope of prebiotics. Nature Reviews Gastroenterology and Hepatology 14: 491-502. https://doi.org/10.1038/nrgastro.2017.75

Gill, R.K., Saksena, S., Alrefai, W.A., Sarwar, Z., Goldstein, J.L., Carroll, R.E., Ramaswamy, K. and Dudeja, P.K., 2005. Expression and membrane localization of MCT isoforms along the length of the human intestine. American Journal of Physiology - Cell Physiology 289: C846-C852. https://doi.org/10.1152/ajpcell.00112.2005

Goverse, G., Molenaar, R., Macia, L., Tan, J., Erkelens, M.N., Konijn, T., Knippenberg, M., Cook, E.C.L., Hanekamp, D., Veldhoen, M., Hartog, A., Roeselers, G., Mackay, C.R. and Mebius, R.E., 2017. Dietderived short chain fatty acids stimulate intestinal epithelial cells to induce mucosal tolerogenic dendritic cells. Journal of Immunology 198: 2172 LP-2181.

Grootaert, C., Van Den Abbeele, P., Marzorati, M., Broekaert, W.F., Courtin, C.M., Delcour, J.A., Verstraete, W. and Van De Wiele, T., 2009. Comparison of prebiotic effects of arabinoxylan oligosaccharides and inulin in a simulator of the human intestinal microbial ecosystem. FEMS Microbiology Ecology 69: 231-242. https://doi.org/10.1111/j.1574-6941.2009.00712.x

Guo, C., Xie, S., Chi, Z., Zhang, J., Liu, Y., Zhang, L., Zheng, M., Zhang, X., Xia, D., Ke, Y., Lu, L. and Wang, D., 2016. Bile acids control inflammation and metabolic disorder through inhibition of NLRP3 inflammasome. Immunity 45: 802-816. https://doi.org/10.1016/j. immuni.2016.09.008 
Gupta, N., Martin, P.M., Prasad, P.D. and Ganapathyet, V., 2006. SLC5A8(SMCT1)-mediated transport of butyrate forms the basis for the tumor suppressive function of the transporter. Life Science 78: 2419-2425.

Gurav, A., Sivaprakasam, S., Bhutia, Yangzom, D., Boettger, T., Singh, N. and Ganapathy, V., 2015. Slc5a8, a Na+-coupled high-affinity transporter for short-chain fatty acids, is a conditional tumour suppressor in colon that protects against colitis and colon cancer under low-fibre dietary conditions. Biochemical Journal 469: 267 278. https://doi.org/10.1042/bj20150242

Gutierrez-Repiso, C., Garcia-Serrano, S., Moreno-Ruiz, F.J., AlcainMartinez, G., Rodriguez-Pacheco, F. and Garcia-Fuentes, E., 2017. Jejunal gluconeogenesis associated with insulin resistance level and its evolution after Roux-en-Y gastric bypass. Surgery for Obesity and Related Diseases 13: 623-630. https://doi.org/10.1016/j. soard.2016.11.021

Hald, S., Schioldan, A.G., Moore, M.E., Dige, A., Lærke, H.N., Agnholt, J., Bach Knudsen, K.E., Hermansen, K., Marco, M.L., Gregersen, S. and Dahlerup, J.F., 2016. Effects of arabinoxylan and resistant starch on intestinal microbiota and short-chain fatty acids in subjects with metabolic syndrome: a randomised crossover study. PLoS ONE 11: e0159223. https://doi.org/10.1371/journal.pone.0159223

Halestrap, A.P. and Meredith, D., 2004. The SLC16 gene family - from monocarboxylate transporters (MCTs) to aromatic amino acid transporters and beyond. Pflugers Archiv European Journal of Physiology 447: 619-628. https://doi.org/10.1007/s00424-003-1067-2

Hallert, C., Björck, I., Nyman, M., Pousette, A., Grännö, C. and Svensson, H., 2003. Increasing fecal butyrate in ulcerative colitis patients by diet: controlled pilot study. Inflammatory Bowel Diseases 9: $116-121$

Hamer, H.M., Jonkers, D., Venema, K., Vanhoutvin, S., Troost, F.J. and Brummer, R.J., 2008. Review article: the role of butyrate on colonic function. Alimentary Pharmacology and Therapeutics 27: 104-119. https://doi.org/10.1111/j.1365-2036.2007.03562.x

Hamer, H.M., Jonkers, D.M.A.E., Bast, A., Vanhoutvin, S.A.L.W., Fischer, M.A.J.G., Kodde, A., Troost, F.J., Venema, K. and Brummer, R.-J.M., 2009. Butyrate modulates oxidative stress in the colonic mucosa of healthy humans. Clinical Nutrition 28: 88-93. https:// doi.org/10.1016/j.clnu.2008.11.002

Hamer, H.M., Jonkers, D.M.A.E., Vanhoutvin, S.A.L.W., Troost, F.J., Rijkers, G., De Bruine, A., Bast, A., Venema, K. and Brummer, R.-J.M., 2010. Effect of butyrate enemas on inflammation and antioxidant status in the colonic mucosa of patients with ulcerative colitis in remission. Clinical Nutrition 29: 738-744. https://doi. org/10.1016/j.clnu.2010.04.002

Han, X., Song, H., Wang, Y., Sheng, Y. and Chen, J., 2015. Sodium butyrate protects the intestinal barrier function in peritonitic mice. International Journal of Clinical and Experimental Medicine 8: 4000-4007.

Harig, J.M., Ng, E.K., Dudeja, P.K., Brasitus, T.A. and Ramaswamy, K., 1996. Transport of n-butyrate into human colonic luminal membrane vesicles. American Journal of Physiology - Gastrointestinal and Liver Physiology 271: G415-G422.
Harig, J.M., Soergel, K.H., Komorowski, R.A. and Wood, C.M., 1989. Treatment of diversion colitis with short-chain-fatty acid irrigation. New England Journal of Medicine 320: 23-28. https:// doi.org/10.1056/nejm198901053200105

Hase, K., Eckmann, L., Leopard, J.D., Varki, N. and Kagnoff, M.F., 2002. Cell differentiation is a key determinant of cathelicidin LL$37 /$ human cationic antimicrobial protein 18 expression by human colon epithelium. Infection and Immunity 70: 953-963. https://doi. org/10.1128/iai.70.2.953-963.2002

Hatayama, H., Iwashita, J., Kuwajima, A. and Abe, T., 2007. The short chain fatty acid, butyrate, stimulates MUC2 mucin production in the human colon cancer cell line, LS174T. Biochemical and Biophysical Research Communications 356: 599-603. https://doi.org/10.1016/j. bbrc.2007.03.025

Hattori, M., Kondo, T., Kishi, M. and Yamagami, K., 2010. A single oral administration of acetic acid increased energy expenditure in C57BL/6J mice. Bioscience, Biotechnology, and Biochemistry 74: 2158-2159. https://doi.org/10.1271/bbb.100486

Hayes, M.T., Foo, J., Besic, V., Tychinskaya, Y. and Stubbs, R.S., 2011. Is intestinal gluconeogenesis a key factor in the early changes in glucose homeostasis following gastric bypass? Obesity Surgery 21: 759-762. https://doi.org/10.1007/s11695-011-0380-7

Healey, G., Murphy, R., Butts, C., Brough, L., Whelan, K. and Coad, J., 2018. Habitual dietary fibre intake influences gut microbiota response to an inulin-type fructan prebiotic: a randomised, doubleblind, placebo-controlled, cross-over, human intervention study. British Journal of Nutrition 119: 176-189. https://doi.org/10.1017/ S0007114517003440

Henagan, T.M., Stefanska, B., Fang, Z., Navard, A.M., Ye, J., Lenard, N.R. and Devarshi, P.P., 2015. Sodium butyrate epigenetically modulates skeletal muscle mitochondrial adaptation, obesity and insulin resistance through nucleosome positioning. BJP 172: 27822798. https://doi.org/10.1111/bph.13058

Henao-Mejia, J., Elinav, E., Jin, C., Hao, L., Mehal, W.Z., Strowig, T., Thaiss, C.A., Kau, A.L., Eisenbarth, S.C., Jurczak, M.J., Camporez, J.P., Shulman, G.I., Gordon, J.I., Hoffman, H.M. and Flavell, R.A., 2012. Inflammasome-mediated dysbiosis regulates progression of NAFLD and obesity. Nature 482: 179-185. https://doi.org/10.1038/ nature10809

Henson, M.A. and Phalak, P., 2017. Byproduct cross feeding and community stability in an in silico biofilm model of the gut microbiome. Processes 5: 13. https://doi.org/10.3390/pr5010013

Hoek, M.J.A. and Merks, R.M.H., 2017. Emergence of microbial diversity due to cross-feeding interactions in a spatial model of gut microbial metabolism. BMC Systems Biology 11: 56-56. https:// doi.org/10.1186/s12918-017-0430-4

Hong, J., Jia, Y., Pan, S., Jia, L., Li, H. and Han, Z., 2016. Butyrate alleviates high fat diet-induced obesity through activation of adiponectin-mediated pathway and stimulation of mitochondrial function in the skeletal muscle of mice. Oncotarget 7:56071-56082.

Hong, Y.H., Nishimura, Y., Hishikawa, D., Tsuzuki, H., Miyahara, H., Gotoh, C., Choi, K.C., Feng, D.D., Chen, C. and Lee, H.G., 2005. Acetate and propionate short chain fatty acids stimulate adipogenesis via GPCR43. Endocrinology 146: 5092-5092. 
Hornung, B., Martins dos Santos, V.A.P., Smidt, H. and Schaap, P.J., 2018. Studying microbial functionality within the gut ecosystem by systems biology. Genes and Nutrition 13: 5. https://doi.org/10.1186/ s12263-018-0594-6

Hu, E.D., Chen, D.Z., Wu, J.L., Lu, F.B., Chen, L., Zheng, M.H., Li, H., Huang, Y., Li, J., Jin, X.Y., Gong, Y.W., Lin, Z., Wang, X.D., Xu, L.M. and Chen, Y.P., 2018. High fiber dietary and sodium butyrate attenuate experimental autoimmune hepatitis through regulation of immune regulatory cells and intestinal barrier. Cellular Immunology 328: 24-32. https://doi.org/10.1016/j.cellimm.2018.03.003

Huang, C., Song, P., Fan, P., Hou, C., Thacker, P. and Ma, X., 2015. Dietary sodium butyrate decreases postweaning diarrhea by modulating intestinal permeability and changing the bacterial communities in weaned piglets. Journal of Nutrition 145: 27742780. https://doi.org/10.3945/jn.115.217406

Hung, T.V. and Suzuki, T., 2016. Dietary fermentable fiber reduces intestinal barrier defects and inflammation in colitic mice. Journal of Nutrition 146: 1970-1979. https://doi.org/10.3945/jn.116.232538

Hung, T.V. and Suzuki, T., 2018. Dietary fermentable fibers attenuate chronic kidney disease in mice by protecting the intestinal barrier. Journal of Nutrition 148: 552-561. https://doi.org/10.1093/jn/nxy008 Huuskonen, J., Suuronen, T., Nuutinen, T., Kyrylenko, S. and Salminen, A., 2004. Regulation of microglial inflammatory response by sodium butyrate and short-chain fatty acids. British Journal of Pharmacology 141: 874-880. https://doi.org/10.1038/sj.bjp.0705682

Inan, M.S., Rasoulpour, R.J., Yin, L., Hubbard, A.K., Rosenberg, D.W. and Giardina, C., 2000. The luminal short-chain fatty acid butyrate modulates NF-kB activity in a human colonic epithelial cell line. Gastroenterology 118: 724-734. https://doi.org/10.1016/S00165085(00)70142-9

Iraporda, C., Errea, A., Romanin, D.E., Cayet, D., Pereyra, E., Pignataro, O., Sirard, J.C., Garrote, G.L., Abraham, A.G. and Rumbo, M., 2015. Lactate and short chain fatty acids produced by microbial fermentation downregulate proinflammatory responses in intestinal epithelial cells and myeloid cells. Immunobiology 220: 1161-1169. https://doi.org/10.1016/j.imbio.2015.06.004

Jain, P.K., McNaught, C.E., Anderson, A.D., MacFie, J. and Mitchell, C.J., 2004. Influence of synbiotic containing Lactobacillus acidophilus La5, Bifidobacterium lactis $\mathrm{Bb} 12$, Streptococcus thermophilus, Lactobacillus bulgaricus and oligofructose on gut barrier function and sepsis in critically ill patients: a randomised controlled trial. Clinical Nutrition 23: 467-475. https://doi.org/10.1016/j. clnu.2003.12.002

Jia, Y., Hong, J., Li, H., Hu, Y., Jia, L., Cai, D. and Zhao, R., 2016. Butyrate stimulates adipose lipolysis and mitochondrial oxidative phosphorylation through histone hyperacetylation-associated beta3adrenergic receptor activation in high-fat diet-induced obese mice. Experimental Physiology 102: 273-281. https://doi.org/10.1113/ EP086114

Jiang, L., Krystal, J.H., Mason, G.F., Jiang, L., Gulanski, B.I., Feyter, H.M.D., Weinzimer, S.A., Pittman, B., Guidone, E., Koretski, J., Harman, S., Petrakis, I.L., Krystal, J.H. and Mason, G.F., 2013. Increased brain uptake and oxidation of acetate in heavy drinkers find the latest version: increased brain uptake and oxidation of acetate in heavy drinkers. Journal of Clinical Investigation 123: 1605-1614. https://doi.org/10.1172/JCI65153.by
Jocken, J.W., Hoebers, N.T., Van der Beek, C.M., Essers, Y.P., Blaak, E.E. and Canfora, E., 2017. Short-chain fatty acids differentially affect intracellular lipolysis in a human white adipocyte model. Frontiers in Endocrinology 8: 372.

Jouet, P., Moussata, D., Duboc, H., Boschetti, G., Attar, A., Gorbatchef, C., Sabate, J.M., Coffin, B. and Flourie, B., 2013. Effect of shortchain fatty acids and acidification on the phasic and tonic motor activity of the human colon. Neurogastroenterology and Motility 25: 943-949. https://doi.org/10.1111/nmo.12212

Jung, T.-H., Park, J.H., Jeon, W.-M. and Han, K.-S., 2015. Butyrate modulates bacterial adherence on LS174T human colorectal cells by stimulating mucin secretion and MAPK signaling pathway. Nutrition Research and Practice 9: 343-349. https://doi.org/10.4162/ nrp.2015.9.4.343

Kaisar, M.M.M., Pelgrom, L.R., Van der Ham, A.J., Yazdanbakhsh, M. and Everts, B., 2017. Butyrate conditions human dendritic cells to prime Type 1 regulatory $\mathrm{T}$ cells via both histone deacetylase inhibition and G protein-coupled receptor 109A signaling. Frontiers in Immunology 8: 1429-1429.

Kang, C., Wang, B., Kaliannan, K., Wang, X., Lang, H., Hui, S., Huang, L., Zhang, Y., Zhou, M., Chen, M., Mi, M., Godoy-Vitorino, F. and Dominguez Bello, M.G., 2017. Gut microbiota mediates the protective effects of dietary capsaicin against chronic low-grade inflammation and associated obesity induced by high-fat diet. mBio 8. https://doi.org/10.1128/mBio.00470-17

Karaki, S., Mitsui, R., Hayashi, H., Kato, I., Sugiya, H., Iwanaga, T., Furness, J.B. and Kuwahara, A., 2006. Short-chain fatty acid receptor, GPR43, is expressed by enteroendocrine cells and mucosal mast cells in rat intestine. Cell Tissue Research 324: 353-360. https://doi. org/10.1007/s00441-005-0140-x

Kashimura, J., Kimura, M. and Itokawa, Y., 1996. The effects of isomaltulose, isomalt, and isomaltulose-based oligomers on mineral absorption and retention. Biological Trace Element Research 54: 239-250. https://doi.org/10.1007/bf02784435

Kelly, C.J., Zheng, L., Campbell, E.L., Saeedi, B., Scholz, C.C., Bayless, A.J., Wilson, K.E., Glover, L.E., Kominsky, D.J., Magnuson, A., Weir, T.L., Ehrentraut, S.F., Pickel, C., Kuhn, K.A., Lanis, J.M., Nguyen, V., Taylor, C.T. and Colgan, S.P., 2015. Crosstalk between microbiotaderived short-chain fatty acids and intestinal epithelial HIF augments tissue barrier function. Cell Host Microbe 17: 662-671. https://doi. org/10.1016/j.chom.2015.03.005

Kien, C.L., Kepner, J., Grotjohn, K., Ault, K. and McClead, R.E., 1992. Stable isotope model for estimating colonic acetate production in premature infants. Gastroenterology 102: 1458-1466. https://doi. org/10.1016/0016-5085(92)91702-6

Kim, M.H., Kang, S.G., Park, J.H., Yanagisawa, M. and Kim, C.H., 2013. Short-chain fatty acids activate GPR41 and GPR43 on intestinal epithelial cells to promote inflammatory responses in mice. Gastroenterology 145: 396-406. https://doi.org/10.1053/j. gastro.2013.04.056

Kimura, I., Inoue, D., Maeda, T., Hara, T., Ichimura, A. and Miyauchi, S., 2011. Short-chain fatty acids and ketones directly regulate sympathetic nervous system via G protein-coupled receptor 41. Proceedings of the National Academy of Sciences of the USA 108: 8030-8035. https://doi.org/10.1073/pnas.1016088108/-/ DCSupplemental.www.pnas.org/cgi/doi/10.1073/pnas.1016088108 
Kimura, I., Ozawa, K., Inoue, D., Imamura, T., Kimura, K., Maeda, T., Terasawa, K., Kashihara, D., Hirano, K., Tani, T., Takahashi, T., Miyauchi, S., Shioi, G., Inoue, H. and Tsujimoto, G., 2013. The gut microbiota suppresses insulin-mediated fat accumulation via the short-chain fatty acid receptor GPR43. Nature Communications 4: 1-12. https://doi.org/10.1038/ncomms2852

Koh, A., De Vadder, F., Kovatcheva-Datchary, P. and Backhed, F., 2016. From dietary fiber to host physiology: short-chain fatty acids as key bacterial metabolites. Cell 165: 1332-1345. https://doi.org/10.1016/j. cell.2016.05.041

Kondo, T., Kishi, M., Fushimi, T. and Kaga, T., 2009. Acetic acid upregulates the expression of genes for fatty acid oxidation enzymes in liver to suppress body fat accumulation. Journal of Agricultural and Food Chemistry 57: 5982-5986.

Kootte, R.S., Levin, E., Salojärvi, J., Smits, L.P., Hartstra, A.V., Udayappan, S.D., Hermes, G., Bouter, K.E., Koopen, A.M., Holst, J.J., Knop, F.K., Blaak, E.E., Zhao, J., Smidt, H., Harms, A.C., Hankemeijer, T., Bergman, J.J.G.H.M., Romijn, H.A., Schaap, F.G., Olde Damink, S.W.M., Ackermans, M.T., Dallinga-Thie, G.M., Zoetendal, E., De Vos, W.M., Serlie, M.J., Stroes, E.S.G., Groen, A.K. and Nieuwdorp, M., 2017. Improvement of insulin sensitivity after lean donor feces in metabolic syndrome is driven by baseline intestinal microbiota composition. Cell Metabolism 26: 611-619. https://doi.org/10.1016/j.cmet.2017.09.008

Kovatcheva-Datchary, P., Egert, M., Maathuis, A., Rajilić-Stojanović, M., De Graaf, A.A., Smidt, H., De Vos, W.M. and Venema, K., 2009. Linking phylogenetic identities of bacteria to starch fermentation in an in vitro model of the large intestine by RNA-based stable isotope probing. Environmental Microbiology 11: 914-926. https:// doi.org/10.1111/j.1462-2920.2008.01815.x

Laurent, C., Simoneau, C., Marks, L., Braschi, S., Champ, M., Charbonnel, B. and Krempf, M., 1995. Effect of acetate and propionate on fasting hepatic glucose production in humans. European Journal of Clinical Nutrition 49: 484.

Le Bourgot, C., Apper, E., Blat, S. and Respondek, F., 2018. Fructooligosaccharides and glucose homeostasis: a systematic review and meta-analysis in animal models. Nutrition and Metabolism 15: 9. https://doi.org/10.1186/s12986-018-0245-3

Lengacher, S., Nehiri-Sitayeb, T., Steiner, N., Carneiro, L., Favrod, C., Preitner, F., Thorens, B., Stehle, J.C., Dix, L., Pralong, F., Magistretti, P.J. and Pellerin, L., 2013. Resistance to diet-induced obesity and associated metabolic perturbations in haploinsufficient monocarboxylate transporter 1 mice. PLoS ONE 8: e82505. https:// doi.org/10.1371/journal.pone.0082505

Lewis, S.J. and Heaton, K.W., 1997. Increasing butyrate concentration in the distal colon by accelerating intestinal transit. Gut 41: 245-251. https://doi.org/10.1136/gut.41.2.245

Li, X., Chen, H., Guan, Y., Li, X., Lei, L., Liu, J., Yin, L., Liu, G. and Wang, Z., 2013. Acetic acid activates the AMP-activated protein kinase signaling pathway to regulate lipid metabolism in bovine hepatocytes. PLoS ONE 8: e67880-e67880.
Li, Z., Yi, C.-x., Katiraei, S., Kooijman, S., Zhou, E., Chung, C.K., Gao, Y., Heuvel, J.K.V.D., Meijer, O.C., Berbée, J.F.P., Heijink, M., Giera, M., Dijk, K.W.V., Groen, A.K., Rensen, P.C.N. and Wang, Y., 2017. Butyrate reduces appetite and activates brown adipose tissue via the gut-brain neural circuit. Gut 67: 1269-1279. https://doi.org/10.1136/ gutjnl-2017-314050

Lim, S.S., Vos, T., Flaxman, A.D., Danaei, G., Shibuya, K., Adair-Rohani, H., AlMazroa, M.A., Amann, M., Anderson, H.R., Andrews, K.G., Aryee, M., Atkinson, C., Bacchus, L.J., Bahalim, A.N., Balakrishnan, K., Balmes, J., Barker-Collo, S., Baxter, A., Bell, M.L., Blore, J.D., Blyth, F., Bonner, C., Borges, G., Bourne, R., Boussinesq, M., Brauer, M., Brooks, P., Bruce, N.G., Brunekreef, B., Bryan-Hancock, C., Bucello, C., Buchbinder, R., Bull, F., Burnett, R.T., Byers, T.E., Calabria, B., Carapetis, J., Carnahan, E., Chafe, Z., Charlson, F., Chen, H., Chen, J.S., Cheng, A.T.-A., Child, J.C., Cohen, A., Colson, K.E., Cowie, B.C., Darby, S., Darling, S., Davis, A., Degenhardt, L., Dentener, F., Des Jarlais, D.C., Devries, K., Dherani, M., Ding, E.L., Dorsey, E.R., Driscoll, T., Edmond, K., Ali, S.E., Engell, R.E., Erwin, P.J., Fahimi, S., Falder, G., Farzadfar, F., Ferrari, A., Finucane, M.M., Flaxman, S., Fowkes, F.G.R., Freedman, G., Freeman, M.K., Gakidou, E., Ghosh, S., Giovannucci, E., Gmel, G., Graham, K., Grainger, R., Grant, B., Gunnell, D., Gutierrez, H.R., Hall, W., Hoek, H.W., Hogan, A., Hosgood, H.D., Hoy, D., Hu, H., Hubbell, B.J., Hutchings, S.J., Ibeanusi, S.E., Jacklyn, G.L., Jasrasaria, R., Jonas, J.B., Kan, H., Kanis, J.A., Kassebaum, N., Kawakami, N., Khang, Y.-H., Khatibzadeh, S., Khoo, J.-P., Kok, C., Laden, F., Lalloo, R., Lan, Q., Lathlean, T., Leasher, J.L., Leigh, J., Li, Y., Lin, J.K., Lipshultz, S.E., London, S., Lozano, R., Lu, Y., Mak, J., Malekzadeh, R., Mallinger, L., Marcenes, W., March, L., Marks, R., Martin, R., McGale, P., McGrath, J., Mehta, S., Memish, Z.A., Mensah, G.A., Merriman, T.R., Micha, R., Michaud, C., Mishra, V., Hanafiah, K.M., Mokdad, A.A., Morawska, L., Mozaffarian, D., Murphy, T., Naghavi, M., Neal, B., Nelson, P.K., Nolla, J.M., Norman, R., Olives, C., Omer, S.B., Orchard, J., Osborne, R., Ostro, B., Page, A., Pandey, K.D., Parry, C.D.H., Passmore, E., Patra, J., Pearce, N., Pelizzari, P.M., Petzold, M., Phillips, M.R., Pope, D., Pope, C.A., Powles, J., Rao, M., Razavi, H., Rehfuess, E.A., Rehm, J.T., Ritz, B., Rivara, F.P., Roberts, T., Robinson, C., Rodriguez-Portales, J.A., Romieu, I., Room, R., Rosenfeld, L.C., Roy, A., Rushton, L., Salomon, J.A., Sampson, U., Sanchez-Riera, L., Sanman, E., Sapkota, A., Seedat, S., Shi, P., Shield, K., Shivakoti, R., Singh, G.M., Sleet, D.A., Smith, E., Smith, K.R., Stapelberg, N.J.C., Steenland, K., Stöckl, H., Stovner, L.J., Straif, K., Straney, L., Thurston, G.D., Tran, J.H., Van Dingenen, R., van Donkelaar, A., Veerman, J.L., Vijayakumar, L., Weintraub, R., Weissman, M.M., White, R.A., Whiteford, H., Wiersma, S.T., Wilkinson, J.D., Williams, H.C., Williams, W., Wilson, N., Woolf, A.D., Yip, P., Zielinski, J.M., Lopez, A.D., Murray, C.J.L. and Ezzati, M., 2012. A comparative risk assessment of burden of disease and injury attributable to 67 risk factors and risk factor clusters in 21 regions, 1990-2010: a systematic analysis for the Global Burden of Disease Study 2010. The Lancet 380: 2224-2260. https://doi. org/10.1016/s0140-6736(12)61766-8 
Lin, H.V., Frassetto Jr, A., E.J.K., Nawrocki, A.R., Lu, M.M., Kosinski, J.R., Hubert, J.A., Szeto, D., Yao, X., Forrest, G. and Marsh, D.J., 2012. Butyrate and propionate protect against diet-induced obesity and regulate gut hormones via free fatty acid receptor 3-independent mechanisms. PLoS ONE 7: 1-9. https://doi.org/10.1371/journal. pone. 0035240

Liu, F., Li, P., Chen, M., Luo, Y., Prabhakar, M., Zheng, H., He, Y., Qi, Q., Long, H., Zhang, Y., Sheng, H. and Zhou, H., 2017. Fructooligosaccharide (FOS) and galactooligosaccharide (GOS) increase Bifidobacterium but reduce butyrate producing bacteria with adverse glycemic metabolism in healthy young population. Science Reports 7: 11789. https://doi.org/10.1038/s41598-01710722-2

Liu, L., Li, L., Min, J., Wang, J., Wu, H., Zeng, Y., Chen, S. and Chu, Z., 2012. Butyrate interferes with the differentiation and function of human monocyte-derived dendritic cells. Cellular Immunology 277: 66-73. https://doi.org/10.1016/j.cellimm.2012.05.011

Louis, P., Duncan, S.H., McCrae, S.I., Millar, J., Jackson, M.S. and Flint, H.J., 2004. Restricted distribution of the butyrate kinase pathway among butyrate-producing bacteria from the human colon. Journal of Bacteriology 186: 2099-2106. https://doi.org/10.1128/ JB.186.7.2099-2106.2004

Louis, P., Young, P., Holtrop, G. and Flint, H.J., 2010. Diversity of human colonic butyrate-producing bacteria revealed by analysis of the butyryl-CoA:acetate CoA-transferase gene. Environmental Microbiology 12: 304-314. https://doi.org/10.1111/j.14622920.2009.02066.x

Lu, Y., Fan, C., Li, P., Lu, Y., Chang, X. and Qi, K., 2016. Short chain fatty acids prevent high-fat-diet-induced obesity in mice by regulating g protein-coupled receptors and gut microbiota. Nature 3: 1-13. https://doi.org/10.1038/srep37589

Lutz, T. and Scharrer, E., 1991. Effect of short-chain fatty acids on calcium absorption by the rat colon. Experimental Physiology 76: 615-618. https://doi.org/10.1113/expphysiol.1991.sp003530

MacFarlane, G.T. and Gibson, G.R., 1995. Microbiological aspects of the production of short-chain fatty acids in the large bowel. In: Cummings, J.H., Rombeau, J.L. and Sakata, S. (eds.) Physiological and clinical aspects of short chain fatty acid metabolism. Cambridge University Press, Cambridge, UK, pp. 87.

MacFarlane, G.T. and MacFarlane, S., 1997. Human colonic microbiota: ecology, physiology and metabolic potential of intestinal bacteria. Scandinavian Journal of Gastroenterology, Suppl. 32: 3-9.

MacFarlane, G.T., Gibson, G.R. and Cummings, J.H., 1992. Comparison of fermentation reactions in different regions of the human colon. Journal of Applied Bacteriology 72: 57-64. https://doi. org/10.1111/j.1365-2672.1992.tb04882.x

Macia, L., Tan, J., Vieira, A.T., Leach, K., Stanley, D., Luong, S., Maruya, M., Ian McKenzie, C., Hijikata, A., Wong, C., Binge, L., Thorburn, A.N., Chevalier, N., Ang, C., Marino, E., Robert, R., Offermanns, S., Teixeira, M.M., Moore, R.J., Flavell, R.A., Fagarasan, S. and Mackay, C.R., 2015. Metabolite-sensing receptors GPR43 and GPR109A facilitate dietary fibre-induced gut homeostasis through regulation of the inflammasome. Nature Communications 6: 6734-6734.
Martínez, I., Kim, J., Duffy, P.R., Schlegel, V.L. and Walter, J., 2010. Resistant starches types 2 and 4 have differential effects on the composition of the fecal microbiota in human subjects. PLoS ONE 5(11): e15046.

Mascolo, N., Rajendran, V.M. and Binder, H.J., 1991. Mechanism of short-chain fatty acid uptake by apical membrane vesicles of rat distal colon. Gastroenterology 101: 331-338. https://doi. org/10.1016/0016-5085(91)90008-9

Masui, R., Sasaki, M., Funaki, Y., Ogasawara, N., Mizuno, M., Iida, A., Izawa, S., Kondo, Y., Ito, Y., Tamura, Y., Yanamoto, K., Noda, H., Tanabe, A., Okaniwa, N., Yamaguchi, Y., Iwamoto, T. and Kasugai, K., 2013. G protein-coupled receptor 43 moderates gut inflammation through cytokine regulation from mononuclear cells. Inflammatory Bowel Diseases 19: 2848-2856. https://doi. org/10.1097/01.MIB.0000435444.14860.ea

Maurer, J.M., Schellekens, R.C.A., Van Rieke, H.M., Wanke, C., Iordanov, V., Stellaard, F., Wutzke, K.D., Dijkstra, G., Van der Zee, M., Woerdenbag, H.J., Frijlink, H.W. and Kosterink, J.G.W., 2015. Gastrointestinal $\mathrm{pH}$ and transit time profiling in healthy volunteers using the IntelliCap system confirms ileo-colonic release of ColoPulse tablets. PLoS ONE 10: e0129076. https://doi. org/10.1371/journal.pone.0129076

McBurney, M.I. and Thompson, L.U., 1989. In vitro fermentabilities of purified fiber supplements. Journal of Food Science 54: 347-350. https://doi.org/10.1111/j.1365-2621.1989.tb03077.x

McKenzie, C., Tan, J., Macia, L. and Mackay, C.R., 2017. The nutrition-gut microbiome-physiology axis and allergic diseases. Immunological Reviews 278: 277-295. https://doi.org/10.1111/ imr.12556

McLoughlin, R.F., Berthon, B.S., Jensen, M.E., Baines, K.J. and Wood, L.G., 2017. Short-chain fatty acids, prebiotics, synbiotics, and systemic inflammation: a systematic review and meta-analysis. American Journal of Clinical Nutrition 106: 930-945. https://doi. org/10.3945/ajcn.117.156265

McNabney, M.S. and Henagan, M.T., 2017. Short chain fatty acids in the colon and peripheral tissues: a focus on butyrate, colon cancer, obesity and insulin resistance. Nutrients 9: 1348. https:// doi.org/10.3390/nu9121348

McNeil, N.I., 1984. The contribution of the large intestine to energy supplies in man. American Journal of Clinical Nutrition 39: 338-342.

McNelis, J.C., Lee, Y.S., Mayoral, R., Van der Kant, R., Johnson, A.M.F., Wollam, J. and Olefsky, J.M., 2015. GPR43 potentiates $\beta$-cell function in obesity. Diabetes 64: 3203-3217.

Miao, W., Wu, X., Wang, K., Wang, W., Wang, Y., Li, Z., Liu, J., Li, L. and Peng, L., 2016. Sodium butyrate promotes reassembly of tight junctions in Caco-2 monolayers involving inhibition of MLCK/ MLC2 pathway and phosphorylation of PKCbeta2. International Journal of Molecular Science 17: 1696. https://doi.org/10.3390/ ijms17101696

Millard, A.L., Mertes, P.M., Ittelet, D., Villard, F., Jeannesson, P. and Bernard, J., 2002. Butyrate affects differentiation, maturation and function of human monocyte-derived dendritic cells and macrophages. Clinical and Experimental Immunology 130: 245255. https://doi.org/10.1046/j.0009-9104.2002.01977.x 
Mineo, H., Hara, H. and Tomita, F., 2001. Short-chain fatty acids enhance diffusional $\mathrm{Ca}$ transport in the epithelium of the rat cecum and colon. Life Sciences 69: 517-526.

Mithieux, G., 2001. New data and concepts on glutamine and glucose metabolism in the gut. Current Opinion in Clinical Nutrition and Metabolic Care 4: 267-271.

Mithieux, G., 2012. Comment about intestinal gluconeogenesis after gastric bypass in human in relation with the paper by Hayes et al., Obes. Surg. 2011. Obesity Surgery 22: 1920-1922. https://doi. org/10.1007/s11695-012-0755-4

Moens, F., Weckx, S. and De Vuyst, L., 2016. Bifidobacterial inulin-type fructan degradation capacity determines cross-feeding interactions between bifidobacteria and Faecalibacterium prausnitzii. International Journal of Food Microbiology 231: 76-85. https:// doi.org/10.1016/j.ijfoodmicro.2016.05.015

Monk, J.M., Lepp, D., Wu, W., Pauls, K.P., Robinson, L.E. and Power, K.A., 2017. Navy and black bean supplementation primes the colonic mucosal microenvironment to improve gut health. Journal of Nutritional Biochemistry 49: 89-100. https://doi.org/10.1016/j. jnutbio.2017.08.002

Morrison, D.J., Mackay, W.G., Edwards, C.A., Preston, T., Dodson, B. and Weaver, L.T., 2006. Butyrate production from oligofructose fermentation by the human faecal flora: what is the contribution of extracellular acetate and lactate? British Journal of Nutrition 96: 570-577. https://doi.org/10.1079/BJN20061853

Muller, M., Hermes, G.D.A., Canfora, E.E., Smidt, H., Masclee, A.A.M., Zoetendal, E.G. and Blaak, E.E., 2020. Distal colonic transit is linked to gut microbiota diversity and microbial fermentation in humans with slow colonic transit. The American Journal of Physiology: Gastrointestinal and Liver Physiology 318: G361-G369. https:// doi.org/10.1152/ajpgi.00283.2019

Muñoz-Tamayo, R., Laroche, B., Walter, É., Doré, J., Duncan, S.H., Flint, H.J. and Leclerc, M., 2011. Kinetic modelling of lactate utilization and butyrate production by key human colonic bacterial species. FEMS Microbiology Ecology 76: 615-624. https://doi.org/10.1111/ j.1574-6941.2011.01085.x

Nagashima, H. and Morio, Y., 2010. High-resolution nuclear magnetic resonance spectroscopic study of metabolites in the cerebrospinal fluid of patients with cervical myelopathy and lumbar radiculopathy. European Spine Journal 19: 1363-1368. https://doi.org/10.1007/ s00586-010-1453-3

Nastasi, C., Candela, M., Bonefeld, C.M., Geisler, C., Hansen, M., Krejsgaard, T., Biagi, E., Andersen, M.H., Brigidi, P., Ødum, N., Litman, T. and Woetmann, A., 2015. The effect of short-chain fatty acids on human monocyte-derived dendritic cells. Scientific Reports 5: 16148-16148. https://doi.org/10.1038/srep16148

Neis, E.P.J.G., Van Eijk, H.M.H., Lenaerts, K., Olde Damink, S.W.M., Blaak, E.E., Dejong, C.H.C. and Rensen, S.S., 2018. Distal versus proximal intestinal short-chain fatty acid release in man. Gut 68: 764-765. https://doi.org/10.1136/gutjnl-2018-316161

Nurmi, J.T., Puolakkainen, P.A. and Rautonen, N.E., 2005. Bifidobacterium Lactis sp. 420 up-regulates cyclooxygenase (Cox)-1 and down-regulates Cox-2 gene expression in a Caco-2 cell culture model. Nutrition and Cancer 51: 83-92. https://doi.org/10.1207/ s15327914nc5101_12
Ohira, H., Fujioka, Y., Katagiri, C., Mamoto, R., Aoyama-Ishikawa, M., Amako, K., Izumi, Y., Nishiumi, S., Yoshida, M., Usami, M. and Ikeda, M., 2013. Butyrate attenuates inflammation and lipolysis generated by the interaction of adipocytes and macrophages. Journal of Atherosclerosis and Thrombosis 20: 425-442. https:// doi.org/10.5551/jat.15065

Olguin, F., Araya, M., Hirsch, S., Brunser, O., Ayala, V., Rivera, R. and Gotteland, M., 2005. Prebiotic ingestion does not improve gastrointestinal barrier function in burn patients. Burns 31: 482488. https://doi.org/10.1016/j.burns.2004.11.017

Park, J., Goergen, C.J., HogenEsch, H. and Kim, C.H., 2016. Chronically elevated levels of short-chain fatty acids induce T cell-mediated ureteritis and hydronephrosis. The Journal of Immunology 196: 2388-2400. https://doi.org/10.4049/jimmunol.1502046

Park, J., Kim, M., Kang, S.G., Jannasch, A.H., Cooper, B., Patterson, J. and Kim, C.H., 2015. Short-chain fatty acids induce both effector and regulatory $\mathrm{T}$ cells by suppression of histone deacetylases and regulation of the mTOR-S6K pathway. Mucosal Immunology 8: 80-93. https://doi.org/10.1038/mi.2014.44

Parnell, J.A. and Reimer, R.A., 2009. Weight loss during oligofructose supplementation is associated with decreased ghrelin and increased peptide YY in overweight and obese adults. American Journal of Clinical Nutrition 89: 1751-1759.

Pedersen, C., Gallagher, E., Horton, F., Ellis, R.J., Ijaz, U.Z., Wu, H., Jaiyeola, E., Diribe, O., Duparc, T., Cani, P.D., Gibson, G.R., Hinton, P., Wright, J., La Ragione, R. and Robertson, M.D., 2016. Host-microbiome interactions in human type 2 diabetes following prebiotic fibre (galacto-oligosaccharide) intake. British Journal of Nutrition 116: 1869-1877. https://doi.org/10.1017/ S0007114516004086

Pelaseyed, T., Bergström, J.H., Gustafsson, J.K., Ermund, A., Birchenough, G.M.H., Schütte, A., Van der Post, S., Svensson, F., Rodríguez-Piñeiro, A.M., Nyström, E.E.L., Wising, C., Johansson, M.E.V. and Hansson, G.C., 2014. The mucus and mucins of the goblet cells and enterocytes provide the first defense line of the gastrointestinal tract and interact with the immune system. Immunological Reviews 260: 8-20. https://doi.org/10.1111/ imr.12182

Peng, L., Li, Z.R., Green, R.S., Holzman, I.R. and Lin, J., 2009. Butyrate enhances the intestinal barrier by facilitating tight junction assembly via activation of AMP-activated protein kinase in Caco-2 cell monolayers. Journal of Nutrition 139: 1619-1625. https://doi. org/10.3945/jn.109.104638

Perry, R.J., Peng, L., Barry, N.A. and Gary, W., 2016. Acetate mediates a microbiome-brain- $\beta$-cell axis to promote metabolic syndrome. Nature 534: 213-217 https://doi.org/10.1038/nature18309

Peters, S.G., Pomare, E.W. and Fisher, C.A., 1992. Portal and peripheral blood short chain fatty acid concentrations after caecal lactulose instillation at surgery. Gut 33: 1249-1252. https://doi.org/10.1136/ gut.33.9.1249

Pingitore, A., Chambers, E.S., Hill, T., Maldonado, I.R., Liu, B., Bewick, G., Morrison, D.J., Preston, T., Wallis, G.A. and Tedford, C., 2017. The diet-derived short chain fatty acid propionate improves beta-cell function in humans and stimulates insulin secretion from human islets in vitro. Diabetes, Obesity and Metabolism 19: 257-265. 
Polyviou, T., Macdougall, K., Chambers, E.S., Viardot, A., Psichas, A., Jawaid, S., Harris, H.C. and Edwards, C.A., 2016. Alimentary pharmacology and therapeutics randomised clinical study: inulin short-chain fatty acid esters for targeted delivery of short-chain fatty acids to the human colon. Alimentary Pharmacology and Therapeutics 44(7): 662-672. https://doi.org/10.1111/apt.13749

Pouteau, E., Ferchaud-Roucher, V., Zair, Y., Paintin, M., Enslen, M., Auriou, N., Macé, K., Godin, J.-P., Ballèvre, O. and Krempf, M., 2010. Acetogenic fibers reduce fasting glucose turnover but not peripheral insulin resistance in metabolic syndrome patients. Clinical Nutrition 29: 801-807.

Priyadarshini, M., Villa, S.R., Fuller, M., Wicksteed, B., Mackay, C.R., Alquier, T., Poitout, V., Mancebo, H., Mirmira, R.G. and Gilchrist, A., 2015. An acetate-specific GPCR, FFAR2, regulates insulin secretion. Molecular Endocrinology 29: 1055-1066.

Psichas, A., Sleeth, M.L., Murphy, K.G., Brooks, L., Bewick, G.A., Hanyaloglu, A.C., Ghatei, M.A., Bloom, S.R. and Frost, G., 2014. The short chain fatty acid propionate stimulates GLP-1 and PYY secretion via free fatty acid receptor 2 in rodents. International Journal of Obesity 39: 424-429. https://doi.org/10.1038/ijo.2014.153

Rabbani, G.H., Teka, T., Saha, S.K., Zaman, B., Majid, N., Khatun, M., Wahed, M.A. and Fuchs, G.J., 2004. Green banana and pectin improve small intestinal permeability and reduce fluid loss in Bangladeshi children with persistent diarrhea. Digestive Diseases and Sciences 49: 475-484. https://doi.org/10.1023/ b:ddas.0000020507.25910.cf

Ramirez-Farias, C., Slezak, K., Fuller, Z., Duncan, A., Holtrop, G. and Louis, P., 2009. Effect of inulin on the human gut microbiota: stimulation of Bifidobacterium adolescentis and Faecalibacterium prausnitzii. British Journal of Nutrition 101: 541-550. https://doi. org/10.1017/S0007114508019880

Rao, M., Gao, C., Xu, L., Jiang, L., Zhu, J., Chen, G., Law, B.Y.K. and Xu, Y., 2019. Effect of inulin-type carbohydrates on insulin resistance in patients with Type 2 diabetes and obesity: a systematic review and meta-analysis. Journal of Diabetes Research: 5101423. https:// doi.org/10.1155/2019/5101423

Raschka, L. and Daniel, H., 2005. Mechanisms underlying the effects of inulin-type fructans on calcium absorption in the large intestine of rats. Bone 37: 728-735. https://doi.org/10.1016/j.bone.2005.05.015

Reichardt, N., Duncan, S.H., Young, P., Belenguer, A., McWilliam Leitch, C., Scott, K.P., Flint, H.J. and Louis, P., 2014. Phylogenetic distribution of three pathways for propionate production within the human gut microbiota. ISME Journal 8: 1323-1335. https://doi. org/10.1038/ismej.2014.14

Reijnders, D., Goossens, G.H., Hermes, G.D., Neis, E.P., Van der Beek, C.M., Most, J., Holst, J.J., Lenaerts, K., Kootte, R.S., Nieuwdorp, M., Groen, A.K., Olde Damink, S.W., Boekschoten, M.V., Smidt, H., Zoetendal, E.G. Dejong, C.H. and Blaak, E.E., 2016. Effects of gut microbiota manipulation by antibiotics on host metabolism in obese humans: a randomized double-blind placebo-controlled trial. Cell Metabolism 24: 341. https://doi.org/10.1016/j.cmet.2016.07.008

Rios-Covian, D., Ruas-Madiedo, P., Margolles, A., Gueimonde, M., De los Reyes-Gavilan, C.G. and Salazar, N., 2016. Intestinal short chain fatty acids and their link with diet and human health. Frontiers in Microbiology 7: 185. https://doi.org/10.3389/fmicb.2016.00185
Robertson, M.D., Bickerton, A.S., Dennis, A.L., Vidal, H. and Frayn, K.N., 2005. Insulin-sensitizing effects of dietary resistant starch and effects on skeletal muscle and adipose tissue metabolism. American Journal of Clinical Nutrition 82: 559-567.

Roediger, W.E., 1980. Role of anaerobic bacteria in the metabolic welfare of the colonic mucosa in man. Gut 21: 793-798.

Roelofsen, H., Priebe, M.G. and Vonk, R.J., 2010. The interaction of short-chain fatty acids with adipose tissue: relevance for prevention of type 2 diabetes. Beneficial Microbes 1: 433-437. https://doi. org/10.3920/bm2010.0028

Rosendale, D.I., Vetharaniam, I., Kelly, W.J., Upsdell, M., Cookson, A.L. and Roy, N., 2017. A case study: using microbial abundance data to mathematically calculate organic acid production by human faecal microbiota within an in vitro batch fermentation. Bioactive Carbohydrates and Dietary Fibre 9: 28-38. https://doi.org/10.1016/j. bcdf.2016.12.004

Rossi, M., Corradini, C., Amaretti, A., Nicolini, M., Pompei, A., Zanoni, S. and Matteuzzi, D., 2005. Fermentation of fructooligosaccharides and inulin by bifidobacteria: a comparative study of pure and fecal cultures. Applied and Environmental Microbiology 71: 6150-6158. https://doi.org/10.1128/AEM.71.10.6150-6158.2005

Rumberger, J.M., Arch, J.R. and Green, A., 2014. Butyrate and other short-chain fatty acids increase the rate of lipolysis in 3T3-L1 adipocytes. PeerJ 2: e611. https://doi.org/10.7717/peerj.611

Russell, W.R., Gratz, S.W., Duncan, S.H., Holtrop, G., Ince, J., Scobbie, L., Duncan, G., Johnstone, A.M., Lobley, G.E., Wallace, R.J., Duthie, G.G. and Flint, H.J., 2011. High-protein, reduced-carbohydrate weight-loss diets promote metabolite profiles likely to be detrimental to colonic health. American Journal of Clinical Nutrition 93: 10621072. https://doi.org/10.3945/ajcn.110.002188

Russo, F., Linsalata, M., Clemente, C., Chiloiro, M., Orlando, A., Marconi, E., Chimienti, G. and Riezzo, G., 2012a. Inulinenriched pasta improves intestinal permeability and modifies the circulating levels of zonulin and glucagon-like peptide 2 in healthy young volunteers. Nutrition Research 32: 940-946. https://doi. org/10.1016/j.nutres.2012.09.010

Russo, I., Luciani, A., De Cicco, P., Troncone, E. and Ciacci, C., 2012b. Butyrate attenuates lipopolysaccharide-induced inflammation in intestinal cells and Crohn's mucosa through modulation of antioxidant defense machinery. PLoS ONE 7: e32841-e32841.

Sahuri-Arisoylu, M., Brody, L.P., Parkinson, J.R., Parkes, H., Navaratnam, N., Miller, A.D., Thomas, E.L., Frost, G. and Bell, J.D., 2016. Reprogramming of hepatic fat accumulation and 'browning' of adipose tissue by the short-chain fatty acid acetate. International Journal of Obesity 40: 955-963. https://doi.org/10.1038/ijo.2016.23

Sakakibara, S., Yamauchi, T., Oshima, Y., Tsukamoto, Y. and Kadowaki, T., 2006. Acetic acid activates hepatic AMPK and reduces hyperglycemia in diabetic KK-A (y) mice. Biochemical and Biophysical Research Communications 344: 597-604.

Samuel, B.S., Shaito, A. Motoike, T., Rey, F.E., Backhed, F., Manchester, J.K., Hammer, R.E., Williams, S.C., Crowley, J., Yanagisawa, M. and Gordon, J.I., 2008. Effects of the gut microbiota on host adiposity are modulated by the short-chain fatty-acid binding G proteincoupled receptor, Gpr41. Proceedings of the National Academy of Sciences of the USA 105: 16767-16772. https://doi.org/10.1073/ pnas.0808567105 
Schauber, J., Dorschner, R.A., Yamasaki, K., Brouha, B. and Gallo, R.L., 2006. Control of the innate epithelial antimicrobial response is cell-type specific and dependent on relevant microenvironmental stimuli. Immunology 118: 509-519. https://doi.org/10.1111/j.13652567.2006.02399.x

Scheppach, W., 1996. Treatment of distal ulcerative colitis with shortchain fatty acid enemas. A placebo-controlled trial. Digestive Diseases and Sciences 41: 2254-2259.

Schilderink, R., Verseijden, C., Seppen, J., Muncan, V., Van den Brink, G.R., Lambers, T.T., Van Tol, E.A. and De Jonge, W.J., 2016. The SCFA butyrate stimulates the epithelial production of retinoic acid via inhibition of epithelial HDAC. American Journal of Physiology - Gastrointestinal and Liver Physiology 310: G1138-G1146. https:// doi.org/10.1152/ajpgi.00411.2015

Schwab, M., Reynders, V., Loitsch, S., Steinhilber, D., Stein, J. and Schröder, O., 2007. Involvement of different nuclear hormone receptors in butyrate-mediated inhibition of inducible NFKB signalling. Molecular Immunology 44: 3625-3632. https://doi. org/10.1016/j.molimm.2007.04.010

Scott, K.P., Gratz, S.W., Sheridan, P.O., Flint, H.J. and Duncan, S.H., 2013. The influence of diet on the gut microbiota. Pharmacology Research 69: 52-60. https://doi.org/10.1016/j.phrs.2012.10.020

Scott, K.P., Martin, J.C., Campbell, G., Mayer, C.D. and Flint, H.J., 2006. Whole-genome transcription profiling reveals genes up-regulated by growth on fucose in the human gut bacterium 'Roseburia inulinivorans'. Journal of Bacteriology 188: 4340-4349. https:// doi.org/10.1128/JB.00137-06

Sellin, J.H., 1999. SCFAs: the enigma of weak electrolyte transport in the colon. News in Physiological Sciences 14: 58-64.

Shetty, S.A., Hugenholtz, F., Lahti, L., Smidt, H. and De Vos, W.M., 2017. Intestinal microbiome landscaping: insight in community assemblage and implications for microbial modulation strategies. FEMS Microbiology Reviews 41: 182-199. https://doi.org/10.1093/ femsre/fuw045

Smith, P.M., Howitt, M.R., Panikov, N., Michaud, M., Gallini, C.A., Bohlooly-Y, M., Glickman, J.N. and Garrett, W.S., 2013. The microbial metabolites, short-chain fatty acids, regulate colonic Treg cell homeostasis. Science 341: 569-573. https://doi.org/10.1126/ science.1241165

Soty, M., Gautier-Stein, A., Rajas, F. and Mithieux, G., 2017. Gut-brain glucose signaling in energy homeostasis. Cell Metabolism 25: 12311242. https://doi.org/10.1016/j.cmet.2017.04.032

Swanson, K.S., De Vos, W.M., Martens, E.C., Gilbert, J.A., Menon, R.S., Soto-Vaca, A., Hautvast, J., Meyer, P.D., Borewicz, K., Vaughan, E.E. and Slavin, J.L., 2020. Effect of fructans, prebiotics and fibres on the human gut microbiome assessed by $16 \mathrm{~S}$ rRNA-based approaches: a review. Beneficial Microbes 11: 101-129. https://doi.org/10.3920/ BM2019.0082

Takebe, K., Nio, J., Morimatsu, M., Karaki, S., Kuwahara, A., Kato, I. and Iwanaga, T., 2005. Histochemical demonstration of a $\mathrm{Na}(+)$-coupled transporter for short-chain fatty acids (slc5a8) in the intestine and kidney of the mouse. Biomedical Research 26: 213-221.
Tan, J., McKenzie, C., Vuillermin, Peter, J., Goverse, G., Vinuesa, Carola, G., Mebius, Reina, E., Macia, L. and Mackay, C.R., 2016. Dietary fiber and bacterial SCFA enhance oral tolerance and protect against food allergy through diverse cellular pathways. Cell Reports 15: 2809-2824. https://doi.org/10.1016/j.celrep.2016.05.047

Teramae, H., Yoshikawa, T., Inoue, R., Ushida, K., Takebe, K., NioKobayashi, J. and Iwanaga, T., 2010. The cellular expression of SMCT2 and its comparison with other transporters for monocarboxylates in the mouse digestive tract. Biomedical Research 31: 239-249. https://doi.org/10.2220/biomedres.31.239

Todesco, T., Rao, A.V., Bosello, O. and Jenkins, D.J., 1991. Propionate lowers blood glucose and alters lipid metabolism in healthy subjects. American Journal of Clinical Nutrition 54: 860-865.

Tolhurst, G., Heffron, H., Lam, Y.S., Parker, H.E., Habib, A.M., Diakogiannaki, E., Cameron, J., Grosse, J., Reimann, F. and Gribble, F.M., 2012. Short-chain fatty acids stimulate glucagon-like peptide-1 secretion via the g-protein-oupled receptor FFAR2. Diabetes 61: 364-371. https://doi.org/10.2337/db11-1019

Tremaroli, V. and Bäckhed, F., 2012. Functional interactions between the gut microbiota and host metabolism. Nature 489: 242.

Trinidad, T.P., Wolever, T.M. and Thompson, L.U., 1997. Effect of short chain fatty acids on calcium absorption in humans. Advances in Experimental Medicine and Biology 427: 183-189.

Trinidad, T.P., Wolever, T.M.S. and Thompson, L.U., 1993. Interactive effects of calcium and short chain fatty acids on absorption in the distal colon of man. Nutrition Research: 417-425. https://doi. org/10.1016/s0271

Trinidad, T.P., Wolever, T.M.S. and Thompson, L.U., 1999. Effects of calcium concentration, acetate, and propionate on calcium absorption in the human distal colon. Nutrition 15: 529-533.

Turroni, F., Milani, C., Duranti, S., Mancabelli, L., Mangifesta, M., Viappiani, A., Lugli, G.A., Ferrario, C., Gioiosa, L., Ferrarini, A., Li, J., Palanza, P., Delledonne, M., Van Sinderen, D. and Ventura, M., 2016. Deciphering bifidobacterial-mediated metabolic interactions and their impact on gut microbiota by a multi-omics approach. ISME Journal 10: 1656-1668. https://doi.org/10.1038/ismej.2015.236 Turroni, F., Özcan, E., Milani, C., Mancabelli, L., Viappiani, A., Van Sinderen, D., Sela, D.A. and Ventura, M., 2015. Glycan cross-feeding activities between bifidobacteria under in vitro conditions. Frontiers in Microbiology 6. https://doi.org/10.3389/fmicb.2015.01030

Van den Abbeele, P., Gérard, P., Rabot, S., Bruneau, A., El Aidy, S., Derrien, M., Kleerebezem, M., Zoetendal, E.G. Smidt, H., Verstraete, W., Van de Wiele, T. and Possemiers, S., 2011. Arabinoxylans and inulin differentially modulate the mucosal and luminal gut microbiota and mucin-degradation in humanized rats. Environmental Microbiology 13: 2667-2680. https://doi. org/10.1111/j.1462-2920.2011.02533.x

Van der Beek, C.M., Bloemen, J.G., Van den Broek, M.A., Lenaerts, K., Venema, K., Buurman, W.A. and Dejong, C.H., 2015. Hepatic uptake of rectally administered butyrate prevents an increase in systemic butyrate concentrations in humans. Journal of Nutrition 145: 2019-2024. https://doi.org/10.3945/jn.115.211193 
Van der Beek, C.M., Canfora, E.E., Lenaerts, K., Troost, F.., Damink, S.W.M.O., Holst, J.J., Masclee, A.A.M., Dejong, C.H.C. and Blaak, E.E., 2016. Distal, not proximal, colonic acetate infusions promote fat oxidation and improve metabolic markers in overweight/obese men. Clinical Science 130: 2073-2082. https://doi.org/10.1042/ cs20160263

Van Herreweghen, F., Van den Abbeele, P., De Mulder, T., De Weirdt, R., Geirnaert, A., Hernandez-Sanabria, E., Vilchez-Vargas, R., Jauregui, R., Pieper, D.H., Belzer, C., De Vos, W.M. and Van de Wiele, T., 2017. In vitro colonisation of the distal colon by Akkermansia muciniphila is largely mucin and pH dependent. Beneficial Microbes 8: 81-96. https://doi.org/10.3920/BM2016.0013

Van Wey, A.S., Lovatt, S.J., Roy, N.C. and Shorten, P.R., 2016. Determination of potential metabolic pathways of human intestinal bacteria by modeling growth kinetics from cross-feeding dynamics. Food Research International 88: 207-216. https://doi.org/10.1016/j. foodres.2016.02.004

Venter, C.S., Vorster, H.H. and Cummings, J.H., 1990. Effects of dietary propionate on carbohydrate and lipid metabolism in healthy volunteers. American Journal of Gastroenterology 85: 549-553.

Veprik, A., Laufer, D., Weiss, S., Rubins, N. and Walker, M.D., 2016. GPR41 modulates insulin secretion and gene expression in pancreatic $\beta$-cells and modifies metabolic homeostasis in fed and fasting states. FASEB Journal 30: 3860-3869.

Verbeke, K., Ferchaud-Roucher, V., Preston, T., Small, A.C., Henckaerts, L., Krempf, M., Wang, H., Vonk, R.J. and Priebe, M.G., 2010. Influence of the type of indigestible carbohydrate on plasma and urine short-chain fatty acid profiles in healthy human volunteers. European Journal of Clinical Nutrition 64: 678-684. https://doi. org/10.1038/ejcn.2010.92

Vernia, P., Marcheggiano, A., Caprilli, R., Frieri, G., Corrao, G., Valpiani, D., Di Paolo, M.C., Paoluzi, P. and Torsoli, A., 1995. Short-chain fatty acid topical treatment in distal ulcerative colitis. Alimentary Pharmacology and Therapeutics 9: 309-313. https:// doi.org/10.1111/j.1365-2036.1995.tb00386.x

Vidyasagar, S., Barmeyer, C., Geibel, J., Binder, H.J. and Rajendran, V.M., 2005. Role of short-chain fatty acids in colonic $\mathrm{HCO}_{3}$ secretion. American Journal of Physiology - Gastrointestinal and Liver Physiology 288: G1217-G1226. https://doi.org/10.1152/ ajpgi.00415.2004

Vinolo, M.A.R., Hatanaka, E., Lambertucci, R.H., Newsholme, P. and Curi, R., 2009. Effects of short chain fatty acids on effector mechanisms of neutrophils. Cell Biochemistry and Function 27: 48-55. https://doi.org/10.1002/cbf.1533

Vinolo, M.A.R., Rodrigues, H.G., Nachbar, R.T. and Curi, R., 2011. Regulation of inflammation by short chain fatty acids. Nutrients 3: 858-876. https://doi.org/10.3390/nu3100858

Vulevic, J., Juric, A., Tzortzis, G. and Gibson, G.R., 2013. A mixture of trans-galactooligosaccharides reduces markers of metabolic syndrome and modulates the fecal microbiota and immune function of overweight adults. Journal of Nutrition 143: 324-331.
Walker, A.W., Ince, J., Duncan, S.H., Webster, L.M., Holtrop, G., Ze, X., Brown, D., Stares, M.D., Scott, P., Bergerat, A., Louis, P., McIntosh, F., Johnstone, A.M., Lobley, G.E., Parkhill, J. and Flint, H.J., 2011. Dominant and diet-responsive groups of bacteria within the human colonic microbiota. ISME Journal 5: 220-230. https:// doi.org/10.1038/ismej.2010.118

Wang, H., Shi, P., Zuo, L., Dong, J., Zhao, J., Liu, Q. and Zhu, W., 2016. Dietary non-digestible polysaccharides ameliorate intestinal epithelial barrier dysfunction in IL-10 knockout mice. Journal of Crohn's and Colitis 10: 1076-1086.

Wang, H.B., Wang, P.Y., Wang, X., Wan, Y.L. and Liu, Y.C., 2012. Butyrate enhances intestinal epithelial barrier function via upregulation of tight junction protein claudin-1 transcription. Digestive Diseases and Sciences 57: 3126-3135. https://doi.org/10.1007/ s10620-012-2259-4

Weaver, C.M., 2015. Diet, gut microbiome, and bone health. Current Osteoporosis Reports 13: 125-130. https://doi.org/10.1007/s11914015-0257-0

West, N.P., Pyne, D.B., Cripps, A.W., Christophersen, C.T., Conlon, M.A. and Fricker, P.A., 2012. Gut balance, a synbiotic supplement, increases fecal Lactobacillus paracasei but has little effect on immunity in healthy physically active individuals. Gut Microbes 3: 221-227. https://doi.org/10.4161/gmic.19579

Westerbeek, E.A., Van den Berg, A., Lafeber, H.N., Fetter, W.P. and van Elburg, R.M., 2011. The effect of enteral supplementation of a prebiotic mixture of non-human milk galacto-, fructo- and acidic oligosaccharides on intestinal permeability in preterm infants. British Journal of Nutrition 105: 268-274. https://doi.org/10.1017/ S0007114510003405

Willemsen, L.E.M., Koetsier, M.A., Van Deventer, S.J.H. and Van Tol, E.A.F., 2003. Short chain fatty acids stimulate epithelial mucin 2 expression through differential effects on prostaglandin $\mathrm{E}(1)$ and E(2) production by intestinal myofibroblasts. Gut 52: 1442-1447.

Wilms, E., Gerritsen, J., Smidt, H., Besseling-Van der Vaart, I., Rijkers, G.T., Garcia Fuentes, A.R., Masclee, A.A. and Troost, F.J., 2016. Effects of supplementation of the synbiotic Ecologic ${ }^{\oplus}$ 825/FOS P6 on intestinal barrier function in healthy humans: a randomized controlled trial. PLoS ONE 11: e0167775. https://doi.org/10.1371/ journal.pone.0167775

Wolever, T.M., Brighenti, F., Royall, D., Jenkins, A.L. and Jenkins, D.J., 1989. Effect of rectal infusion of short chain fatty acids in human subjects. American Journal of Gastroenterology 84: 1027-1027.

Wolever, T.M., Spadafora, P. and Eshuis, H., 1991. Interaction between colonic acetate and propionate in humans. American Journal of Clinical Nutrition 53: 681-687.

Wu, W., Sun, M., Chen, F., Cao, A.T., Liu, H., Zhao, Y., Huang, X., Xiao, Y., Yao, S., Zhao, Q., Liu, Z. and Cong, Y., 2017. Microbiota metabolite short-chain fatty acid acetate promotes intestinal IgA response to microbiota which is mediated by GPR43. Mucosal Immunology 10: 946-956. https://doi.org/10.1038/mi.2016.114

Yamashita, H., Fujisawa, K., Ito, E., Idei, S., Kawaguchi, N., Kimoto, M., Hiemori, M. and Tsuji, H., 2007. Improvement of obesity and glucose tolerance by acetate in type 2 diabetic Otsuka Long-Evans Tokushima Fatty (OLETF) rats. Bioscience, Biotechnology, and Biochemistry 71: 1236-1243. 
Yamashita, H., Maruta, H., Jozuka, M., Kimura, R., Iwabuchi, H., Yamato, M., Saito, T., Fujisawa, K., Takahashi, Y. and Kimoto, M., 2009. Effects of acetate on lipid metabolism in muscles and adipose tissues of type 2 diabetic Otsuka Long-Evans Tokushima Fatty (OLETF) rats. Bioscience, Biotechnology, and Biochemistry 73: 570-576.

Yan, H. and Ajuwon, K.M., 2017. Butyrate modifies intestinal barrier function in IPEC-J2 cells through a selective upregulation of tight junction proteins and activation of the Akt signaling pathway. PLoS ONE 12: e0179586. https://doi.org/10.1371/journal.pone.0179586

Zasloff, M., 2006. Inducing endogenous antimicrobial peptides to battle infections. Proceedings of the National Academy of Sciences 103: 8913-8914.

Ze, X., Duncan, S.H., Louis, P. and Flint, H.J., 2012. Ruminococcus bromii is a keystone species for the degradation of resistant starch in the human colon. ISME Journal 6: 1535-1543. https://doi. org/10.1038/ismej.2012.4
Zhao, L., Zhang, F., Ding, X., Wu, G., Lam, Y.Y., Wang, X., Fu, H., Xue, X., Lu, C. and Ma, J., 2018. Gut bacteria selectively promoted by dietary fibers alleviate type 2 diabetes. Science 359: 1151-1156. Zheng, L., Kelly, C.J., Battista, K.D., Schaefer, R., Lanis, J.M., Alexeev, E.E., Wang, R.X., Onyiah, J.C., Kominsky, D.J. and Colgan, S.P., 2017. Microbial-derived butyrate promotes epithelial barrier function through IL-10 receptor-dependent repression of claudin-2. Journal of Immunology 199: 2976-2984.

Zhou, D., Pan, Q., Xin, F.-Z., Zhang, R.-N., He, C.-X., Chen, G.-Y., Liu, C., Chen, Y.-W. and Fan, J.-G., 2017. Sodium butyrate attenuates high-fat diet-induced steatohepatitis in mice by improving gut microbiota and gastrointestinal barrier. World Journal of Gastroenterology 23: 60-75. https://doi.org/10.3748/wjg.v23.i1.60 
